Archive for

Organic Chemistry

Arkivoc 2020, part i, 219-271

\title{
1,2,3- Triazoles: general and key synthetic strategies
}

\section{Cosme Silva Santos, ${ }^{a}$ Romário Jonas de Oliveira, ${ }^{a}$ Ronaldo Nascimento de Oliveira, ${ }^{* a}$ and Juliano Carlo Rufino Freitas*a,b}

${ }^{a}$ Departamento de Química, Universidade Federal Rural de Pernambuco, Recife-PE, 52171-900, Brazil

${ }^{b}$ Centro de Educação e Saúde, Universidade Federal de Campina Grande, Cuité-PB 58175-000, Brasil

Email: julianocrufino@pq.cnpq.br, ronaldo.noliveira@ufrpe.br, ronaldon38@gmail.com

\section{Abstract}

The applications of the $1 \mathrm{H}-1,2,3$-triazole derivatives are particularly attractive and have received prominent attention in scientific research. The characteristics of these heterocycles motivated the development of different strategies for their preparation and molecular diversification. Most of the synthetic procedures available in the literature are based on catalysis with copper salts. Therefore, this review has as complementary central focus and updates the information about the properties and the main methods for the preparation of $1 \mathrm{H}-1,2,3$-triazole derivatives, with emphasis on methods involving 1,3-dipolar cycloaddition between organic azides and terminal alkynes catalyzed by copper.

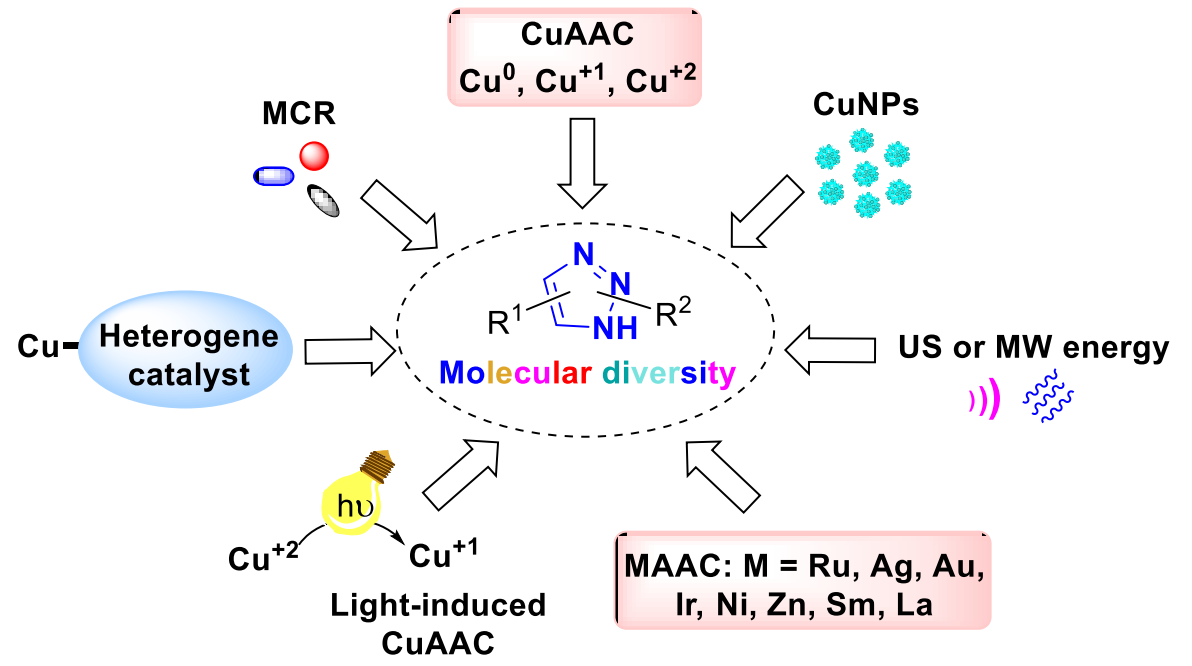

Keywords: Click chemistry, CuAAC, catalysis, synthesis, $1 \mathrm{H}-1,2,3$-triazole derivatives 


\section{Table of Contents}

1. Introduction

2. Generalities: Structure, Classification, and Main Properties

3. Key Strategies for Synthetic Preparation of $1 H-1,2,3-$ Triazole Derivatives

3.1 Historic aspects of $1 \mathrm{H}$-1,2,3-triazole derivatives and thermal 1,3-dipolar azide-alkyne cycloaddition (AAC)

3.2 $\mathrm{Cu}(\mathrm{I})$-catalyzed 1,3-dipolar cycloaddition between azides and alkynes

3.3 CuAAC reaction mechanism

3.3.1 Main sources of $\mathrm{Cu}(\mathrm{I})$ used in CuAAC reactions

3.3.2 Main sources of $\mathrm{Cu}$ (II) used in CuAAC reactions

3.3.3 Heterogeneous CuAAC reactions

3.3.4 Use of copper nanoparticles (CuNPs) in CuAAC reactions

3.3.5 Use of ultrasonic energy in CuAAC reactions

3.3.6 Use of microwave in CuAAC reactions

3.3.7 Multicomponent CuAAC reactions

3.3.8 CuAAC light-induced reactions

3.3.9 Use of other transition metals in cycloaddition reactions involving azides and alkynes (MAAC)

4. Conclusions

5. Acknowledgements

References

\section{Introduction}

Heterocycles are cyclic compounds with at least one heteroatom in their molecular architecture. They constitute an enormous class of organic compounds with applications in different industrial sectors. Its numerous applications are justified by the fact that $50 \%$ of the 20 million identified chemical compounds, to date, have at least one heterocyclic ring in their molecular structure. ${ }^{1-3}$ It should be noted that $70 \%$ of all marketed drugs and agrochemicals have in their structure one or more heterocyclic units. ${ }^{4}$

Today, heterocycles represent one of the most important structural scaffolds present in a variety of natural products, synthetics, pharmaceuticals and materials of general interest. ${ }^{5}$ In addition, numerous molecules of biological importance to living organisms are made up of one or more heterocyclic rings, to mention some: vitamins, enzymes, hormones, proteins, carbohydrates, alkaloids, steroids, nucleic acids and various other bioactive molecules. ${ }^{6}$ In addition, these rings often act as a pharmacophore group when present in drug structure. ${ }^{7}$

Amidst the numerous categories of heterocyclic compounds, $1 \mathrm{H}-1,2,3$-triazole and their derivatives stand out as they constitute an important class of heterocycles in scientific academic and industrial research. For example, studies involving $1 \mathrm{H}$-1,2,3-triazole derivatives report a number of important biological activities, such as antimicrobial, ${ }^{8}$ antiviral, ${ }^{9}$ antineoplastic, ${ }^{10}$ trypanosomicide, ${ }^{11}$ antimalarial, ${ }^{12}$ antibacterial, ${ }^{13}$ antiinflammatory, ${ }^{14}$ antituberculosis ${ }^{15}$ and leishmanicidal. ${ }^{16}$ These derivatives have also become relevant in bioconjugation strategies ${ }^{17}$ and have been extensively used as synthetic intermediates in many industrial applications such as manufacturing of agrochemicals, ${ }^{18}$ corrosion inhibitors, ${ }^{19}$ photostabilizers ${ }^{20}$ and dyes. ${ }^{21}$ 
They also play an important role in supramolecular chemistry, ${ }^{22}$ in liquid crystals ${ }^{23}$ and polymeric materials. ${ }^{24}$ It has also been reported that compounds containing $1 \mathrm{H}-1,2,3$-triazole core have been applied in the development of biosensors used in clinical diagnostic assays. ${ }^{25}$

In addition to these applications, the $1 \mathrm{H}-1,2,3$-triazole ring is present in the structure of different commercial drugs, such as tazobactam, ${ }^{26}$ cefatrizine ${ }^{27}$ and rufinamide ${ }^{28}$ (Figure 1 ). In addition, other $1 \mathrm{H}-1,2,3-$ triazole derivatives leads like carboxyamidotriazole, ${ }^{29}$ radezolid $^{30}$ and $t$-butyldimethylsilylspyroaminooxathioledioxide (TSAO) ${ }^{31}$ are currently at the discovery phase (Figure 1).

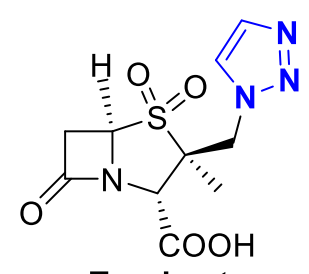

Tazobactam

Antibiotic

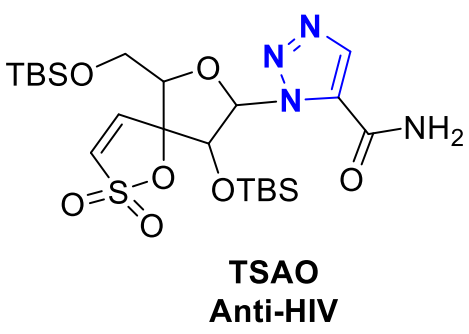<smiles>NC(=O)c1cn(Cc2c(F)cccc2F)nn1</smiles>

Rufinamid Anticonvulsant<smiles>N[C@@H](C(=O)NC1C(=O)N2C(C(=O)O)=C(CSc3c[nH]nn3)CS[C@H]12)c1ccc(O)cc1</smiles>

Cefatrizine Antibiotic<smiles>NC(=O)c1nnn(Cc2cc(Cl)c(C(=O)c3ccc(Cl)cc3)c(Cl)c2)c1N</smiles>

Figure 1. Commercial drugs and drug prototypes in preclinical phase containing the $1 H-1,2,3-$ triazole nucleus.

The interest in this class of compounds is justified by the increasing number of publications in the last two decades, as according to a research in three of the largest journal search platforms (Web of Science, ${ }^{32}$ PubMed ${ }^{33}$ and Scopus ${ }^{34}$ ) using the keyword "1,2,3-triazoles" (Figure 2).

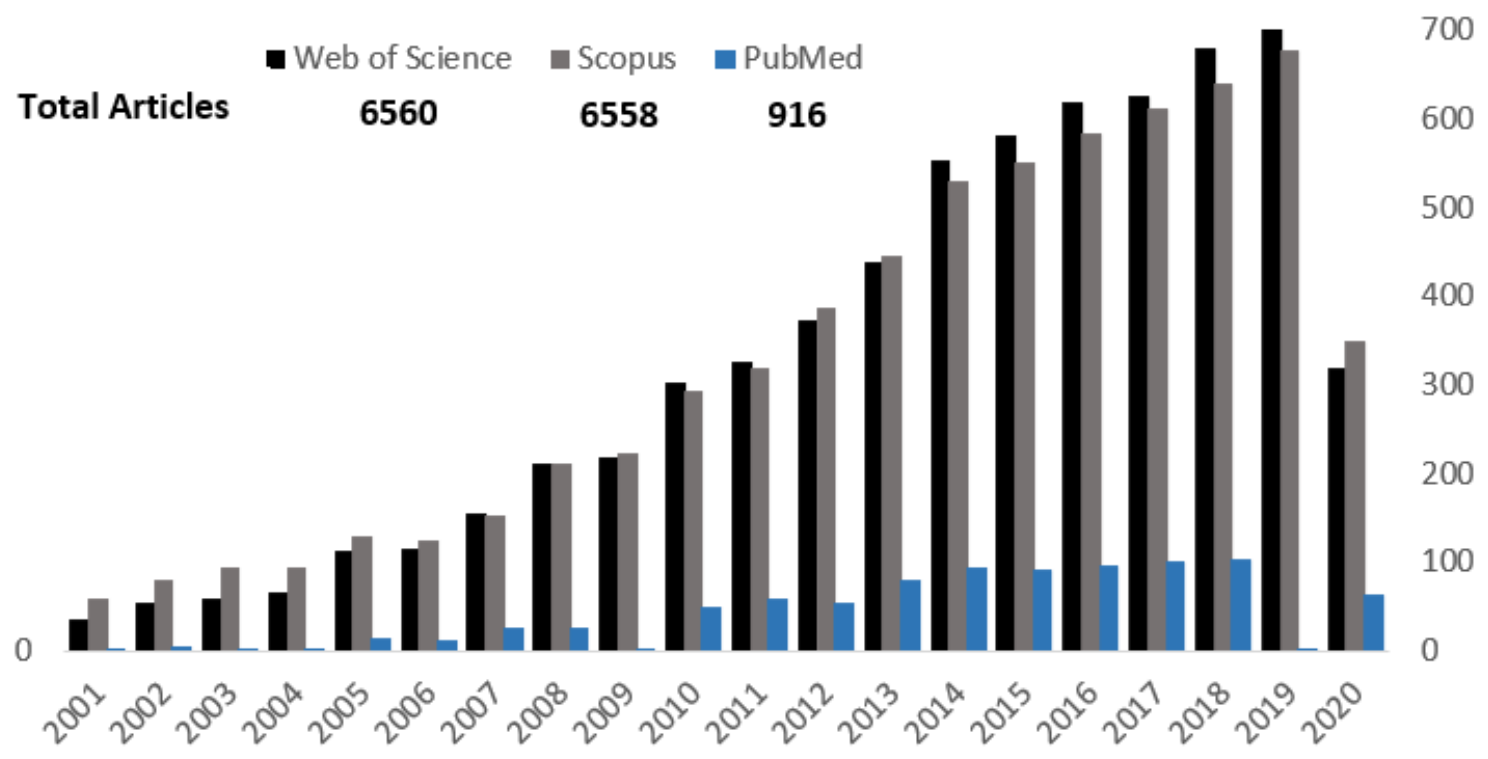

Figure 2. Publications of the last 20 years on 1,2,3-triazoles in scientific search platforms. $^{32-34}$ 
The literature describes different synthetic strategies for the preparation of $1 \mathrm{H}$-1,2,3-triazolic derivatives and the vast majority of methods exist based on the chemistry of copper salts, although recently other metals have been used. ${ }^{35}$ Therefore, the main focus of this review is to complement and update information on the properties and main methods of preparation of $1 \mathrm{H}-1,2,3$-triazole derivatives, with an emphasis on methods involving organic azides and copper-catalyzed terminal alkynes. Emphasis will also be given to the mechanisms associated during the construction of the triazole nucleus.

\section{Generalities: Structure, Classification and Main Properties}

Parent triazoles, also known as pyrrodiazoles, have in their structure two carbon atoms, three hydrogen atoms. This five-membered heteroaromatic ring has molecular formula $\mathrm{C}_{2} \mathrm{H}_{3} \mathrm{~N}_{3}$ and has two isomeric structures called symmetric triazoles or "s-triazoles" (1,2,4-triazoles) and vicinal triazoles or " $v$-triazoles" (1,2,3-triazoles). ${ }^{36}$ Moreover, when there are no substituent groups on the structure of these rings, each of these isomeric classes can have equilibrium in two distinct $\mathrm{NH}$-tautomers, structures (a) and (b) (Scheme 1). ${ }^{37}$ The structures (c) and (f) tautomers do not have aromatic characteristics or stability in this equilibrium.

1,2,3-triazole tautomers (vicinal triazoles)

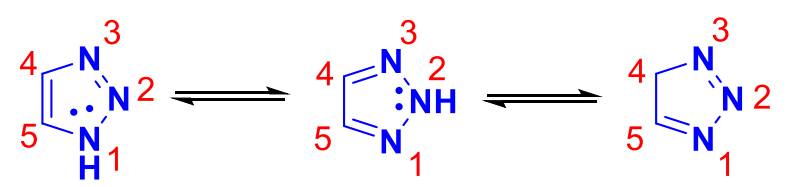

(c) (a)

(b)

$1 H$-1,2,3-triazole $\quad 2 H-1,2,3$-triazole

\section{1,2,4-triazole tautomers (symmetric triazoles)}

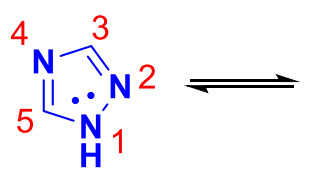

(d)

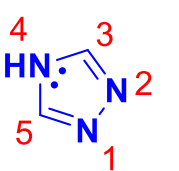

(e)

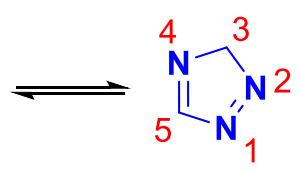

(f)

4H-1,2,3-triazole $\quad 1 H-1,2,4$-triazole $\quad 4 H-1,2,4$-triazole

$3 H-1,2,4$-triazole

Monocyclic 1,2,3-triazoles

Monocyclic 1,2,4-triazoles

Scheme 1. 1,2,3-triazoles and 1,2,4-triazole derivatives and their tautomers. Adapted from Melo et al. ${ }^{36}$

The aromatic structures of $1 \mathrm{H}$-1,2,3-triazole (a) and $2 \mathrm{H}$-1,2,3-triazole (b) (Scheme 1 ) are the most stable tautomeric forms of the 1,2,3-triazolic ring. The nitrogen atoms present in these tautomers have distinct basicity, since one of the nitrogen atoms donates its electron pair to complete the pyrrole-like aromatic sextet, while the other two nitrogens have isolated electron pairs that are not part of the aromatic sextet, similar to pyridine (Scheme 2). Also, in the pyrrole type nitrogen, the $\mathrm{N}-\mathrm{H}$ bond is weakly acidic, whereas pyridine nitrogen is basic and nucleophilic. ${ }^{38}$

In the structure of $1 \mathrm{H}-1,2,3$-triazole the three adjacent nitrogen atoms cause a strong polarization in the structure of this triazole ring. ${ }^{39}$ This polarization is easily seen when comparing the resonance contributors of the most relevant tautomers of $1 \mathrm{H}$-1,2,3-triazole (Scheme 3). In the contributors of the 1H-1,2,3-triazole tautomer (a), the carbon atoms and position 1 nitrogen have positive partial charge density, while positions 2 and 3 nitrogen have negative charge density, generating a high polarization and a dipole moment of 4.55 D. ${ }^{40,41}$ By contrast, in the contributors of the $2 \mathrm{H}-1,2,3$-triazole tautomer (b), the carbon atoms and nitrogen of position 2 have a positives partial charge density and nitrogen at positions 1 and 3 have a negative partial charge, which causes a lower polarization and a smaller dipole moment of 0.12 D. ${ }^{40,41}$ 
Pyrrole type nitrogen

Electrons located in the $p$ orbital<smiles>c1ccc2[nH]ccc2c1</smiles>

Pyrrole

Pyridine type nitrogen

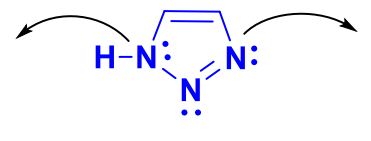

1H-1,2,3-triazole

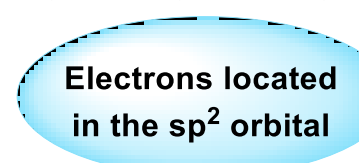<smiles>c1ccncc1</smiles>

Pyridine

Scheme 2. Similarity of $1 H$-1,2,3-triazole nitrogen to pyrrole and pyridine nitrogen. Adapted from Schulze and Schubert. $^{22}$
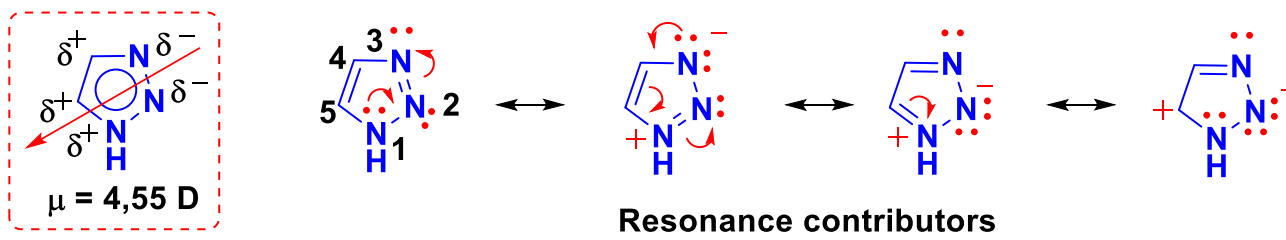

Resonance contributors

1H-1,2,3-triazole dipole moment (a)
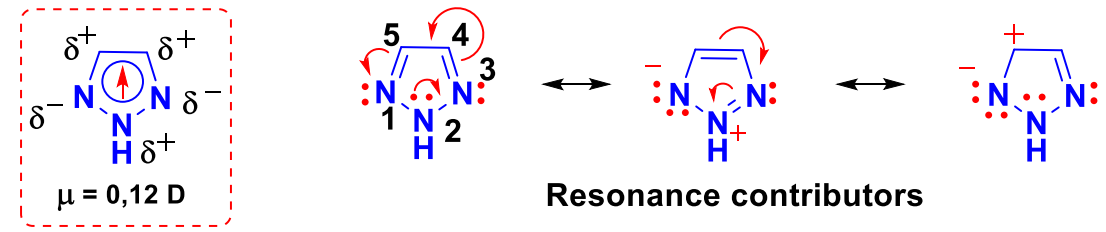

2H-1,2,3-triazole dipole moment (b)

Scheme 3. Resonance contributors of the two most stable tautomers of $1 H-1,2,3$-triazole. Adapted from Schulze, 2014. ${ }^{22}$

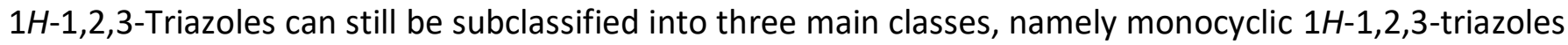
(Scheme 1), benzotriazoles and 1,2,3-triazolium salts (Scheme 4). These last two classes may exist in an isomeric equilibrium. ${ }^{42}$

As a result of the numerous studies on $1 \mathrm{H}$-1,2,3-triazoles it has been found that they have important peculiarities, to cite, strong resistance to certain reaction conditions without undergoing chemical changes in their structures, they are weakly reactive towards acidic or basic hydrolysis, under oxidative or reducing conditions and even enzymatic degradation. ${ }^{43,44}$ However, under strongly alkylating conditions they may undergo alkylation reactions. ${ }^{45}$

$1 H-1,2,3$-Triazoles have dipole-dipole interactions, are hydrogen bond donors and acceptors, have $\pi$ stacking, ${ }^{46}$ and the nitrogen in this ring behaves as weak bases, which are not protonated at physiological $\mathrm{pH}$, facilitating their interaction with high-affinity biological targets. ${ }^{47}$ These heterocycles are also able to mimic various functional groups in the biological environment, such as amides, esters, carboxylic acids, and act as analogs of olefins and other nitrogen-containing five-membered heterocyclic rings. ${ }^{48}$ 


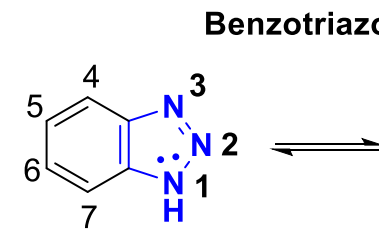

(g)

$1 H$-benzotriazole

Isomers of monocyclic 1,2,3-triazole salts

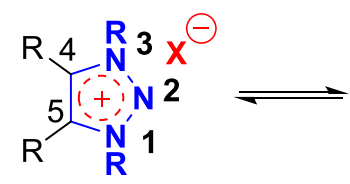

(i)

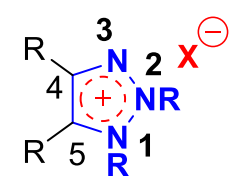

(j)

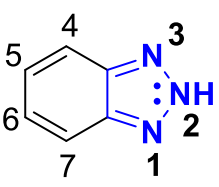

(h)

2H-benzotriazole

Isomers of benzotriazolic salts

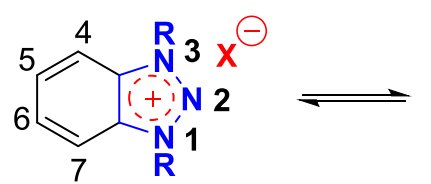

(k)

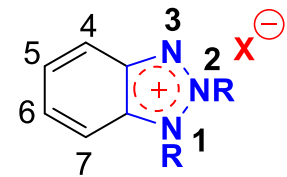

(I)

Scheme 4. Structure of benzotriazoles and 1,2,3-triazole salts. Adapted from Dheer, $2017 .{ }^{42}$

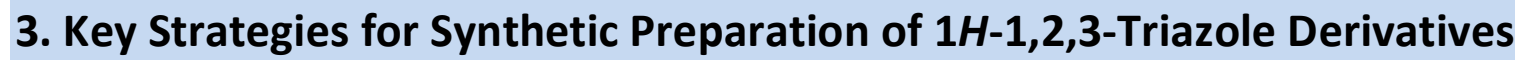

\subsection{Historic aspects of $1 \mathrm{H}-1,2,3$-triazole derivatives and thermal 1,3-dipolar azide-alkyne cycloaddition (AAC)}

To date, no natural product containing a triazole unit in its molecular architecture has been described, thus they are exclusively of synthetic origin. ${ }^{49,50}$ However, their stability, versatility and easy preparation make 1,2,3-triazoles compounds with a wide field of applications, which undoubtedly drives the research and development of synthetic strategies for their preparation.

The first reports of the preparation of a $2 \mathrm{H}-1,2,3$-triazole derivative date from the 19th century, more specifically from 1888, when the German chemist Hans von Pechmann reported the preparation of 2-aryl-2H1,2,3-triazoles from reaction of bis-phenylhydrazones with nitric acid under heating (Scheme 5). ${ }^{51}$

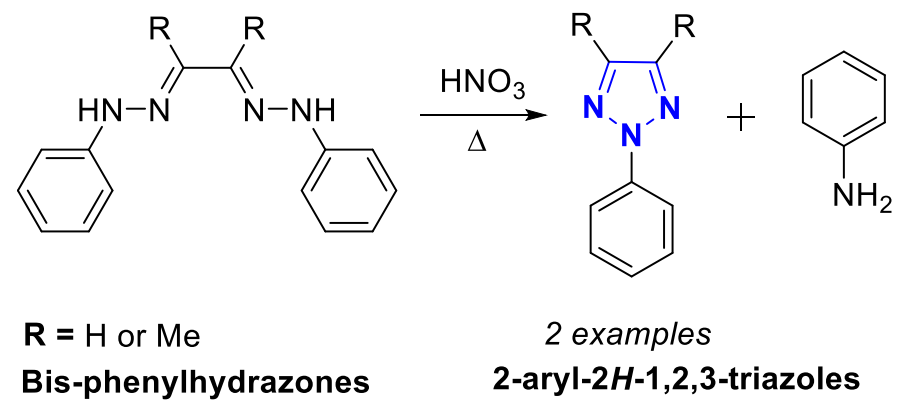

Scheme 5. Pioneer synthesis of the 1,2,3-triazolic ring. Adapted from Melo, 2006. ${ }^{36}$

In 1893, researcher Arthur Michael discovered that the reaction between dimethyl acetylenedicarboxylate and phenyl azide led to the formation of a product containing the $1 \mathrm{H}-1,2,3$-triazole ring called 1,1'-(1-phenyl-1H-1,2,3-triazol-4,5-diyl)bis(ethan-1-one), which was isolated by distillation (Scheme 6). ${ }^{52}$ This report was marked as the first 1,3-dipolar cycloaddition reaction between an organic azide and an alkyne. 


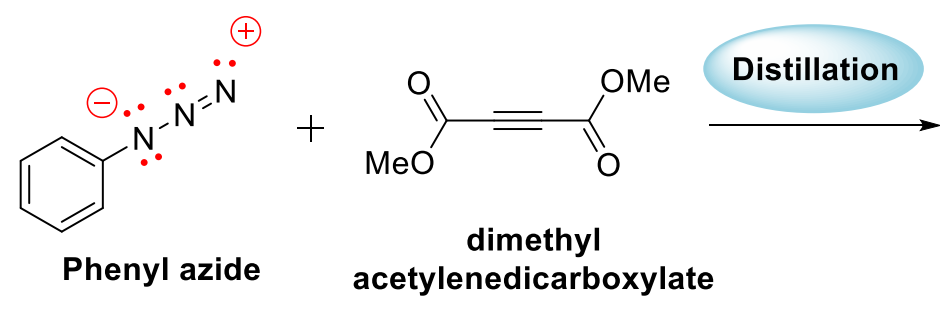<smiles>COC(=O)c1nnn(-c2ccccc2)c1C(=O)OC</smiles>

1,4,5-trisubstituted triazole

Scheme 6. First 1,3-dipolar cycloaddition between an organic azide and an alkyne. Adapted from Melo, $2006 .{ }^{36}$

However, this research did not call the interest of the scientific community and only 70 years later this reaction was carefully examined by Rolf Huisgen in 1963, who classified it as $(3+2)$ 1,3-dipolar cycloaddition. ${ }^{53,54}$ According to Huisgen, a 1,3-dipolar (dipole) substance reacts with a multiple bond or a $\pi$ system (dipolarophilic) by means of a concerted mechanism involving a transition state of six electrons, leading to the formation of a variety of five-membered heterocyclic compounds (Scheme 7). Since Huisgen's work involved the cycloaddition reactions between organic azides and alkynes, this type of reaction has been known in the literature as Huisgen's cycloaddition (abbreviated as AAC: alkyne-azide cycloaddition).

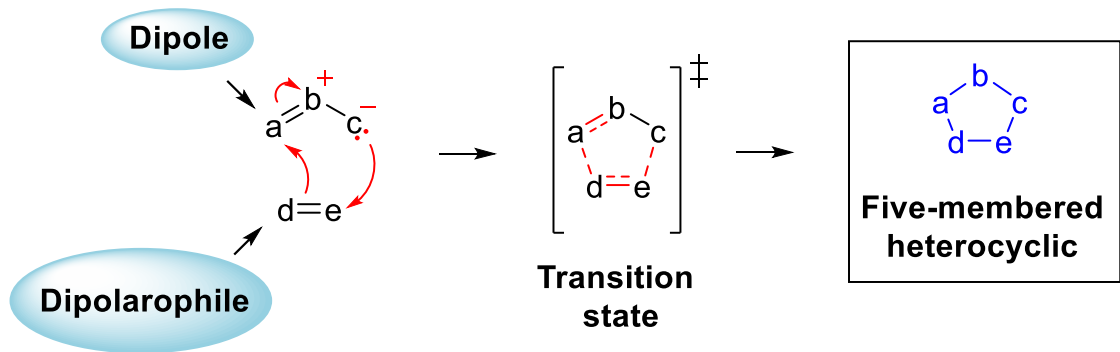

Concerted mechanism

Scheme 7. Cycloaddition mechanism proposed by Huisgen. Adapted from Bräse, $2010 .^{55}$

The 1,3-dipolar cycloaddition reaction is a type of pericyclic reaction in which Huisgen and colleagues ${ }^{56-58}$ have intensively studied the route for the synthesis of di- or trisubstituted $1 \mathrm{H}-1,2,3$-triazoles from the reaction between organic azides and alkynes. In these reactions, the acetylenic derivatives are mixed with the organic azides and the contents are typically refluxed in toluene or heated without solvent. However, these reactions need caution during execution as some cases of explosions have been reported. ${ }^{59-61}$ In addition, cycloaddition reactions have particular limitations, such as highly exothermic processes $\left(\Delta \mathrm{H}^{0}\right.$ between -50 and $-65 \mathrm{kcal}$ mol $\left.{ }_{1}^{1}\right)^{62}$ with high activation energy (approximately $25 \mathrm{kcal} \mathrm{mol}^{-1}$ ); for instance, the reaction between methyl azide and propyne requires and high temperatures. ${ }^{63}$ Another important limitation is the very low or nonexistent regioselectivity, since the products of thermal cycloaddition are formed as a mixture of 1,4 and 1,5disubstituted regioisomers. Additionally, these triazole products are obtained in low yields after long reaction times (Scheme 8). 


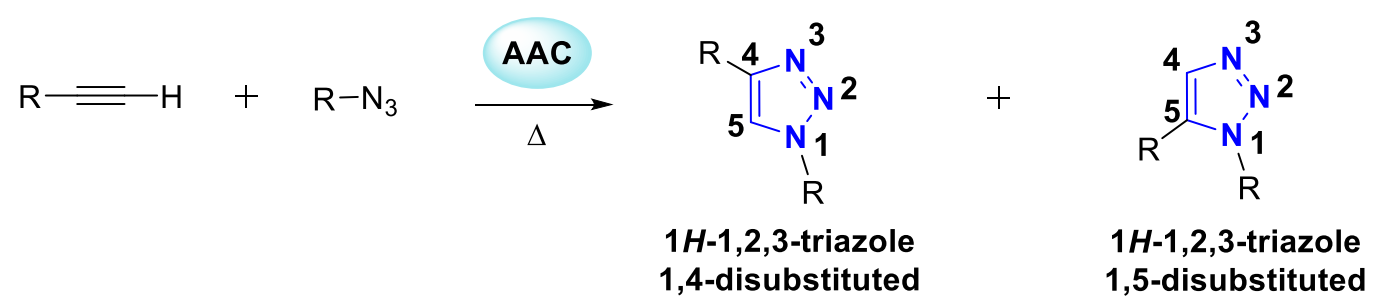

Scheme 8. Triazole regioisomers formed from 1,3-dipolar thermal cyclization. ${ }^{63}$

To understand some phenomena associated with 1,3-dipolar cycloaddition, Sustmann ${ }^{64,65}$ and Houk $^{66}$ used frontier molecular orbitals (FMO) models to describe the observed velocity and regioselectivity for cycloaddition reactions. In their models, they assumed that the reaction between 1,3-dipole and dipolarophile occurs essentially through the interaction of the highest occupied molecular orbital (HOMO) of a reagent and the lowest unoccupied molecular orbital (LUMO) of the other reagent where the reaction rate depends on the energy difference between them.

The energy differences between the frontier molecular orbitals HOMO and LUMO of azides and alkynes are of similar magnitude and when electron donating group (EDG) or electron releasing groups (ERG) are directly linked to dipolarophiles (alkynes) or 1,3-dipoles (azides), frontier orbital energies and coefficients are subject to variations that directly influence the reactivity of cycloaddition reactions. ${ }^{67}$ An electron donating group increases HOMO energy, while an electron withdrawing group decreases LUMO energy, this causes the reaction rate to increase and, furthermore, the EDGs and EWGs will polarize the $\pi$-system influencing the regioselectivity of the reaction, since the interaction will occur such that the orbitals with higher coefficients

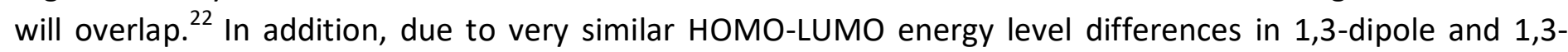
dipolarophile, the cycloaddition reaction may proceed through a dipole-HOMO, forming the 1,4-disubstituted regioisomers or dipole-LUMO controlled favoring the 1,5-disubstituted regioisomers (Scheme 9). ${ }^{22,68}$
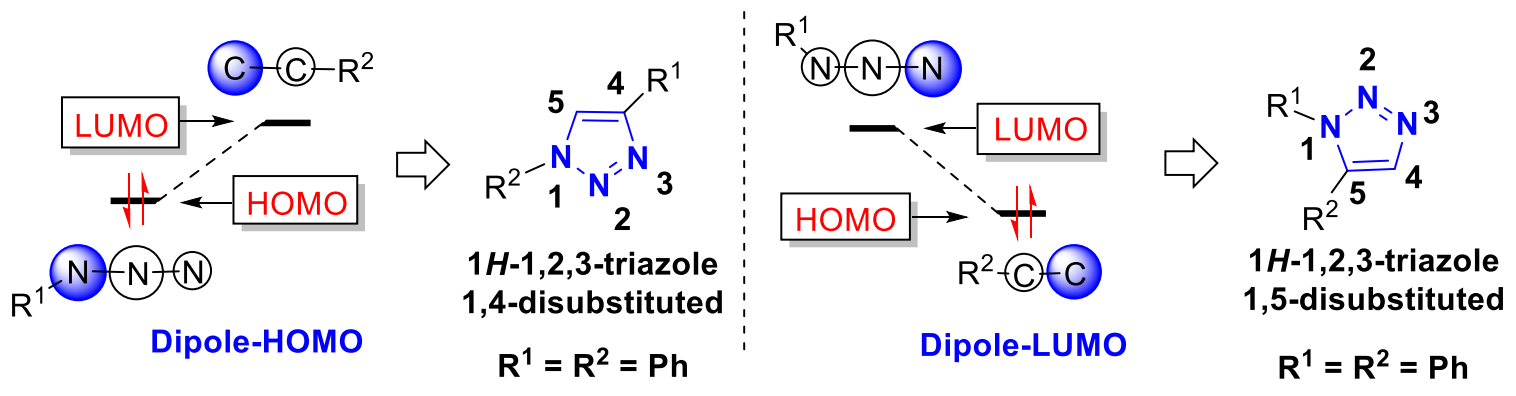

Scheme 9. Interpretation of FMO in 1,3-dipolar cycloaddition between azides and alkynes. Adapted from Schulze, 2014. ${ }^{22}$

\section{2 $\mathrm{Cu}(\mathrm{I})$-catalyzed 1,3-dipolar cycloaddition between azides and alkynes}

Although the 1,3-dipolar thermal cycloaddition reaction between azides and alkynes leads to relatively easy formation of $1 \mathrm{H}$-1,2,3-triazole derivatives, the limitations imposed by this reaction, in particular its low regioselectivity and the need for high temperatures, caused the AAC reaction to remain underused and ignored for decades. It is noteworthy that some research groups have studied the regioselectivity of this reaction, ${ }^{69-71}$ however, the development of a robust method for regiospecific formation of a specific triazole regioisomer was not achieved until the early 2000 s. 
In 2002 this scenario changed when Morten P. Meldal ${ }^{72}$ in Denmark and Karl Barry Sharpless ${ }^{73}$ in the United States independently reported the use of copper in the 1,3-dipolar cycloaddition between organic azides and terminal alkynes in a highly efficient manner. This discovery heralded a revival in triazole chemistry. Despite the importance of these studies, it is relevant to mention that the use of copper was first reported in 1984 by Gerrit L'abbé when using copper chloride ( $\mathrm{CuCl}$ ), lithium azide $\left(\mathrm{LiN}_{3}\right)$ and an internal alkyne in order to obtain azidoallenes in one-pot form. ${ }^{74}$ Although L'abbé did not expect the formation of 1,2,3-triazole derivatives, they were formed as a byproduct due to a side reaction that resulted in triazole derivatives with yields ranging from 6 to $24 \%$ and, in addition, 50 to $70 \%$ of the starting reagents were recovered without reaction (Scheme 10).

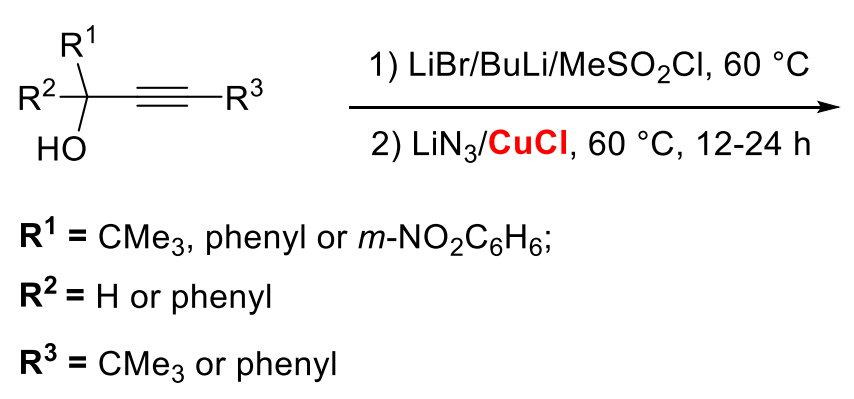

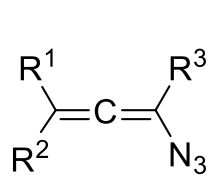

Azidoallenes $0 \%$

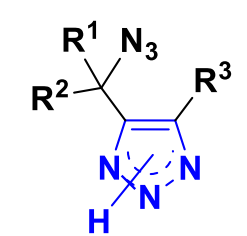

Byproduct $6-24 \%$ 12 examples

Scheme 10. First report of the use of copper in the formation of 1,2,3-triazole derivatives. ${ }^{74}$

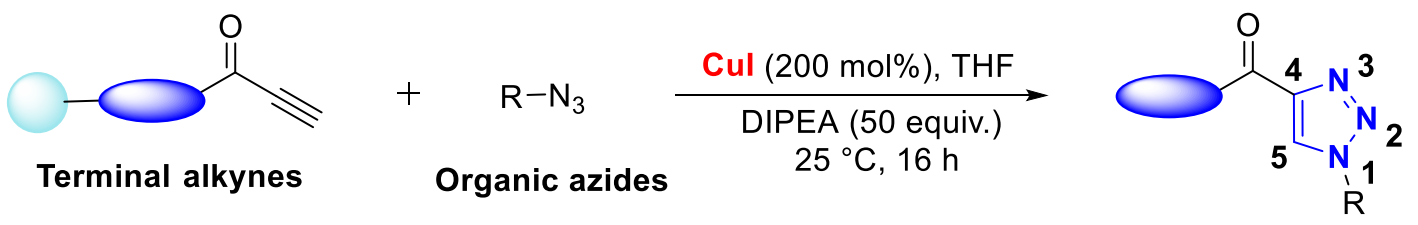

$=$ HMBA-PEGA800

= Peptide: Phe-Gly-Phe-Gly

1,4-disubstituted $1 H$-1,2,3-triazole

Group $\mathbf{R}$ variation<smiles>CC(C)(C)C(=O)OC(=O)C(C)(C)C(=O)O</smiles><smiles>CCC(CC)C(=O)O</smiles>

$95 \%$<smiles>CCC(CC)(CC)C(=O)O</smiles>

$95 \%$<smiles>CCCC(CCCCC(=O)O)(CCC(=O)O)C(=O)O</smiles>

$95 \%$

17 examples<smiles>CCC(CC)C(=O)O</smiles>

$95 \%$<smiles>CCC(C)C(=O)O</smiles>

$91 \%$<smiles>CCC(C(=O)O)c1ccccc1CCc1ccc(N)cc1</smiles><smiles>CCC[C@H](N)CC(=O)O</smiles><smiles>CCCCN</smiles>

$75 \%$<smiles>[Y6]C1[C@H](O)[C@@H](O)[C@@H](CO)O[C@@]1(S)c1ccccc1</smiles>

Scheme 11. Synthesis of peptidotriazoles on solid phase. ${ }^{72}$ 
Given the low yields and the unexpected formation of triazoles, no other research related to the observation of L'abbé ${ }^{74}$ was conducted for approximately two decades, until the studies of Meldal $^{72}$ and Sharpless ${ }^{73}$ were published. Meldal et al. ${ }^{72}$ reported the preparation of peptidotriazoles from amino acids containing terminal alkynes bound to a solid resin (HMBA-PEGA ${ }_{800}$ ). They observed that the use of copper iodide induced the exclusive formation of 1,4-disubstituted $1 \mathrm{H}-1,2,3$-triazole, even employing primary, secondary, and tertiary azides (Scheme 11).

Meldal et al. ${ }^{72}$ also found that the cycloaddition reaction when performed in the presence of copper (I) halides and organic solvents formed oxidative coupling byproducts and $1 \mathrm{H}-1,2,3$-triazole derivative was obtained in moderate yield ${ }^{62}$ (Scheme 12).

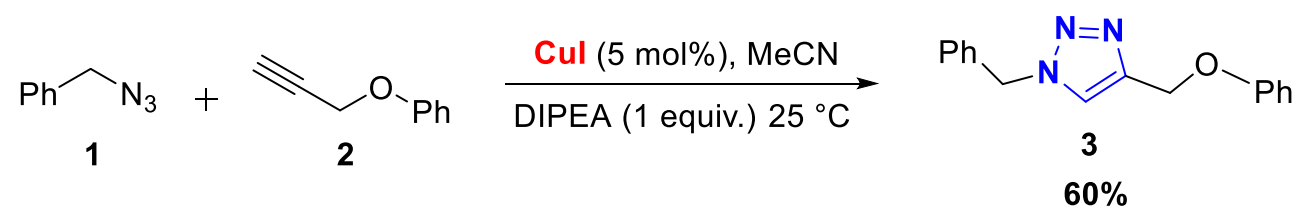

Oxidative coupling byproducts

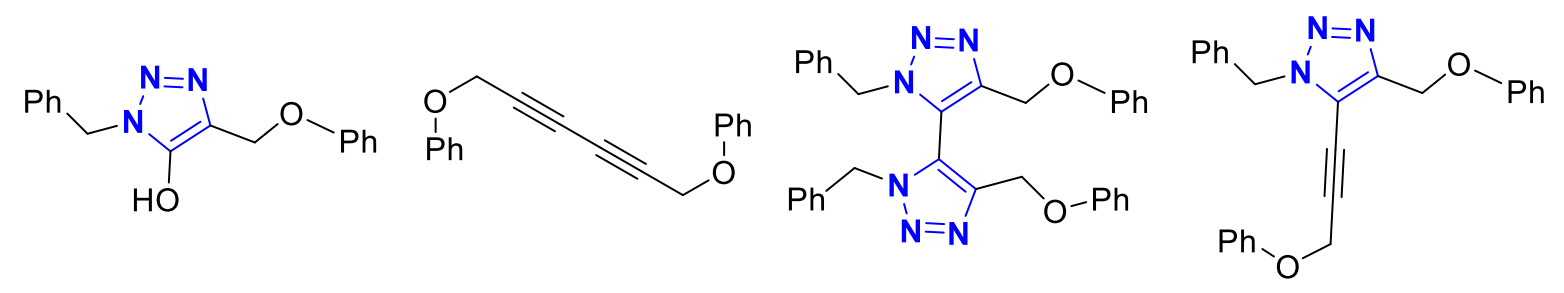

Scheme 12. Byproducts reported by the Meldal group during synthesis of product $\mathbf{3}^{72}$

Unlike the work of Meldal et al., ${ }^{72}$ Professor Sharpless ${ }^{13}$ research group reported milder conditions for the preparation of triazole units by reducing $\mathrm{Cu}(\mathrm{II})$ in situ from copper sulfate pentahydrate $\left(\mathrm{CuSO}_{4} \cdot 5 \mathrm{H}_{2} \mathrm{O}\right)$ to $\mathrm{Cu}(\mathrm{I})$ using sodium ascorbate ( $\mathrm{ASCNa}$ ) as reducing agent. In addition, the reaction described by Sharpless led to the 1,4-disubstituted $1 \mathrm{H}$-1,2,3-triazole exclusively and in better yields using a hydroalcoholic system (Scheme 13).

In general, when the cycloaddition reaction between organic azides and alkynes is catalyzed by $\mathrm{Cu}(\mathrm{I})$, the reaction are more quickly and regioselective. Fokin and colleagues ${ }^{63}$ found that these reactions were 107 times faster when compared to the thermal process described by Huisgen. As usual when salts of $\mathrm{Cu}(\mathrm{I})$ were employed 1,4-disubstituted triazolic regioisomers are formed exclusively. Other aspect is that cycloaddition catalyzed by $\mathrm{Cu}(\mathrm{I})$ is less affected by the steric or electronic effects from the groups linked to alkynes or azides and, consequently, differently substituted terminal alkynes and primary, secondary and tertiary azides can be used in this reaction. ${ }^{62}$

Given the contributions of Sharpless and Meldal, the 1,3-dipolar cycloaddition reaction between a terminal alkyne and a copper catalyzed organic azide has become the most widely used method for the preparation of $1 \mathrm{H}-1,2,3$-triazoles and is known to the scientific community as a CuAAC (copper(I)-catalyzed alkyne-azide cycloaddition).

It is noteworthy that CuAAC is part of a select group of reactions known as click chemistry, Karl Barry Sharpless ${ }^{75}$ introduced this term in 2001. Thus, a reaction to be considered a click-process must meet the following criteria: "the reaction must be modular, wide in scope, give very high yields, generate only inoffensive byproducts that can be removed by nonchromatographic methods, and be stereospecific (but not 
necessarily enantioselective). The required process characteristics include simple reaction conditions (ideally, the process should be insensitive to oxygen and water), readily available starting materials and reagents, the use of no solvent or a solvent that is benign (such as water) or easily removed, and simple product isolation. Purification - if required - must be by non-chromatographic methods, such as crystallization or distillation, and the product must be stable under physiological conditions".
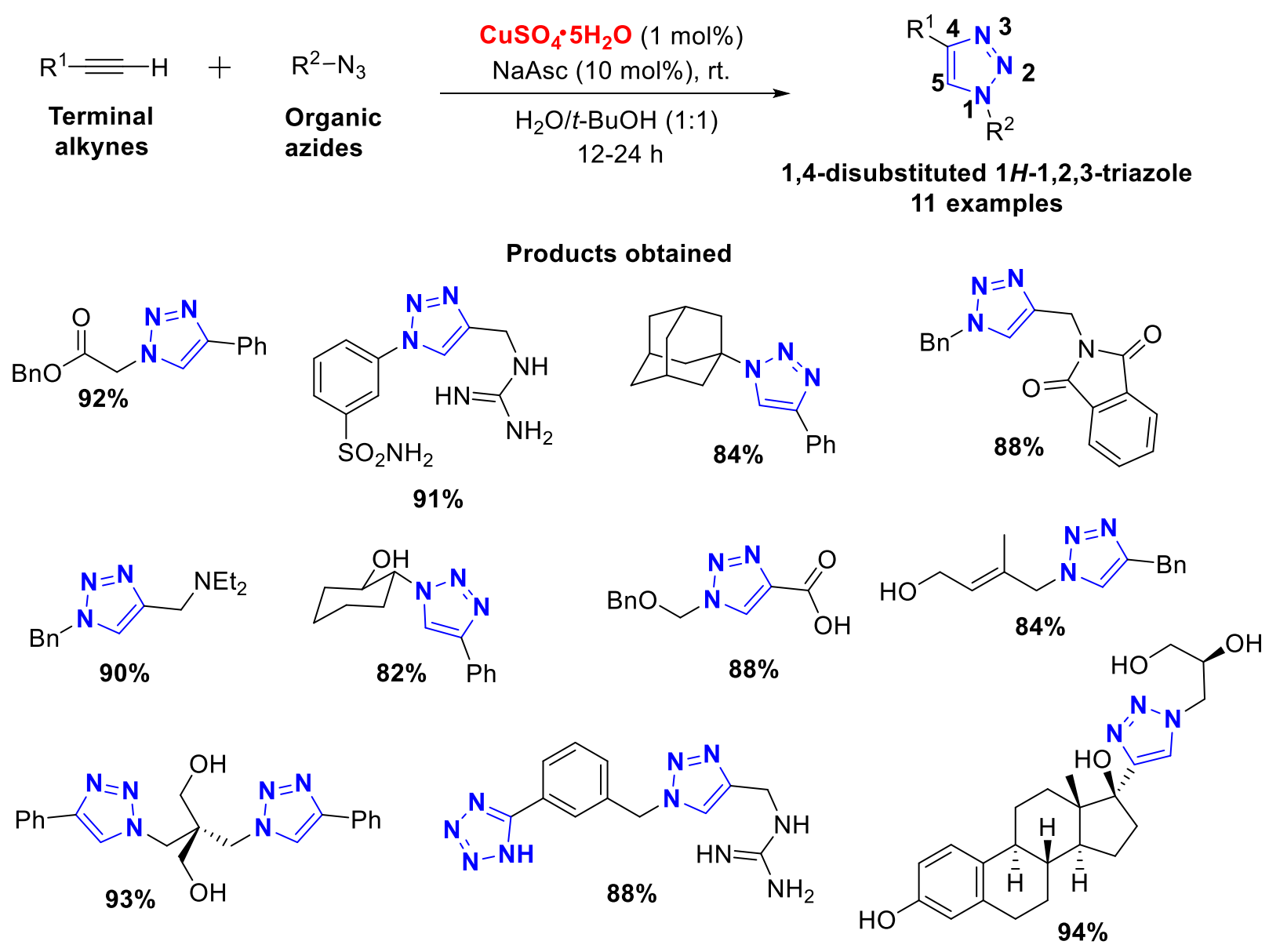

Scheme 13. First report of the use of $\mathrm{CuSO}_{4} \cdot 5 \mathrm{H}_{2} \mathrm{O}$ and $\mathrm{AScNa}$ in the preparation of 1,4-disubstituted $1 \mathrm{H}-1,2,3-$ triazole. $^{73}$

\subsection{CuAAC reaction mechanism}

In the investigation of mechanism of the CuAAC reaction, the exact function of copper and a plausible proposal for this mechanism have been discussed by several researchers until the present days and numerous experimental and theoretical studies can be found in the literature. ${ }^{63,73,76-91}$ The first plausible proposal for a CuAAC reaction mechanism was developed by Sharpless and colleagues in 2002 (Scheme 14). ${ }^{73}$ It starts with the a $\pi$-interaction of the copper (I) species to the alkyne terminal, forming the mononuclear copper (I) acetylide (1). Subsequently, alkyd nitrogen from organic azide coordinates with copper (I) acetylide leading to the formation of the intermediate complex (2). Then, the six-membered copper (III) metallacycle is formed, containing the covalent $\mathrm{C}-\mathrm{N}$ bond (3). The mechanism continues with the contraction of the metallacycle, together with the reduction of copper (III) to copper (I), forming the cuprous triazolide (4). In this step, if there is no proton source available, the cuprous triazolide should acquire a proton from an alkaline molecule, 
completing the formation of 1,4-disubstitued $1 \mathrm{H}-1,2,3$-triazole (5) and releasing copper (I) to enter again in the catalytic cycle.

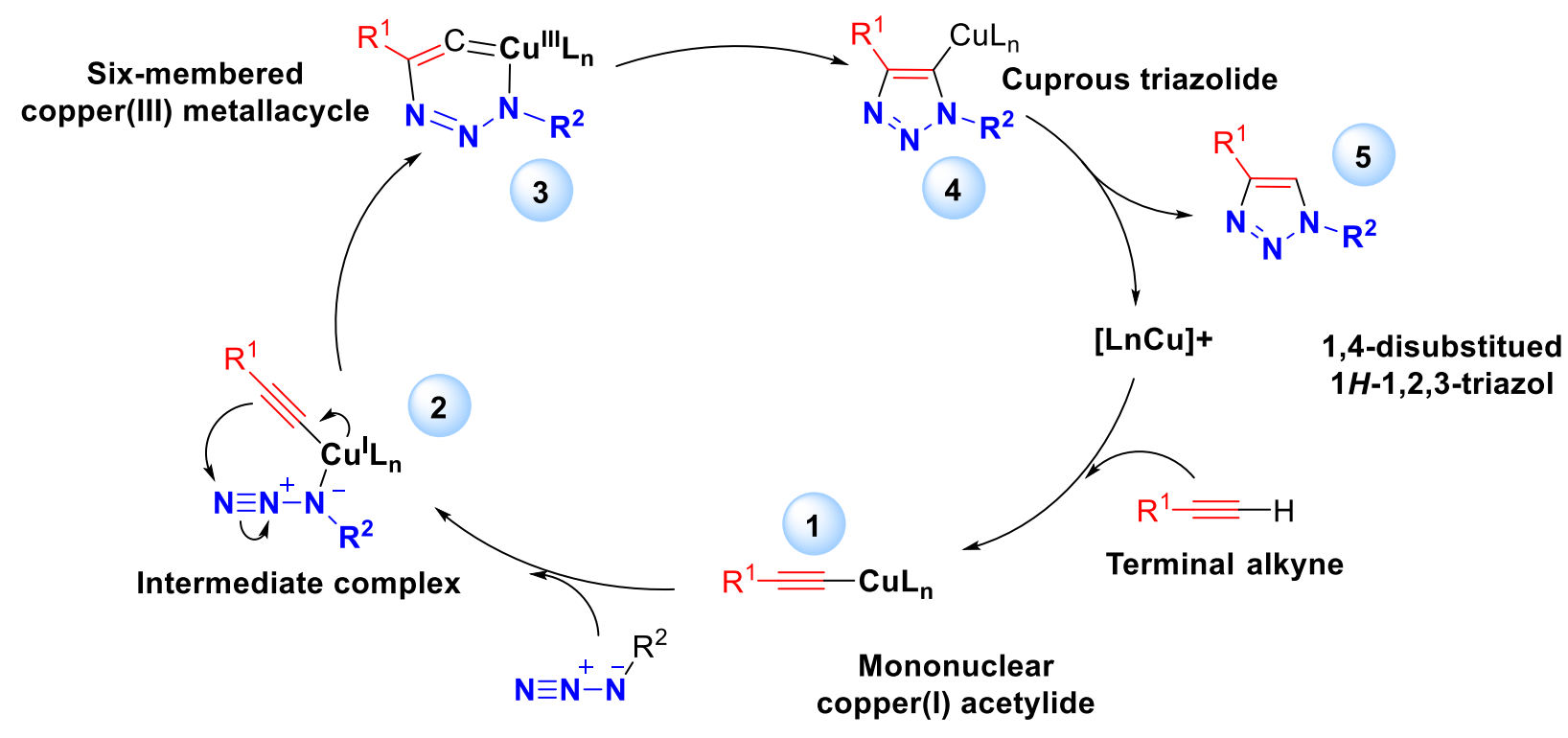

Scheme 14. First proposal for a CuAAC reaction mechanism. ${ }^{73}$

This initial proposal for a mechanism was supported by DFT calculations carried out by Fokin and collaborators in $2005 .^{63}$ The results of this study indicated that the complexation of copper (I) with the $\pi$ system of the terminal alkyne decreases the $\mathrm{pK}_{\mathrm{a}}$ of the terminal proton by 9.8 units, facilitating the deprotonation stage from the intermediate $\pi$-alkyne-Cupper (I) for the formation $\sigma$-alkyne-Cu (I) species even in aqueous systems, without the need for base addition. Their calculations also predicted that the activation barrier for the formation of a six-membered copper (III) metallacycle was $14.9 \mathrm{kcal} \mathrm{mol}^{-1}$. In comparison with a $25.7 \mathrm{kcal} \mathrm{mol}^{-1}$ barrier for non-catalyzed cycloaddition, justifying the drastic increase in the rate of the cycloaddition reaction in the presence of copper (I). However, theoretical and experimental considerations about the mechanism of the CUAAC reactions were published and added to this initial proposal.

The results of the first experimental investigation of the CuAAC reaction mechanism were reported by Fokin and colleagues in $2005 .^{76}$ In this work, a careful kinetic investigation of the reaction between phenylacetylene and benzyl azide revealed a strict second order dependence on copper (I) under the employed catalytic conditions. However, it was found that the experimental rate law for the CuAAC reaction varied in complex ways with the concentration of $\mathrm{Cu}(\mathrm{I})$, the presence of chloride ions and accelerator ligands. ${ }^{77}$ In view of these experimental results, the authors considered the possibility of the involvement of polynuclear copper (I) intermediates; however, theoretical studies published in 2007 indicated that dinuclear copper (I) intermediates were favored. ${ }^{78,79}$ The results from these theoretical studies pointed out that the introduction of another copper atom could ease the tension in the six-membered copper (III) metallacycle. Furthermore, the complexes formed between organoazides and $\mathrm{Cu}(\mathrm{I})$-acetylides were just assumptions made by Sharpless's group, until direct evidence was provided in 2007 by Straub and collaborators. ${ }^{80}$ The authors isolated and characterized for the first time the intermediate $\mathrm{Cu}(\mathrm{I})$-triazolide (4, Scheme 14), which is formed by the interaction between organoazides and $\mathrm{Cu}(\mathrm{I})$-acetylides.

An important study for understanding the mechanism was reported by Fokin and collaborators in 2009. ${ }^{81}$ This study, involving cycloadditions between 1-iodoalkynes and organic azides, revealed that breaking 
the alkyne-halogen terminal bond to form copper (I) acetylide is not necessary for cycloaddition to occur. Thus, the authors concluded that the copper (I) catalyst was bound purely through weak $\pi$-interactions with 1 iodoalkynes. This strengthened the idea that this type of interaction can also occur with terminal alkynes.

An elegant isotopic study by Fokin and colleagues in $2013^{82}$ revealed that, in fact, there is the formation of a dinuclear species with two copper atoms playing different roles. One of the copper atoms forms a $\sigma$-bond with the terminal alkaline and the other atom performs a complexation with the $\pi$-system of the alkaline. Thus, Fokin and collaborators proposed a more detailed interpretation of the mechanism (Scheme 15), gathering theoretical and experimental evidence.

First, the formation of $\sigma, \pi$-bis(copper) acetylide (A) occurs, which reversibly coordinates with the substituted nitrogen of the organic azide to form the (B) complex. The selectivity in favor of the 1,4disustitued regioisomer is justified by the second species of $\mathrm{Cu}(\mathrm{l})$ that performs $\pi$-coordination with the $\alpha$ carbon from terminal alkyne. Thus, the nucleophilic attack of $\beta$-vinylidene carbon is directed to the terminal nitrogen of the azide moiety, leading to the formation of the intermediate $(\mathbf{C})$ and the first covalent $\mathrm{C}-\mathrm{N}$ bond.

The mechanism follows with an interaction of the pair of non-bonding electrons of the N-1 with the antiligand orbital of the $\alpha$-carbon from acetylene, forming the cuprous triazolide (D) and the second covalent $\mathrm{C}-\mathrm{N}$ bond. In the last stage of the mechanism, protonation of the intermediate (D) occurs with the formation of 11,4-disubstitued $H$-1,2,3-triazole (E), releasing $\mathrm{Cu}(\mathrm{I})$ in the catalytic cycle.

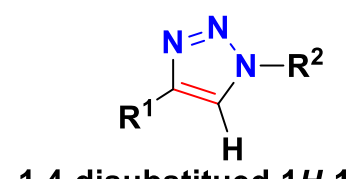

1,4-disubstitued $1 H-1,2,3-$ triazol
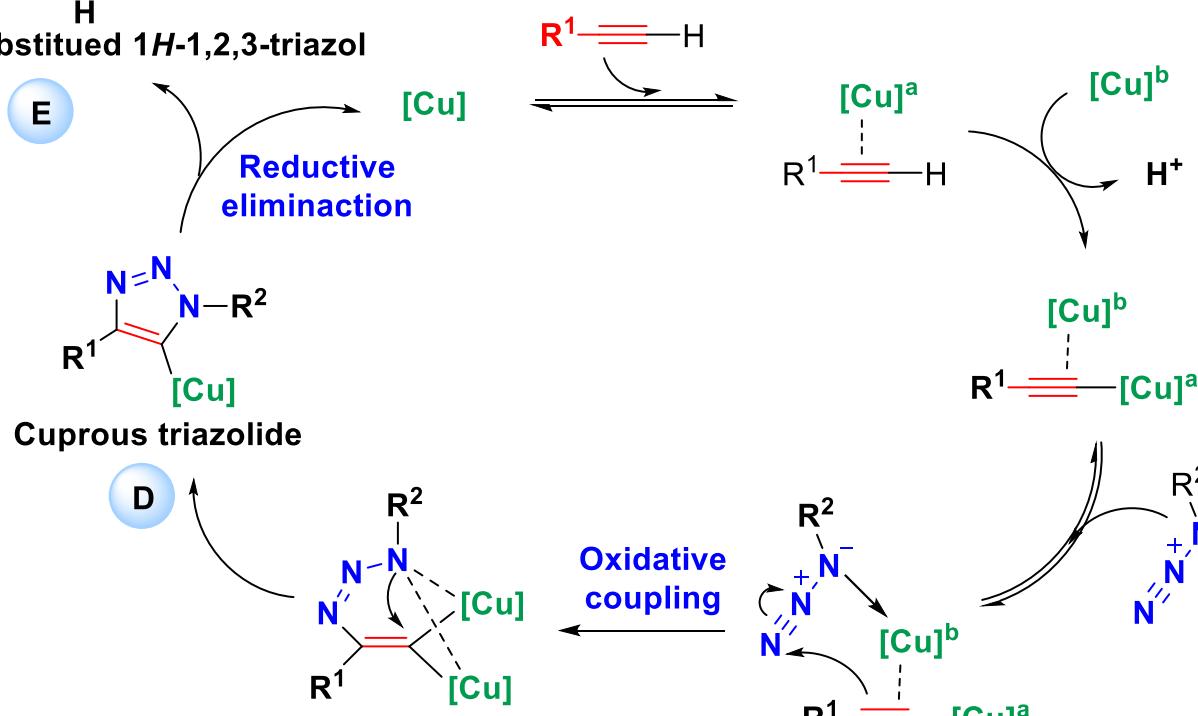

Six-membered copper(III) metallacycle
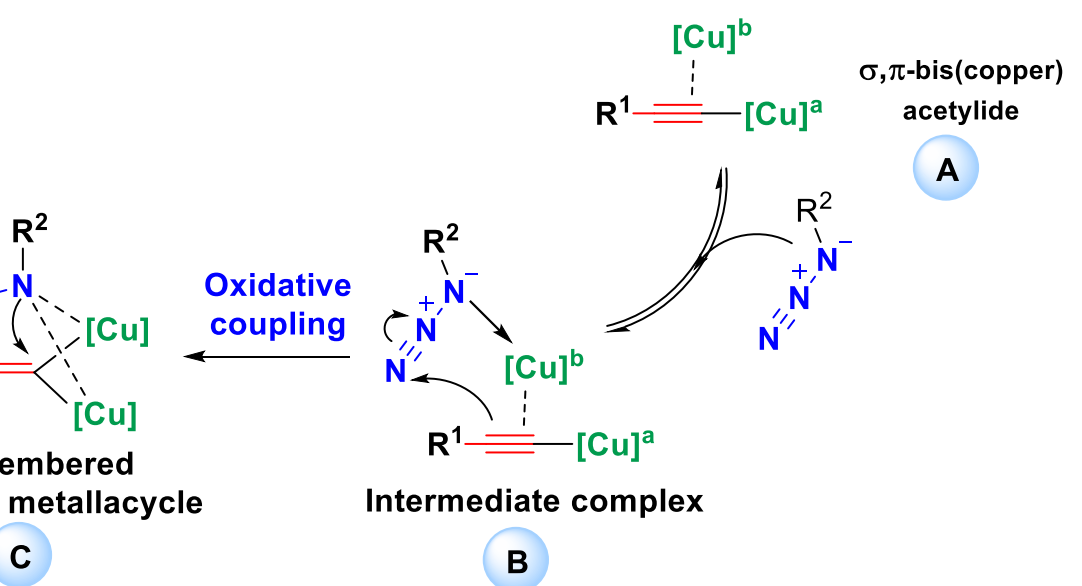

B

Scheme 15. CuAAC reaction mechanism proposed by Fokin and collaborators. ${ }^{82}$

Despite the detailed proposal for the reaction mechanism suggested by Fokin and colleagues, no direct observation of the copper dinuclear intermediates had been reported. However, in 2015, Bertrand et al. ${ }^{83}$ isolated and characterized $\pi, \sigma$-bis(copper) acetylide (A, Scheme 15 ), indicating that the reaction mechanism occurs via the formation of this intermediate. Besides that, the authors concluded that the alkyne deprotonation was considered rate determinant step, as evidenced by previous studies. ${ }^{84-86}$ We emphasize 
that Angelis et al. ${ }^{87}$ first identified the intermediate complex (B) using electrospray ionization mass spectrometry (ESI-MS), however, without isolating this intermediate complex.

Besides that, other experimental and theoretical studies on the structural characteristics of dinuclear intermediates ${ }^{88-91}$ support the dinuclear mechanism proposed by Fokin and collaborators. ${ }^{82}$

The isolation of intermediates, the study of reaction kinetics and, more recently, computational studies, are arguably the most informative knowledge to elucidate and elaborate a proposal for a reaction mechanism. Thus, the study of the CuAAC reaction mechanism has been marked by discoveries that involved the kinetic study, as well as the isolation of intermediates, and theoretical studies. Figure 3 shows a timeline of the main events that led to a better understanding about this mechanism.

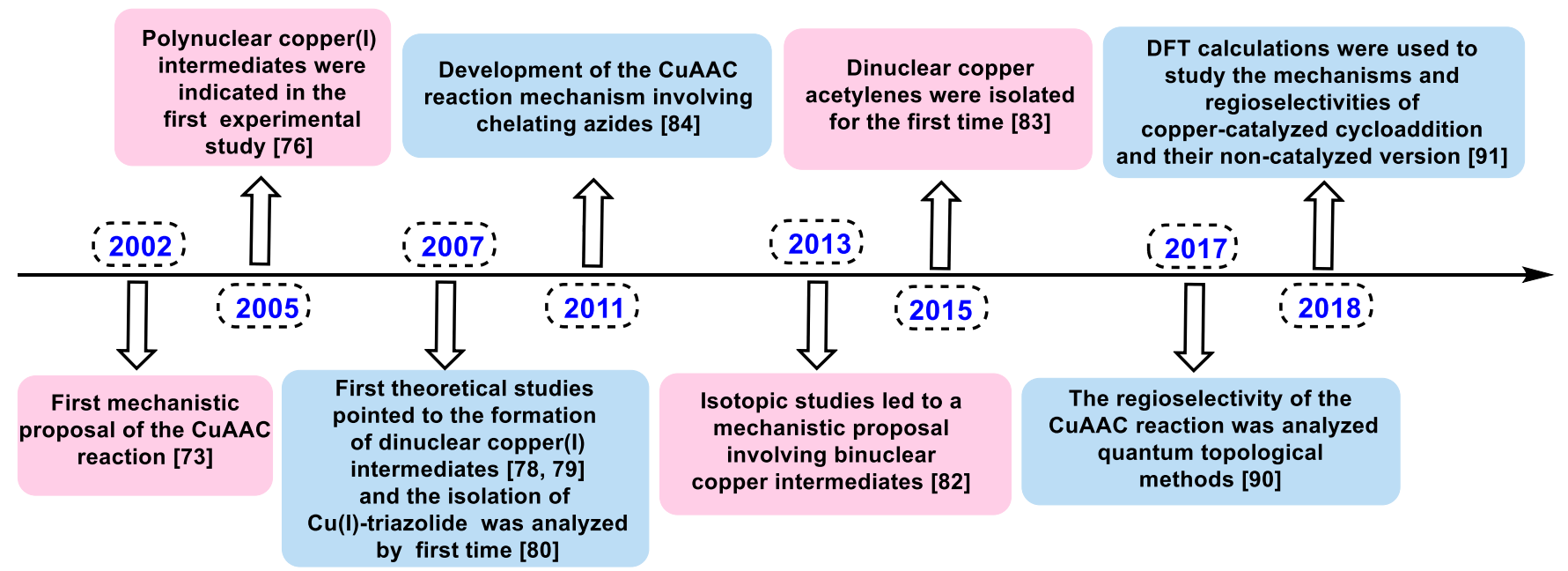

Figure 3. Timeline of the main events that led to a better understanding of the mechanism of the CuAAC reaction.

3.3.1 Main sources of $\mathrm{Cu}(\mathrm{I})$ used in CUAAC reactions. Direct use of a $\mathrm{Cu}(\mathrm{I})$ salt without a reducing agent is a well-established catalytic protocol for CuAAC reactions. Different $\mathrm{Cu}(\mathrm{I})$ copper sources may be used in this reaction, citing copper iodide (Cul) as described by the group of Meldal et al. ${ }^{72}$ (Scheme 11). Although copper iodide is efficient in the preparation of triazole units, its use has become the least recommended, since in recent studies it has been found that the use of this reagent contributes to the formation of polynuclear acetylide complexes that interfere with the catalytic cycle and reduces catalytic activity of copper (I) species. ${ }^{92}$

Another source of $\mathrm{Cu}(\mathrm{I})$ used in the CuAAC reaction is copper bromide $(\mathrm{CuBr}) .{ }^{93}$ Wang et al. ${ }^{94}$ for example, have described the preparation of different compounds containing the 1,2,3-triazole unit quickly, efficiently, at room temperature and in aqueous medium. The authors used $10 \mathrm{~mol} \%$ of $\mathrm{CuBr}$ and $50 \mathrm{~mol} \%$ of $\mathrm{PhSMe}$ as a binder to catalyze the reaction between different terminal alkynes and organic azides (Scheme 16).

$$
\begin{aligned}
& \mathrm{R}^{1}=\mathrm{H}+\mathrm{R}^{2}-\mathrm{N}_{3} \underset{\mathrm{H}_{2} \mathrm{O}, 25^{\circ} \mathrm{C}, 0.17-6 \mathrm{~h}}{\operatorname{CuBr}(10 \mathrm{~mol} \%)}{ }_{\mathrm{R}^{2}}^{\mathrm{PhSMe}(50 \mathrm{~mol} \%)} \\
& \mathbf{R}^{\mathbf{1}}=\mathbf{R}^{\mathbf{2}}=\text { Alkyl, Aryl } \\
& 82-98 \%
\end{aligned}
$$

Scheme 16. Use of $\mathrm{CuBr}$ in the preparation of $1 \mathrm{H}-1,2,3$-triazole derivatives. ${ }^{94}$ 
The use of copper chloride ( $\mathrm{CuCl}$ ) has also been described. ${ }^{95,96}$ Zhou et al. $^{97}$ described the preparation of the first triazole compounds in a highly enantioselective manner. The authors used $\mathrm{CuCl}(15 \mathrm{~mol} \%)$ as catalytic system and a chiral ligand (L) (18 mol\%) to obtain triazole products with 84 to $98 \%$ enantiomeric excess (Scheme 17).

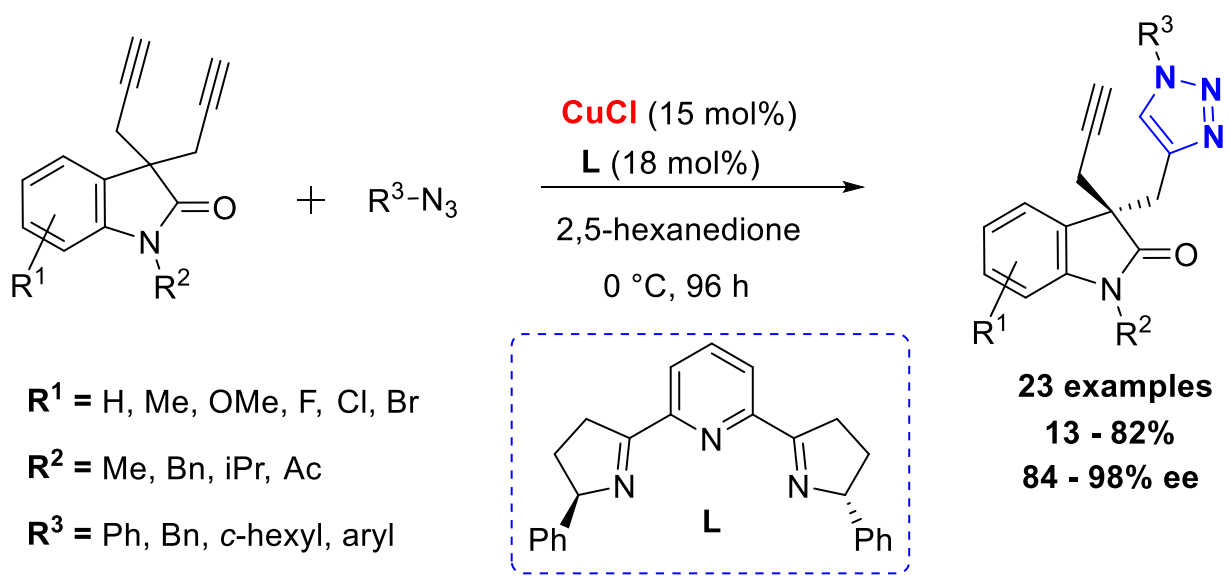

Scheme 17. Use of $\mathrm{CuCl}$ in enantioselective synthesis of $1 H-1,2,3$-triazole derivatives. ${ }^{97}$

Sharpless and colleagues reported the use of the salts $\left[\mathrm{Cu}\left(\mathrm{CH}_{3} \mathrm{CN}\right)_{4}\right] \mathrm{PF}_{6}$ and $\mathrm{CuOTf} \cdot \mathrm{C}_{6} \mathrm{H}_{6}$ in the absence of a reducing agent, however, it was necessary to use a nitrogen base to facilitate the terminal acetylene deprotonation step, citing, 2,6-lutidine, triethylamine, diisopropylethylamine or pyridine, the structures of which can be seen in figure $4 .^{73}$

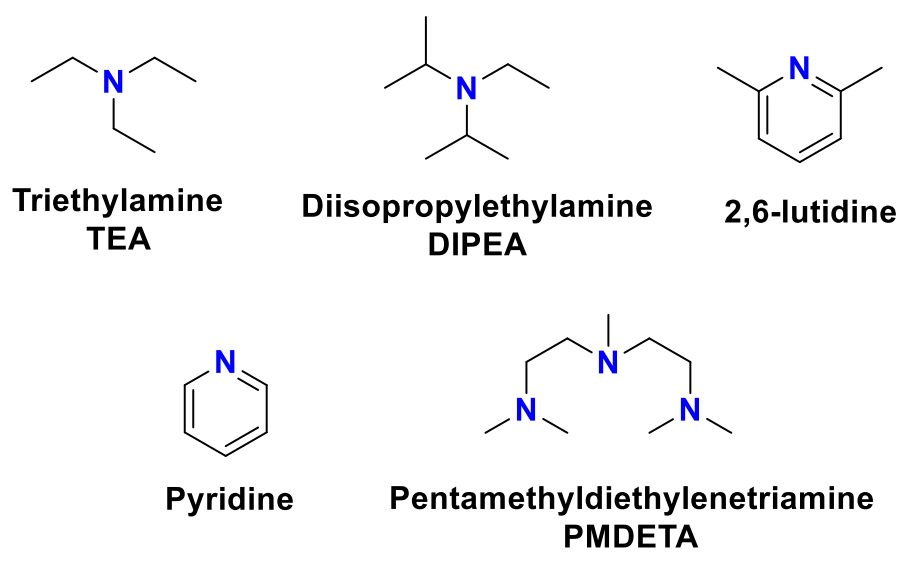

Figure 4. Main nitrogenous bases used in CuAAC reactions. ${ }^{73}$

However, due to the thermodynamic instability of the $\mathrm{Cu}(\mathrm{I})$ species, procedures that make direct use of copper (I) halides often require the use of an inert atmosphere to prevent oxidation from $\mathrm{CU}(\mathrm{I})$ to $\mathrm{CU}(\mathrm{II})$ and to prevent disproportionation reaction occurrence for metallic copper $\left(\mathrm{Cu}^{0}\right)$ during the reaction. ${ }^{98}$

The use of anhydrous organic solvents is often necessary, as well as the excess of nitrogen base is indispensable to facilitate the deprotonation of the terminal alkyne and to help stabilize the active species of $\mathrm{Cu}(\mathrm{I})$. However, the presence of these bases (Figure 4) decreases the reaction yield, due to the formation of by-products via homo-coupling reaction of alkynes and triazoles. ${ }^{99,100}$ 
Recently, the use of $\mathrm{Cu}(\mathrm{I})$ complexes acting as pre-catalysts in the CuAAC reaction has been described, since the use of these complexes avoids the excessive use of bases and additives, besides simplifying the purification of the product and allowing a better control over the stereoelectronic properties of $\mathrm{Cu}(\mathrm{l})$ species. ${ }^{101}$ Thus, several complexes containing nitrogenous ligands have been reported in the preparation of 1,2,3-triazoles, for example $\left[\mathrm{CuBr}\left(\mathrm{PPh}_{3}\right)_{3}\right](6),{ }^{102}\left[\mathrm{Cu}(\right.$ phen $\left.)\left(\mathrm{PPh}_{3}\right)_{2}\right] \mathrm{NO}_{3} \quad(7),{ }^{103}\left[\mathrm{Cu}\left(\mathrm{C} 18_{6}\right.\right.$ tren $\left.)\right] \mathrm{Br} \quad(8),{ }^{104}$ [Cu(hexabenzyl)tren]Br (9) ${ }^{105}$ (Figure 5).

Pericàs et al. ${ }^{106}$ reported the synthesis of a $\mathrm{Cu}(\mathrm{I})$ complex containing a tris(triazolyl) methanol (TTAM) ligand, which was stable in air and humidity (10). Gomes and collaborators completely synthesized and characterized bis-chelated (11) and mono-chelated (12) complexes of $\mathrm{Cu}(\mathrm{I})$ stabilized by a bis(aryl)acenaphthenequinonediimine ligand (Ar-BIAN). ${ }^{107}$ Neutral and cationic $\mathrm{Cu}(\mathrm{I})$ complexes with $\alpha$-diimine ligands have also been reported by Barta and González and the best performing catalyst was a bis-chelated cationic complex with cyclohexyl substituents on the diimine ligands (13). ${ }^{108}$ The structures of these complexes can be seen in Figure 5.

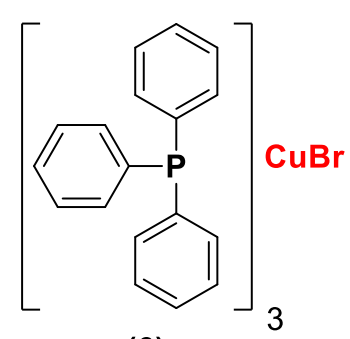

(6)

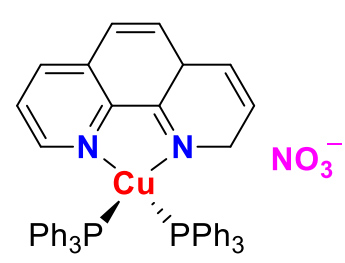

(7)

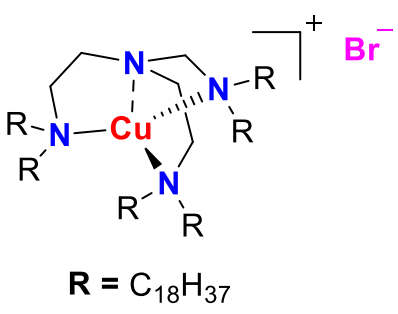

(8)

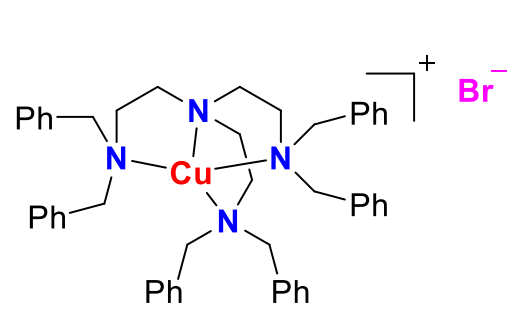

(9)

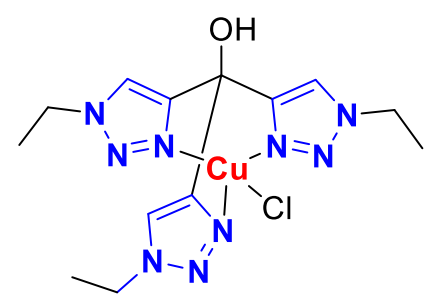

(10)

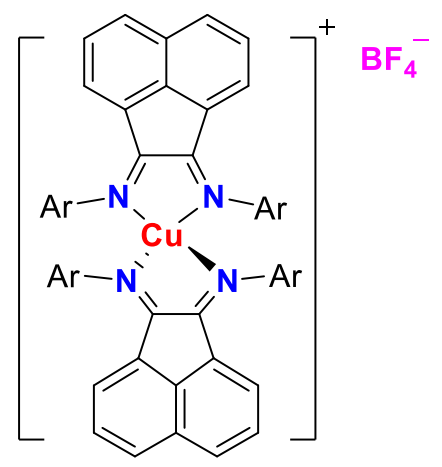

(11)

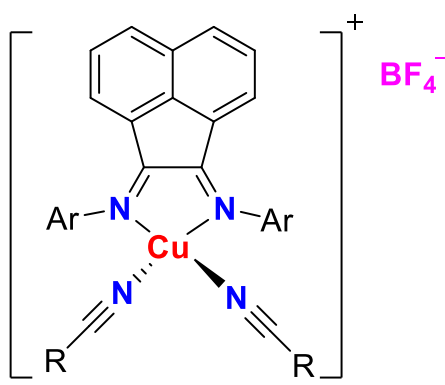

(12)

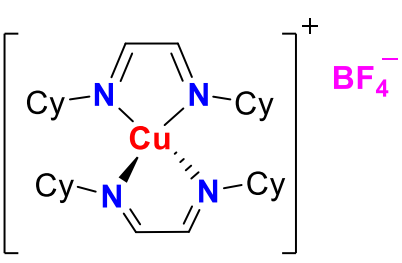

(13)

Figure 5. $\mathrm{Cu}(\mathrm{I})$ complexes most used in CuAAC reactions.

3.3.2 Main sources of $\mathrm{Cu}$ (II) used in CuAAC reactions. Given the limitations due to the direct use of $\mathrm{Cu}(\mathrm{I})$ species, the most widely used procedure for the preparation of $1 \mathrm{H}-1,2,3$-triazoles, due to its practicality and efficiency, is the reduction in situ of $\mathrm{Cu}(\mathrm{II})$ salts, usually $\mathrm{CuSO}_{4} \cdot 5 \mathrm{H}_{2} \mathrm{O}$ or $\mathrm{Cu}(\mathrm{OAc})_{2}$, by excess use of the sodium ascorbate reducing agent, which is used in most procedures. It is noteworthy that other reducing conditions 
such as the use of hydrazine, ${ }^{109}$ tris(2-carboxyethyl)phosphine (TCEP) $)^{110}$ and electrochemical reduction ${ }^{111}$ have been reported.

A new reducing condition was described by Wang et al. ${ }^{112}$ in 2017 . The authors synthesized a variety of 1,4-disubstituted $1 \mathrm{H}$-1,2,3-triazoles in good to excellent yields using the $\mathrm{CuSO}_{4} \cdot 5 \mathrm{H}_{2} \mathrm{O} / 1$-(4-methoxyphenyl)-3phenylthiourea catalytic system in aqueous solution (Scheme 18). According to the authors, functionalized thiourea (L) acted as a ligand and as a reducing agent of the $\mathrm{Cu}(\mathrm{II})$ species.

$$
\begin{aligned}
& \mathrm{R}^{1}=\mathrm{H}+\mathrm{R}^{2}-\mathrm{N}_{3} \frac{\mathrm{CuSO}_{4} \cdot 5 \mathrm{H}_{2} \mathrm{O}(1 \mathrm{~mol} \%)}{\mathrm{H}_{2} \mathrm{O}, 25^{\circ} \mathrm{C}, \mathrm{L}(1 \mathrm{~mol} \%)} \\
& \mathbf{R}^{\mathbf{1}}=\text { Phenyl, alkyl, aryl, heteroaryl } \\
& \mathbf{R}^{\mathbf{2}}=\text { Phenyl, alkyl, aryl, heteroaryl, cycloalkyl, } \\
& \text { trimethylsilyl, carbonyl }
\end{aligned}
$$<smiles>[R]c1cn([R])nn1</smiles>

37 examples $78-99 \%$

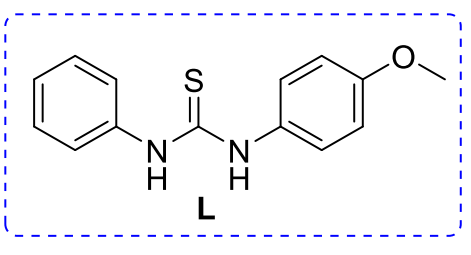

Scheme 18. Use of 1-(4-methoxyphenyl)-3-phenylthiourea (L) as a reductant in the CuAAC reaction. ${ }^{112}$

It is interesting to clarify that some years ago it was believed that only $\mathrm{Cu}(\mathrm{I})$ complexes were able to catalyze CUAAC reactions and, therefore, $\mathrm{Cu}(\mathrm{II})$ salts were always used in the presence of a reducing agent. However, recent publications have described the use of $\mathrm{Cu}$ (II) complexes as catalysts without the use of reducing agents. ${ }^{113-120}$ Bagherzadeh et al. ${ }^{121}$ reported in 2019 the preparation of two $\mathrm{Cu}(\mathrm{II})$ complexes (Figure 6) and studied their catalytic potentials against the CuAAC reaction in the absence of reducing agents. The authors were able to prepare different $1 \mathrm{H}$-1,2,3-triazole derivatives from a multicomponent reaction between benzyl chloride, sodium azide and different terminal alkynes with good yields. In addition, complex $\mathbf{A}$ was relatively more efficient and was reused for four reaction cycles.
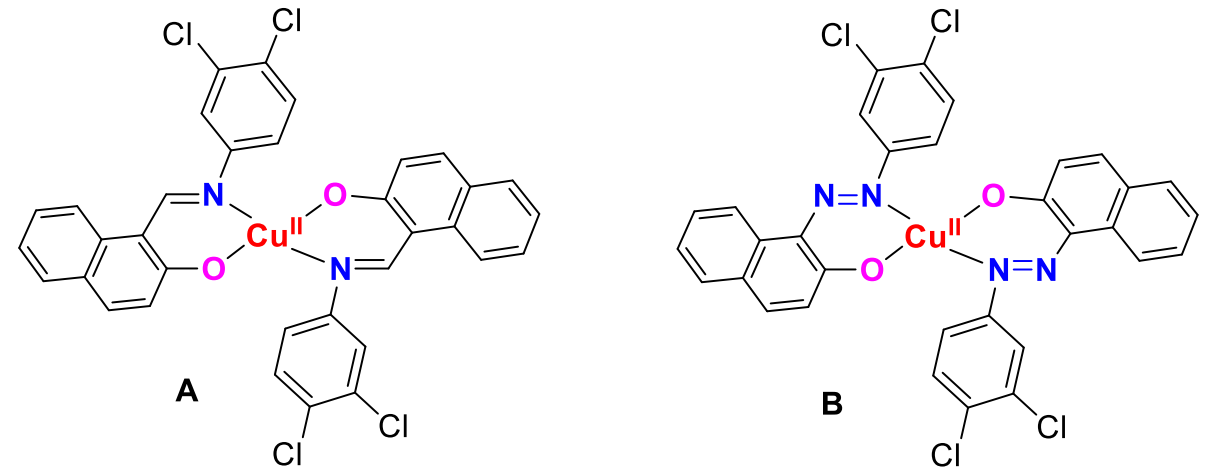

Figure 6. Copper (II) complexes used in CuAAC. ${ }^{121}$

Even with these advances, most studies in the literature make use of the $\mathrm{Cu}$ (II)/NaAsc catalytic system for the preparation of new triazole compounds, due to its practicality and efficiency. As an example, we can mention the work of Bakherad and collaborators published in $2018 .{ }^{122}$ These authors reported the preparation of a series of new functionalized pyrimidines containing the 1,2,3-triazole ring. For that, they used 2 mol\% $\mathrm{Cu}(\mathrm{OAc})_{2}, 4 \mathrm{~mol} \%$ sodium ascorbate and $2 \mathrm{~mol} \%$ o-phenylenediamine in ethanolic medium (Scheme 19). In addition, some of the compounds synthesized by Bakherad et al. showed activity against three bacterial strains (Micrococcus luteus, Pseudomonas aeruginosa and Bacillus subtilis). 


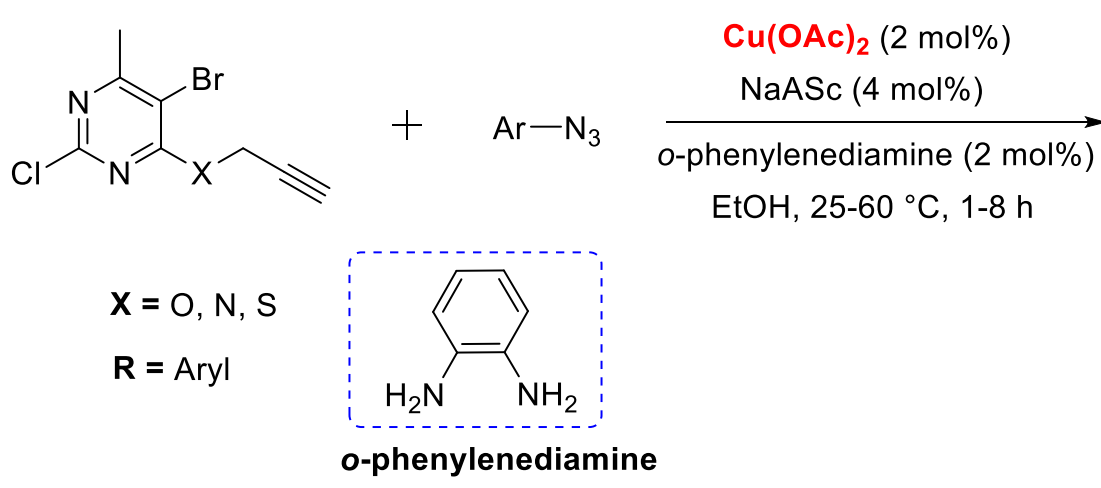<smiles>[X]c1nc(Cl)nc(C)c1Br</smiles>

16 examples

$72-98 \%$

Scheme 19. Synthesis of functionalized pyrimidines containing the $1 H-1,2,3$-triazole ring. ${ }^{122}$

Another study involving the use of the $\mathrm{Cu}(\mathrm{II}) / \mathrm{NaAsc}$ catalytic system was reported by Teixeira et al. in $2019,{ }^{123}$ in which the authors prepared a series of 1,2,3-triazole compounds from the natural product nerol (Scheme 20). Most compounds showed activity against HL60 human leukemic cells, as well as B16F10 cell lines.

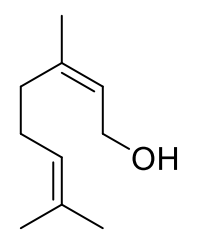

Nerol $\mathbf{R}=$ Aryl i. $\mathrm{NaH}, \mathrm{THF}$, alkynes, $15 \mathrm{~h}, 72 \%$

ii. $\mathrm{CuSO}_{4} \cdot 5 \mathrm{H}_{2} \mathrm{O}(0.15 \mathrm{mmols})$

$\mathrm{NaASc}(0.75 \mathrm{mmols})$

$\mathrm{H}_{2} \mathrm{O} / \mathrm{DCM}, 25^{\circ} \mathrm{C}, 24 \mathrm{~h}$

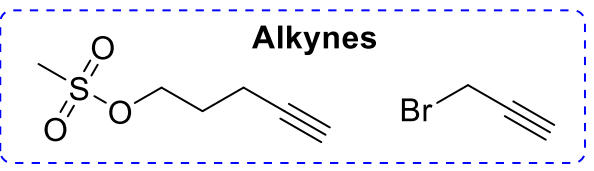

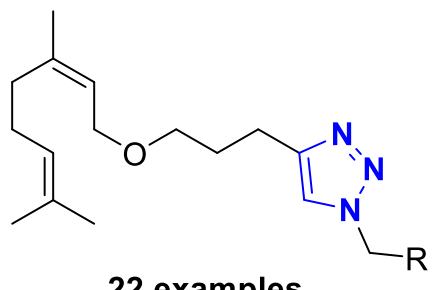

22 examples

$40-96 \%$

Scheme 20. Synthesis of $1 H$-1,2,3-triazole derivatives from the natural product Nerol. ${ }^{123}$

One of the most positive points of the $\mathrm{Cu}(\mathrm{II}) / \mathrm{NaAsc}$ system is that it is compatible with both oxygen and water, not requiring anhydrous solvents or inert atmosphere. However, $\mathrm{Cu}(\mathrm{I})$ residue is cytotoxic and can bind to the active site of many enzymes, blocking or reducing their biological activity. ${ }^{124,125}$

One way to minimize this problem is based on the use of ligands in an attempt to increase the stability of the active $\mathrm{Cu}(\mathrm{I})$ species in aqueous media by ligand coordination, helping to reduce the concentration of toxic copper ions in solution and decreasing the formation of undesirable products. ${ }^{101}$ In addition, the ligand may accelerate the cycloaddition reaction depending on its denticity, as while tridentate ligands dramatically accelerate the reaction rate, the use of tetradentate ligands saturates the $\mathrm{Cu}(\mathrm{I})$ coordination site, having a slightly weaker effect over CuAAC. ${ }^{109,126}$ Additionally, possible binder residues may hinder purification of the triazole product. ${ }^{127}$

The first report of the use of a ligand in the CuAAC reaction was described by Wang et al. ${ }^{110}$ when using tris[(1-benzyl-1H-1,2,3-triazole-4-yl)methyl]amine (TBTA) (Figure 7). This ligand was carefully examined by the group of Fokin et al. ${ }^{126}$ has been shown to be effective in accelerating the reaction and stabilization of the $\mathrm{Cu}(\mathrm{I})$ copper species. However, problems related to copper cytotoxicity and the low solubility of this ligand in water continued to persist. Given this, studies involving BPS and 4,4'-dimethyl-2,2'-bipyridine ligands (Figure 
7), which are derived from 1,10-phenanthroline and 2,2'-bipyridine, respectively, have been shown to be effective ligands in the CUAAC reactions. ${ }^{128}$ Although these ligands had better water solubility than TBTA derivatives, a lower stabilization effect of $\mathrm{Cu}(\mathrm{l})$ species was found. This motivated the development of other ligands based on the TBTA structure, which presented better properties, such as better water solubility, better stabilization of $\mathrm{Cu}(\mathrm{I})$ species and biocompatibility. Among the major ligands in this class are THPTA, ${ }^{129}$ $\mathrm{BTTAA}^{130} \mathrm{BTTP}^{131}$ and tris(1-benzyl-1H-1,2,3-triazol-4-yl)methanol ${ }^{106}$ (Figure 7).

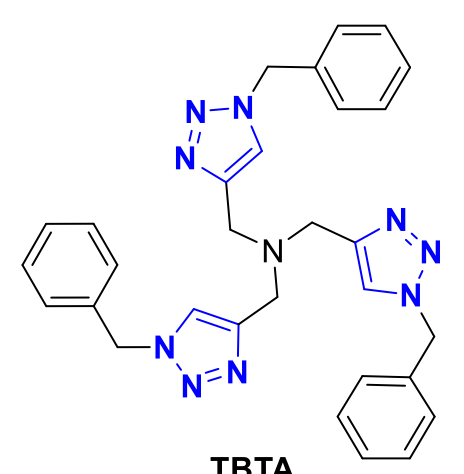

TBTA

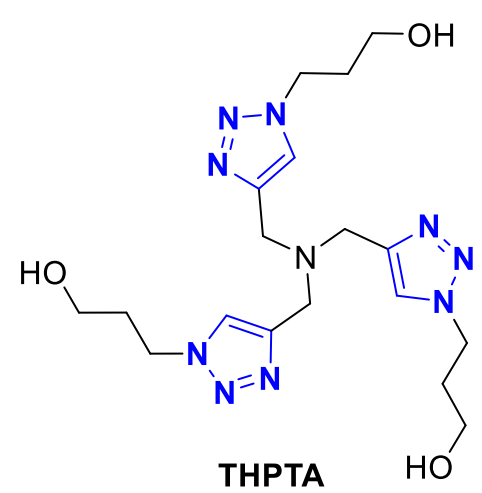

THPTA
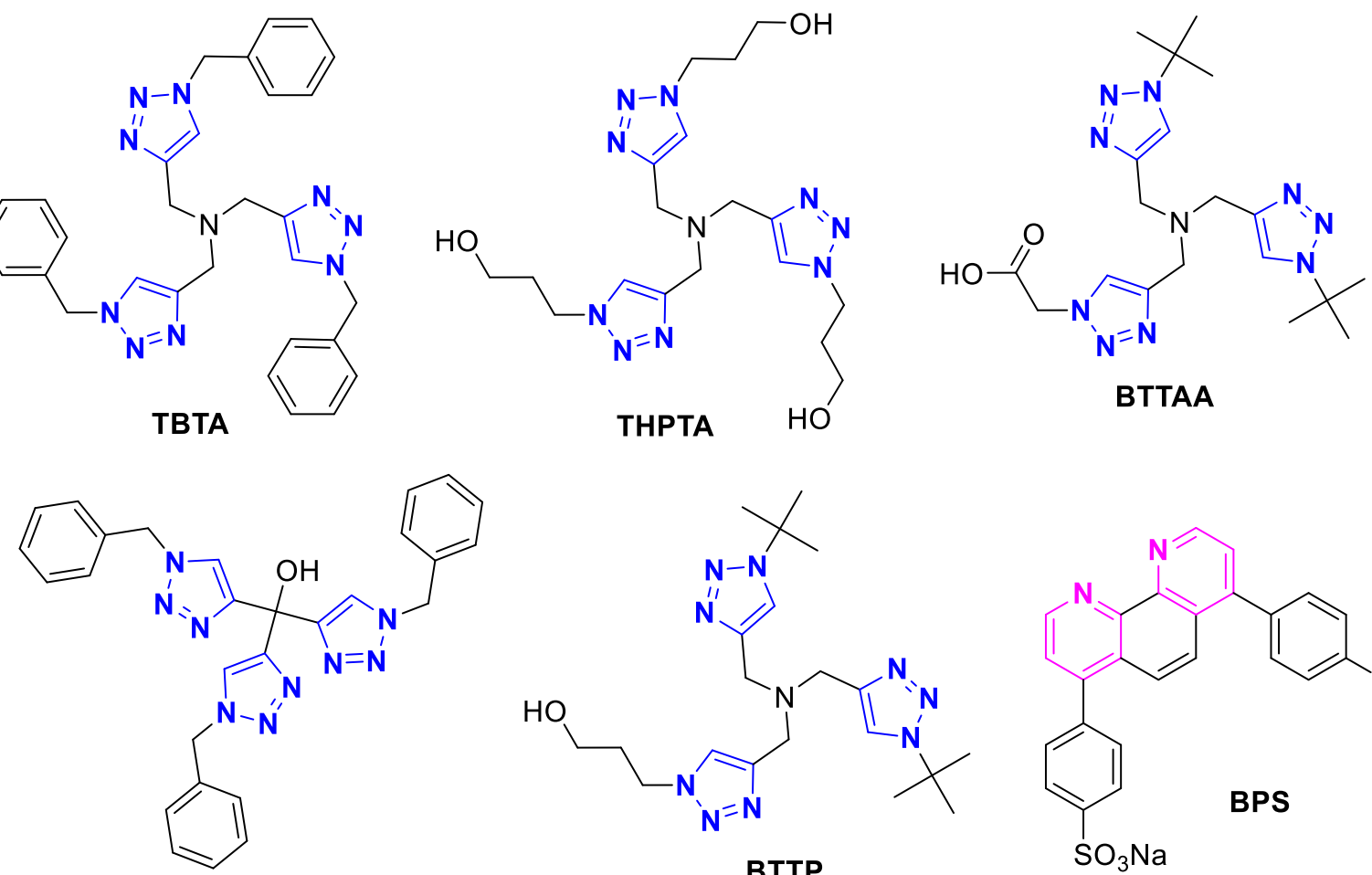

tris(1-benzyl-1H-1,2,3-triazol-4-yl)methanol<smiles>Cc1ccnc(-c2cc(C)ccn2)c1</smiles>

4,4'-Dimethyl-2,2'-dipyridyl

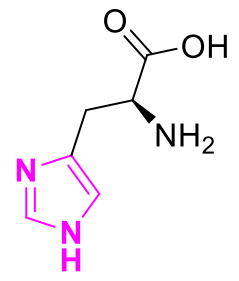

L-histidine

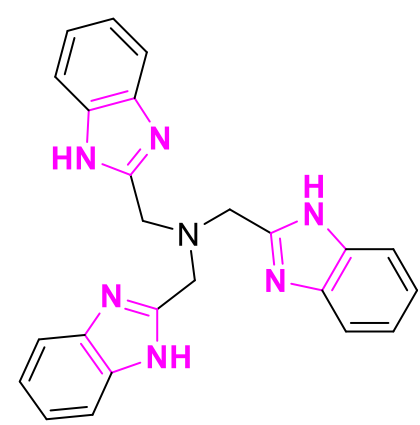

$(\mathrm{BimH})_{3}$

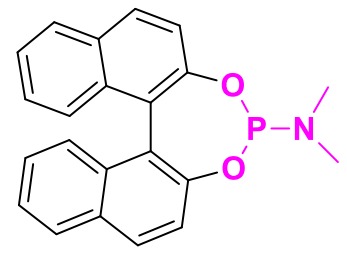

MonoPhos

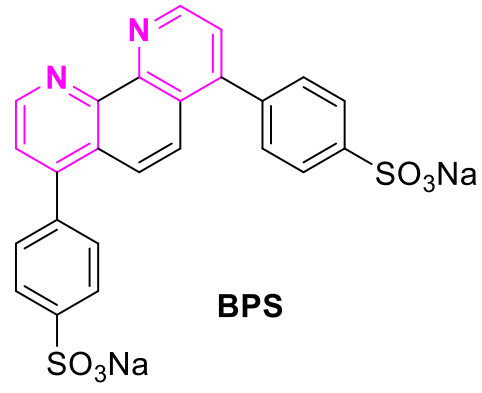

$(\text { Bth })_{3}$<smiles>c1ccc(P(c2ccccc2)c2ccccc2)cc1</smiles>

Triphenylphosphine

Figure 7. Most used CuAAC reaction ligands. 
In addition, another similar class of ligands involves the presence of the tris(heteroarylmethyl)amine group, and the major representatives of this class are tris(2-benzimidazolylmethyl)amine $(B i m H)_{3}$ and tris(benzothiazole)amine $(B t h)_{3}{ }^{77}$ (Figure 7). Using this class of ligands increases the reaction rate with low copper concentrations.

Studies involving L-histidine (Figure 7) revealed that this natural amino acid can act as a ligand and facilitate the CuAAC reaction. ${ }^{132}$ One of the key advantages of the $\mathrm{Cu}(\mathrm{I})$-L-histidine complex is lower toxicity, found in four different cell lines in comparison to BPS, TBTA and some of their derivatives. Additionally, MonoPhos and triphenylphosphine ligands (Figure 7) were also used to accelerate CuAAC reactions in aqueous medium. ${ }^{133}$ However, their efficiency in the CuAAC reaction was low compared to TBTA derived ligands.

The azide-alkyne cycloaddition is highly relevant for biological applications. However, in vivo applications are limited by the fact of the toxicity of copper ions for living organisms. Even though great strides in reducing the amount of copper have been made, one limitation that still persists is the low solubility of the organic substrates and ligands employed to stabilize the active copper species. ${ }^{55}$ To minimize this problem, phase transfer catalysts and surfactants have been employed. ${ }^{134-138}$ An interesting example was described in 2017 by Shin et al. ${ }^{139}$ in which the authors used betaine, a readily available and biocompatible zwitterionic surfactant. In this work, different 1,4-disubstituted $1 \mathrm{H}$-1,2,3-triazoles were synthesized with excellent yields from azides and terminal alkynes in aqueous medium using the $\mathrm{Cu}$ (II)/NaAsc catalytic system (Scheme 21). This method resulted in the noticeable reduction of $\mathrm{CuSO}_{4} \cdot 5 \mathrm{H}_{2} \mathrm{O}$ concentration to levels ranging from 2.5 to $200 \mathrm{ppm}$.

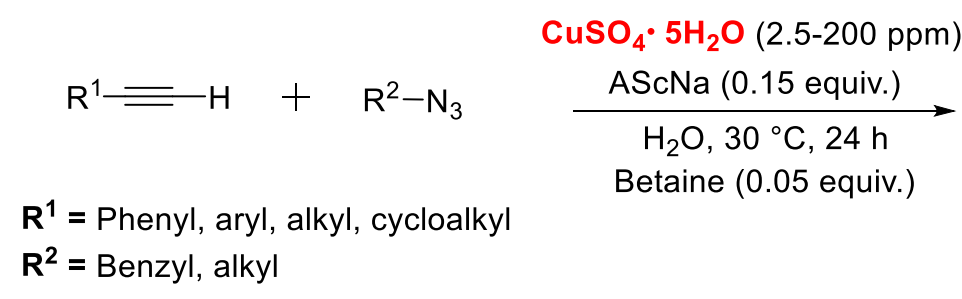

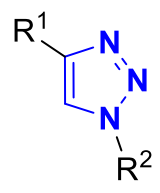

27 examples

$83-100 \%$

Scheme 21. Use of the betaine surfactant in the preparation of $1 H-1,2,3$-triazole derivatives. ${ }^{139}$

It has also been described the use of metallic copper in the form of wire, filings, dust or agglomerate in the CuAAC reaction. ${ }^{140-143}$ The main advantage of this method is the lower level of copper contamination in products, although generally larger amounts of catalysts and longer reaction times are required when compared to the system using $\mathrm{Cu}(\mathrm{II}) / \mathrm{NaAsc}$.

Although cycloaddition reactions between azides and alkynes catalyzed by the direct use of $\mathrm{Cu}(\mathrm{I})$ or the use of $\mathrm{Cu}(\mathrm{II})$ salts in the presence of a reducing agent leads to the formation of 1,4-disubstituted $1 \mathrm{H}-1,2,3-$ triazoles, recently Kumar et al. ${ }^{144}$ reported the first regioselective synthesis of 1,5 -disubstituted $1 \mathrm{H}$-1,2,3triazoles by the use of copper (II) trifluoromethanesulfonate $\left(\mathrm{Cu}(\mathrm{OTf})_{2}\right)$ (Scheme 22). A variety of triazole compounds were obtained from cinnamic acid and organic azides in good yields and the simplicity and regioselectivity of this methodology is comparable to the ease in obtaining the classic 1,4 -disubstituted $1 H$ 1,2,3-triazoles. 


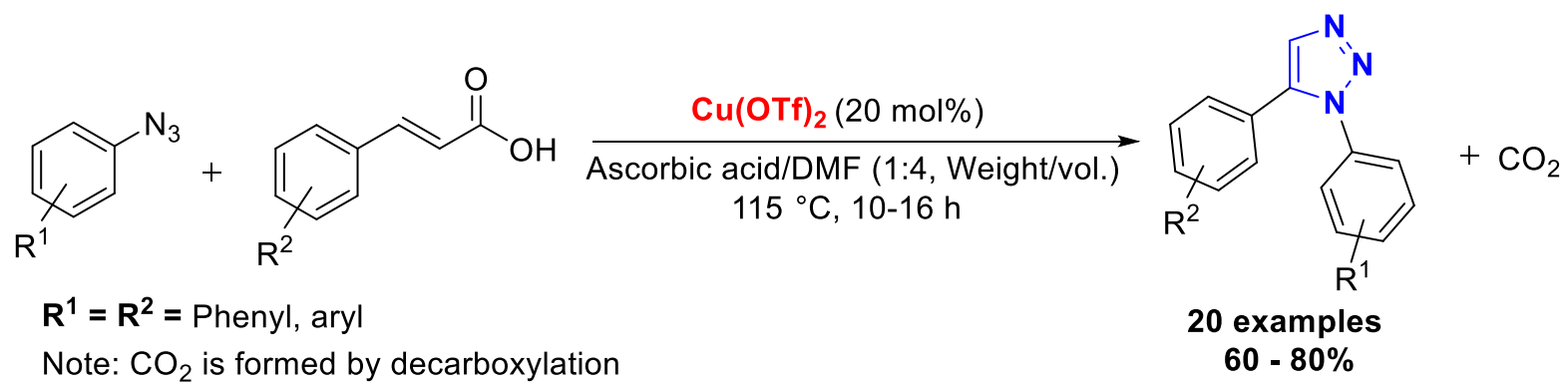

Scheme 22. First report of regioselective synthesis of 1,5 -disubstituted $1 H-1,2,3$-triazoles using a Cu(II) salt. ${ }^{144}$

3.3.3 Heterogeneous CuAAC Reactions. The interest in heterogeneous catalytic systems involving copper metal in CuAAC reactions is a growing strategy. ${ }^{145}$ The advantage of these methods lies not only in obtaining products of higher purity, but in the possibility of catalyst recyclability.

One of the most widely implemented strategies for heterogenizing catalysts in CuAAC reactions is by covalently attaching a copper or salt ligand to a solid support. The first example involving this strategy was described in 2006, when Girard et al., ${ }^{146}$ reported immobilization of Cul on Amberlyst A-21 resin to prepare a series of 1,4-disubstituted $1 \mathrm{H}$-1,2,3-triazoles, which were yields ranging from poor to excellent (Scheme 23). Amberlyst A-21 was selected because of its dimethylaminomethyl moiety, which acted as both a ligand and a base. In addition, the catalyst was reused for four reaction cycles without significant yield variations. It is noteworthy that, in 2009, the Girard et al. ${ }^{147}$ research reported the use of this same catalyst for the preparation of 1,4-disubstituted $1 \mathrm{H}$-1,2,3-triazoles under solvent free conditions. However, in some cases, this heterogeneous catalyst led to the formation of 5-iodotriazole. ${ }^{148}$

$$
\begin{aligned}
& \mathrm{R}^{1}=\mathrm{H}+\mathrm{R}^{2}-\mathrm{N}_{3} \\
& \underset{\text { MeCN ou DCM, } 25^{\circ} \mathrm{C}, 12 \mathrm{~h}}{\stackrel{\text { Cul }(8 \mathrm{~mol} \%), \text { A-21 }(13 \mathrm{~mol} \%)}{\longrightarrow}} \\
& \mathbf{R}^{1}=\mathrm{CH}_{2} \mathrm{NPhth}, \mathrm{CH}_{2} \mathrm{OPh}, \mathrm{CH}_{2} \mathrm{OH} \text {, } \\
& \mathrm{CH}(\mathrm{OEt})_{2}, \mathrm{CO}_{2} \mathrm{Me} \\
& \mathbf{R}^{2}=\text { Alkyl, benzyl }
\end{aligned}
$$

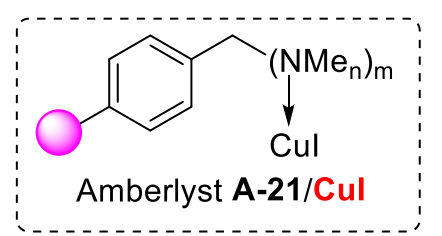

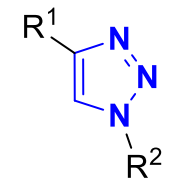

15 examples

$13-99 \%$

Scheme 23. First report of Cul immobilization on Amberlyst A-21 in the catalysis of CuAAC reactions. ${ }^{146}$

From the pioneering work of researcher Girard, the development of reagents supported on organic polymers has become well known in CuAAC reactions. Several catalysts based on copper complexes with nitrogen ligands incorporated in polymers were developed and applied in the CuAAC reaction catalysis. As some examples, the immobilization of $\mathrm{Cul}$ in 1,5,7-triazabicyclo-[4.4.0]-dec-5-ene (PS-TBD) polystyrene-linked is highlighted $^{149}$ (Figure 8a); immobilization of $\mathrm{Cu}(\mathrm{I}) \mathrm{N}$-heterocyclic carbenes complexes (NHC's) on silica ${ }^{150,151}$ (Figure 8b); copper ion complexation in polystyrene-divinylbenzene-based polymeric materials (DIAION CR11 and $\left.\mathrm{CR}_{20}\right)^{152}$ (Figure 8c); incorporation of copper sulphate into poly(vinylpyridine) ${ }^{153}$ (Figure 8d); Cul immobilization in cryptand 22 attached to a polystyrene resin ${ }^{154}$ (Figure 8e); immobilization of Cul on 1,10phenanthroline bound to Merrifield resin (Figure $8 \mathrm{f})^{155}$ and immobilization of copper acetate on imidazole moieties bound to Merrifield resin ${ }^{156}$ (Figure $8 \mathrm{~g}$ ). 


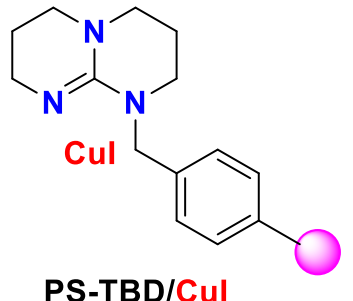

(a)

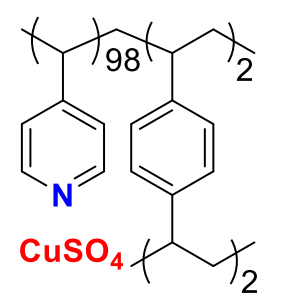

[P4-VP]CuSO4

(d)

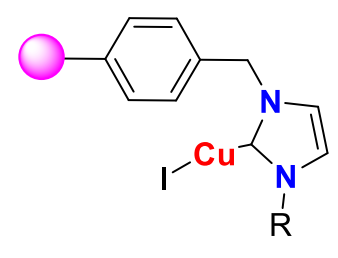

$\mathrm{SiO}_{2}-\mathrm{NHC}-\mathrm{Cul}$

(b)

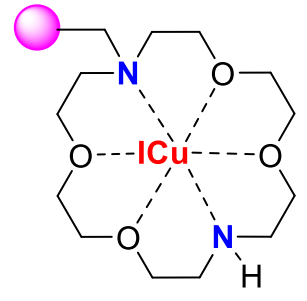

PS-C22-Cul

(e)

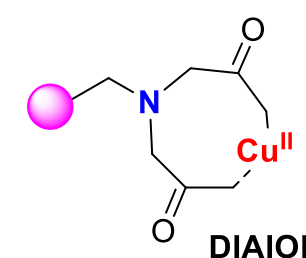

DIAION CR11

(c)

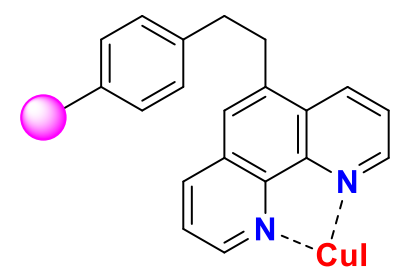

Cul-PS-Phen

(f)

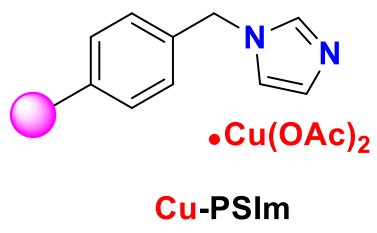

(g)

Figure 8. Different copper catalysts embedded in polymers.

In addition, ligands commonly used to increase the speed of CuAAC reactions have been incorporated into polymeric resins and applied in this reaction ${ }^{145}$ and different copper catalysts supported on polyacrylonitrile fibers (PANF) that have recently been developed to efficiently catalyze CuAAC reactions. ${ }^{157}$

Several materials have been used as solid supports for the preparation of heterogeneous copper catalysts and applied in the preparation of $1 \mathrm{H}-1,2,3$-triazole derivatives. The most reported are biopolymers, ${ }^{158}$ coal, $^{159,160}$ carbon nanotubes (NCTs), ${ }^{161,162}$ graphene, ${ }^{163,164}$ silica-based materials, ${ }^{165,166}$ alumina, ${ }^{167}$ titanium, ${ }^{168}$ zeolites, ${ }^{169,170}$ MOFs, ${ }^{171,172}$ magnetic nanocomposites ${ }^{173}$ and clays. ${ }^{174-177}$

In a recent study published in 2019, Bahsis et al. ${ }^{178}$ reported the preparation of a new heterogeneous catalyst from copper iodide and aminomethyl polystyrene (AMPS). This catalyst was found to be highly active, supplying the regioselective 1,4-disubstituted $1 \mathrm{H}$-1,2,3-triazole at room temperature and using water as a solvent (Scheme 24). The authors also performed a mechanistic study using the Density Functional Theory (DFT) to explain the reactivity and selectivity observed for the $\mathrm{Cu}(\mathrm{I})$-AMPS catalyst, which was reused for four reaction cycles.

$$
\begin{aligned}
& \mathrm{R}^{1}=\mathrm{H}+\mathrm{R}^{2} \mathrm{~N}_{3} \stackrel{\mathrm{Cu}(\mathrm{I}) \text {-AMPS }(1 \mathrm{~mol} \%)}{\mathrm{H}_{2} \mathrm{O}, 25^{\circ} \mathrm{C}, 1-2 \mathrm{~h}} \\
& \mathbf{R}^{1}=\text { Phenyl, alkyl, aryl } \\
& \mathbf{R}^{2}=\text { Alkyl }
\end{aligned}
$$

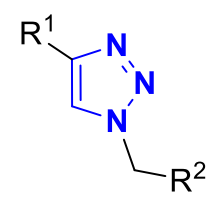

12 examples

$80-98 \%$

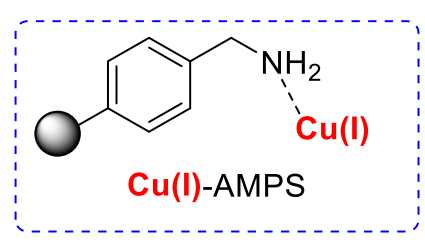

Scheme 24. Use of Cu (I)-AMPS as a heterogeneous catalyst in CuAAC reactions. ${ }^{178}$

Additionally, in recent years the use of plant biomass for the development of heterogeneous catalysts has been an excellent alternative for the enhancement of green chemistry. In this sense, the use of chitosan polysaccharide has been reported as a convenient reusable support for copper (II) ions, which has been shown to be efficient in catalyzing CuAAC reactions. ${ }^{179}$ Based on this work, Bahsis et al. ${ }^{180}$ reported in 2018 the use of 
cellulose macromolecule to immobilize copper (II) and copper (I) ions, generating recyclable heterogeneous catalysts (Scheme 24). These catalysts were efficient in catalyzing the cycloaddition reaction between azides and alkynes in aqueous medium, producing 1,4-disubstituted $1 \mathrm{H}-1,2,3$-triazole compounds in excellent yields and in the absence of any external reducing agent, and Cul-cellulose proved slightly more efficient than $\mathrm{CuSO}_{4}$ cellulose (Scheme 25). Additionally, a recyclability study has shown that these catalysts can be reused for up to five reaction cycles without loss of catalytic activity or change in their compositions.
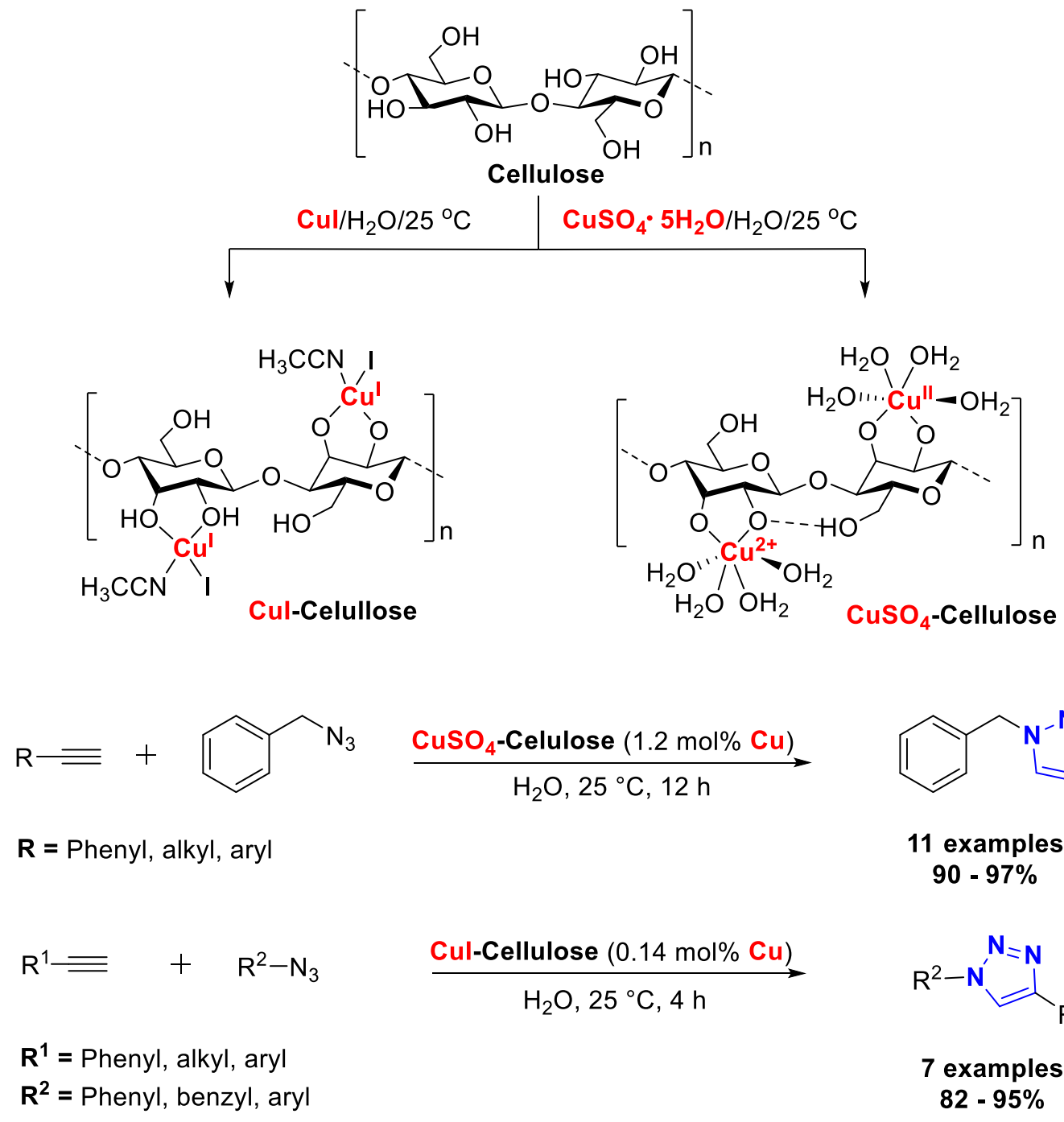

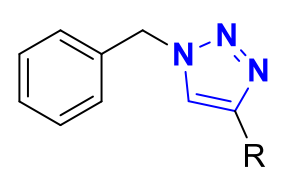

11 examples $90-97 \%$<smiles>[R]c1cn([R])nn1</smiles>

7 examples $82-95 \%$

Scheme 25. Copper catalysts (I) and (II) supported on a cellulose-based vegetable polymer. ${ }^{180}$

Recently, a new copper (I) catalyst supported on an activated carbon prepared from waste vegetable biomass from Argan nutshell, called Cu-CANS, was developed by Aflak et al. in $2019 .{ }^{181}$ Several azides and alkynes can be combined to form $1 \mathrm{H}-1,2,3$-triazoles using this catalyst as shown in Scheme 26. A Cu-CANS recyclability study revealed this catalyst was reused for up to ten reaction cycles without significant loss of catalytic activity or its selectivity. In addition, the use of water as a solvent at room temperature makes the entire catalytic procedure environmentally friendly. 


$$
\begin{aligned}
& \mathrm{R}^{1}=\mathrm{H}+\mathrm{R}^{2}-\mathrm{N}_{3} \frac{\text { Cu-CANS }(0.5 \mathrm{~mol} \%)}{\mathrm{H}_{2} \mathrm{O}, 25^{\circ} \mathrm{C}, 6 \mathrm{~h}} \mathrm{R}^{1} \overbrace{\mathrm{R}^{2}}^{\mathrm{N}^{\prime} \mathrm{N}} \\
& \mathbf{R}^{1}=\text { Phenyl, aryl, cooEt } \\
& \mathbf{R}^{2}=\text { Phenyl, benzyl }
\end{aligned}
$$

Scheme 26. Catalyst and copper (I) supported on Argan nutshell waste. ${ }^{181}$

3.3.4 Use of copper nanoparticles (CuNPs) in CuAAC reactions. Metal nanoparticles have different properties compared to atomic, molecular, or macroscopic solid systems. These peculiarities are attributed mainly to the large surface area of these nanoscale materials. Generally, the benefits of using metal nanoparticles as catalysts provide advantages such as: i) a high surface-to-volume ratio of metal nanoparticles, which ensures a large number of active sites per unit area; ii) increased reactivity, which avoids the use of ligands or additives; and iii) ease of separation and recycling, which minimizes contamination of the products of interest. ${ }^{182-184}$ In this sense, copper nanoparticles (CuNPs) have been used with considerable efficiency in CuAAC reactions. Further details on the methods of preparing these CuNPs can be found in the review published in 2016 by Gawande et al. ${ }^{185}$

The first examples of the use of CuNPs to catalyze CuAAC reactions were independently published in 2005 by the research groups of Orgueira (Scheme 27A) ${ }^{186}$ and Rhothenberg (Scheme 27B). ${ }^{141}$ In these studies, the authors used CuNPs to prepare 1,4-disubstituted $1 H$-1,2,3-triazoles from organic azides and terminal alkynes.

A. Work of the Orqueira's group

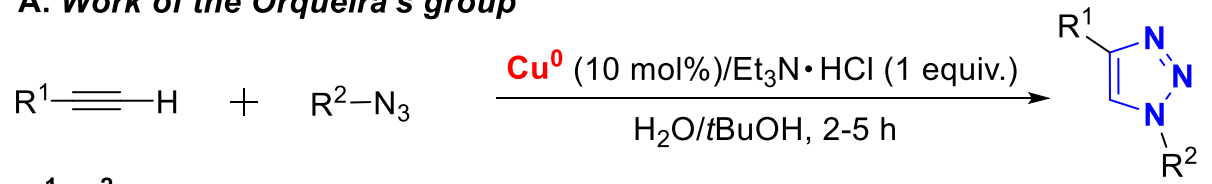

$\mathbf{R}^{\mathbf{1}}, \mathbf{R}^{\mathbf{2}}=$ Alkyl, benzyl, aryl

$$
\begin{gathered}
16 \text { examples } \\
83-96 \%
\end{gathered}
$$

B. Work of the Rhothenberg's group

$$
\begin{aligned}
& \mathrm{R}^{1}=\mathrm{H}+\mathrm{R}^{2}-\mathrm{N}_{3} \\
& \mathbf{R}^{1}=\text { Phenyl, alkyl, aryl } \\
& \mathbf{R}^{\mathbf{2}}=\text { Phenyl, benzyl }
\end{aligned}
$$

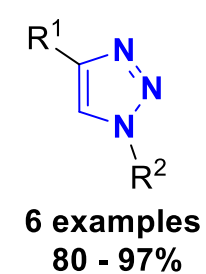

Scheme 27. Early reports of CuNPs use in CuAAC reactions. ${ }^{141,186}$

From these pioneering works, interesting examples of this strategy can be found in the literature, which report the use of nanoparticles (NPs) with or without solid supports. ${ }^{187-192}$ Supported NPs offer several advantages over the use of unsupported NPs, such as better control of metal dispersion and particle morphology, inhibition of particle aggregation, and generally better reuse of the catalytic system. Given these attributes, different supported and recyclable CuNPs were employed in CuAAC reactions, among the supports employed are alumina, ${ }^{193}$ aluminum oxyhydroxide, ${ }^{194}$ montmorillonite, ${ }^{195}$ MOF, ${ }^{196-198}$ Cellulose, ${ }^{199}$ SBA-15, ${ }^{200}$ Zeolite, ${ }^{201}$ and more recently graphene oxide. ${ }^{202}$ 
In a study published in 2019 by Gholinejad et al. ${ }^{203}$ clinochlore was first reported as a very inexpensive and available support for the stabilization of copper nanoparticles and their application as a recyclable catalyst for the formation of $1 \mathrm{H}$-1,2,3-triazoles at room temperature and in aqueous medium. This new catalyst (AAClin- $\mathrm{Cu}$ ) was prepared by immobilizing copper sulphate pentahydrate in the clinochlore clay following chemical reduction in situ with sodium borohydride. Benzyl halides and aliphatics as well as arylboronic acid reacted efficiently in the presence of sodium azide and different alkynes, generating the 1,4-disubstituted $1 H$ 1,2,3-triazoles in good yields (Scheme 28). In addition, this catalyst can be reused up to four times without significantly diminishing its catalytic properties.

$$
\begin{aligned}
& \mathrm{R}^{1}-\mathrm{X}+\mathrm{R}^{2} \equiv+\mathrm{NaN}_{3} \\
& \mathbf{X}=\mathrm{Cl}, \mathrm{Br}, \mathrm{B}(\mathrm{OH})_{2}, \mathrm{~N}_{2}{ }^{+} \mathrm{BF}_{4}^{-} \\
& \mathbf{R}^{1}=\text { Aryl, alkyl, benzyl } \\
& \mathbf{R}^{2}=\text { Alkyl, aryl, }
\end{aligned}
$$

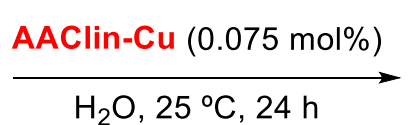

$\mathrm{H}_{2} \mathrm{O}, 25^{\circ} \mathrm{C}, 24 \mathrm{~h}$

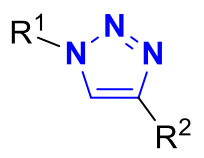

27 examples

$75-97 \%$

Scheme 28. First report of clinochlore clay as a support for copper nanoparticles in CuAAC reaction catalysis. $^{203}$

3.3.5 Use of ultrasonic energy in CuAAC reactions. Ultrasound reactions are milder and have the advantage of accelerating the reaction in heterogeneous or homogeneous systems. Ultrasonic energy increases system efficiency by activating the catalyst surface area and removing deposited impurities. ${ }^{204}$ The use of ultrasonic energy has been reported by several research groups for the preparation of 1,2,3-triazoles from CuAAC reactions, ${ }^{205-207}$ in which different sources of $\mathrm{Cu}(\mathrm{I})$ or $\mathrm{Cu}(\mathrm{II})$ were used.

Stefani et al. $^{208}$ have developed an efficient method for the synthesis of $C$-glycosyl $1 H$-1,2,3-triazoles through CUAAC reactions between $C$-alkynyl-glycoside protected with the TMS group and different organic azides. In this study, the authors used ultrasonic energy to lead to 1,2,3-triazoles in good yields in the absence of nitrogenous bases (Scheme 29).

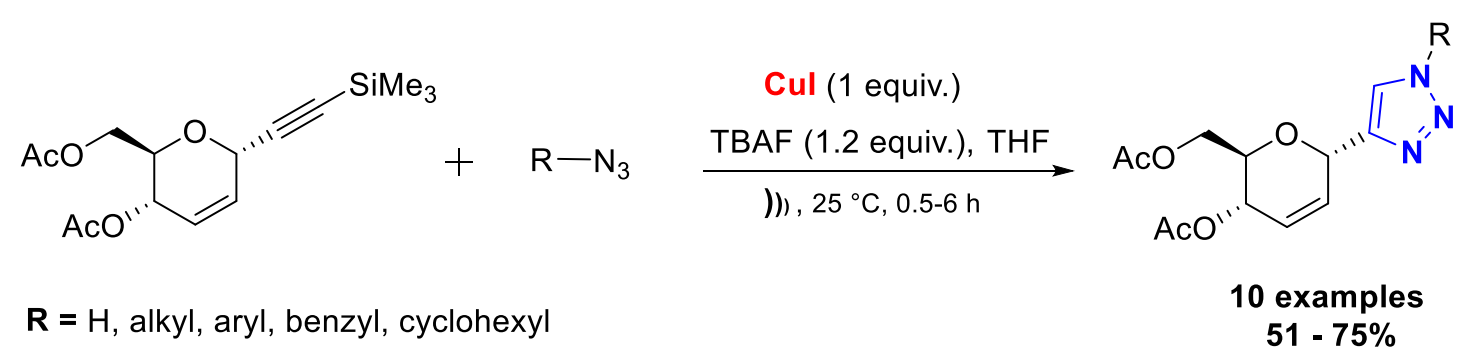

Scheme 29. Synthesis of functionalized C-glycosides through CuAAC reactions. ${ }^{208}$

Another interesting study was reported by Silva et al. ${ }^{209}$ in 2013 , which describes the synthesis of various $N$-glycosyl-1,2,3-triazoles from the reaction between the 2,3,4,6-tetra-O-acetyl- $\beta$-D-glucopyranosyl azide and different terminal alkynes under ultrasound energy (Scheme 30). Additionally, the benzoheterocyclic conjugated compounds exhibited potent anti-inflammatory activity. 


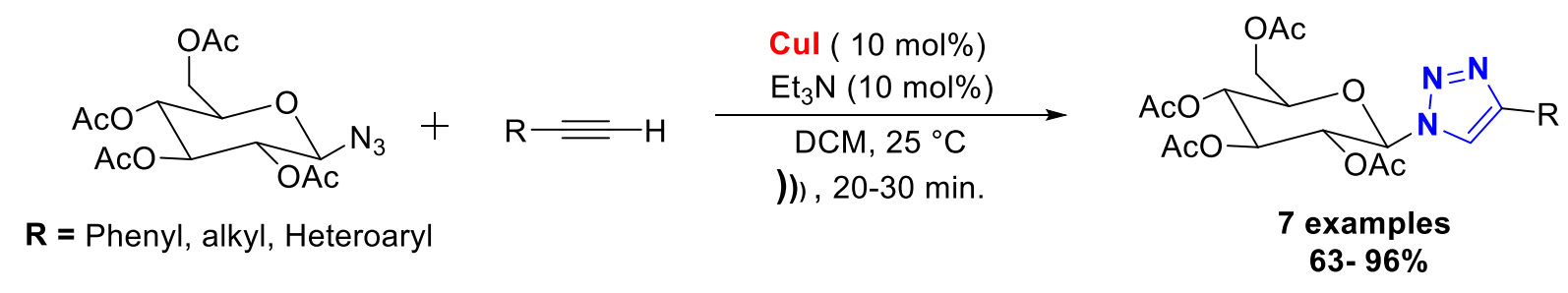

Scheme 30. Synthesis of $N$-glycosyl-1,2,3-triazoles using ultrasonic energy. ${ }^{209}$

In 2015 Nallapati et al. $^{210}$ made changes in the structure of the antipsychotic drug olanzapine by incorporating the $1 \mathrm{H}$-1,2,3-triazoles ring. The formation of this triazole unit was performed by the CuAAC reaction, using Cul and DIPEA (diisopropylethylamine) as a catalytic system and ultrasonic energy that allowed rapid access to the desired compounds (Scheme 31).

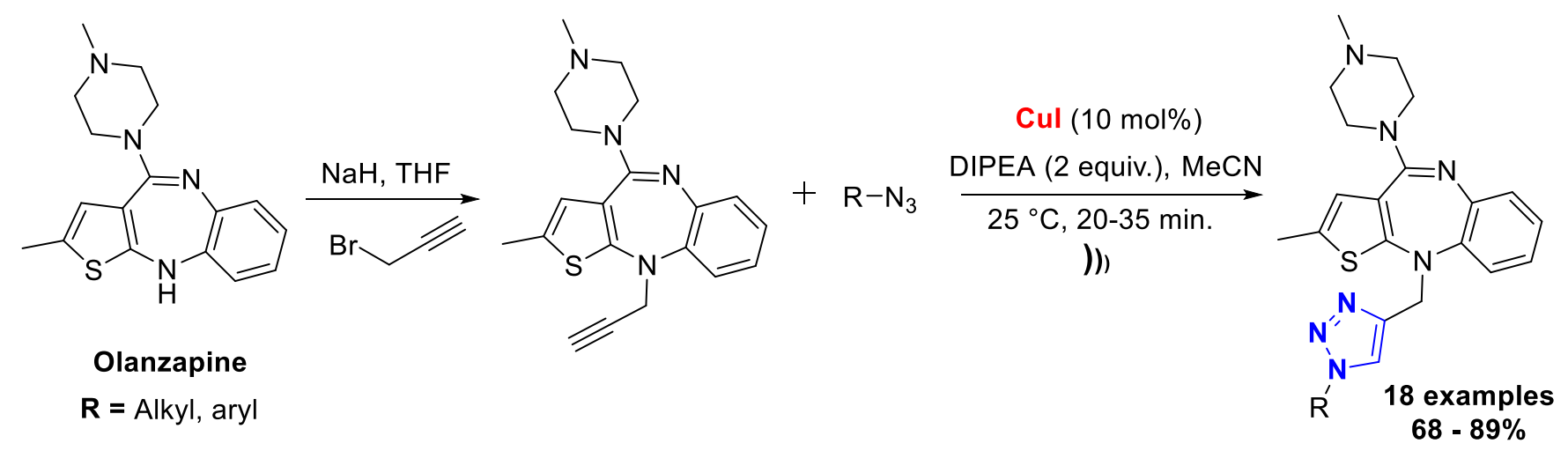

Scheme 31. Incorporation of the 1,2,3-triazole ring in the antipsychotic olanzapine structure. ${ }^{210}$

Zhang et al. ${ }^{211}$ described the synthesis of 1,4-disubstituted $1 \mathrm{H}-1,2,3$-triazoles containing an isoxazole and thymidine unit in their structure. These compounds were synthesized from different functionalized isoxazoles with terminal triple bonds and azide $\beta$-thymidine derivatives via the CuAAC reaction using copper acetate and sodium ascorbate as the catalytic system under ultrasound-assisted conditions (Scheme 32). According to the authors, these compounds exhibited a promising antibacterial potential.

Additionally, other studies that use ultrasonic energy to prepare compounds containing the $1 \mathrm{H}-1,2,3-$ triazole unit can be found in the literature. ${ }^{212-214}$ In all cases the use of ultrasound significantly increased the speed of reactions. 


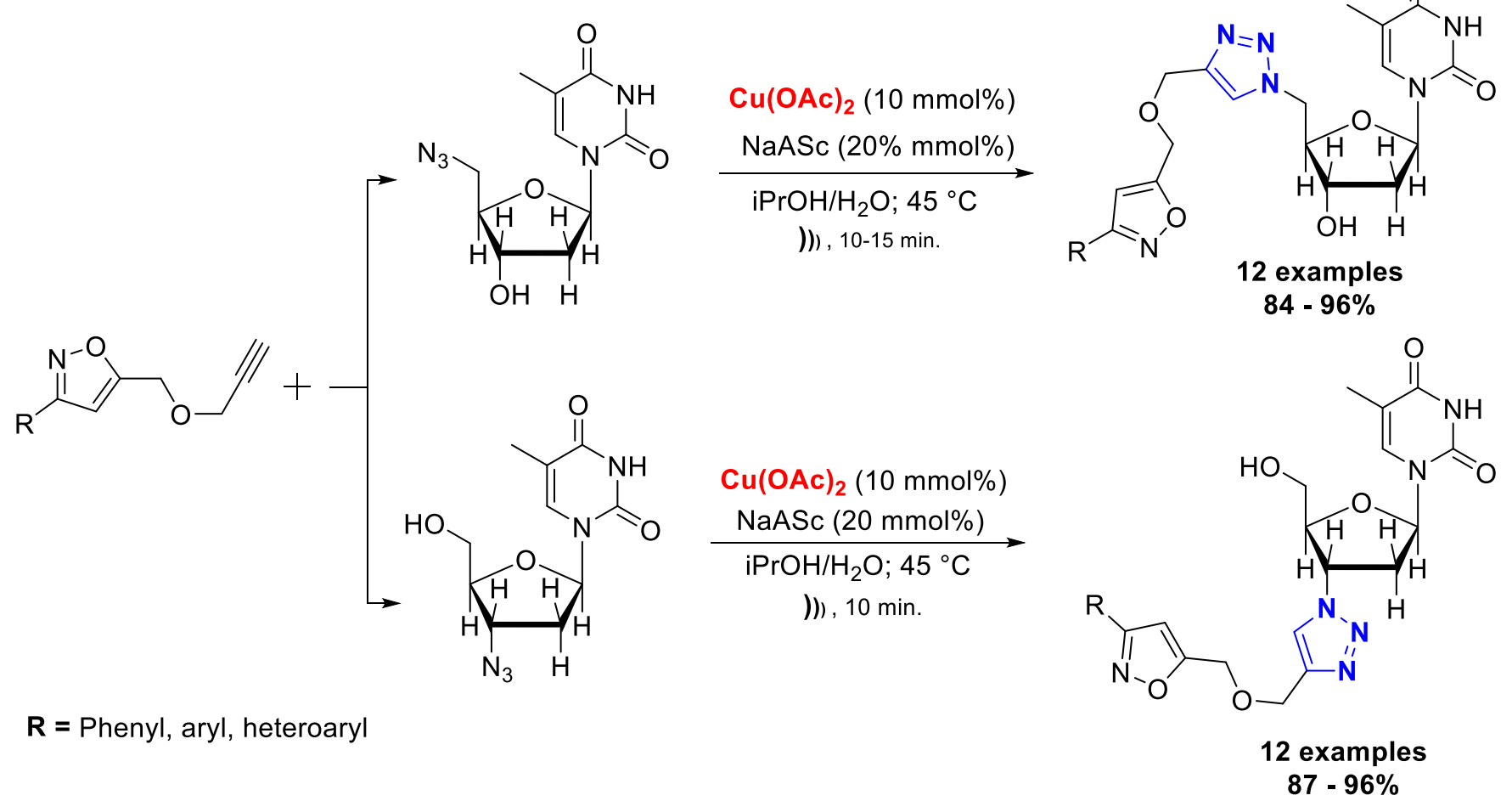

Scheme 32. Use of ultrasonic energy in the synthesis of $1 H-1,2,3$-triazoles containing an isoxazole and thymidine unit in its structure. ${ }^{211}$

3.3.6 Use of microwave in CuAAC reactions. Microwave-assisted CuAAC reactions have also been extensively studied, as this form of energy enables efficient internal heat transfer and therefore reduces reaction time as well as increases reaction rate and yield, furthermore, elevated temperatures can be used for short periods avoiding decomposition or polymerization. ${ }^{204}$ Thus, the first reports of the use of this energy form were described by the research groups of Khanetskyy ${ }^{215}$ and Appukkuttan, ${ }^{216}$ who independently reported in 2004 the use of microwave irradiation for synthesis of 1,4-disubstituted 1H-1,2,3-triazoles. In the work of the Khanetskyy group the authors used the $\mathrm{Cu}$ (II)/NaAsc catalytic system, while the work of the Appukkuttan group was employed elemental copper and copper sulfate as reaction catalysts (Scheme 33).

Based on these works, several authors have described excellent yields, high purity and short reaction times during the synthesis of $1 \mathrm{H}-1,2,3$-triazoles under copper-catalyzed microwave irradiation and in most cases the main advantages are an increase reaction rate and better yields. ${ }^{217-221}$ Additionally, microwave irradiation has been applied in the preparation of different classes of molecules containing the $1 \mathrm{H}-1,2,3-$ triazolic moiety, such as peptides ${ }^{222,223}$ macromolecules, ${ }^{224-226}$ oligonucleotides, ${ }^{227,228}$ carbohydrates, ${ }^{229,230}$ and nucleoside analogs. ${ }^{228,231}$

A recent work that deserves attention was conducted by Souza et al. ${ }^{232}$ who described a general and efficient method for the synthesis of new $1 \mathrm{H}-1,2,3$-triazoles based on a multicomponent microwave assisted reaction involving $\alpha$-thio aldehydes, propargylamine and arylazides. In this method copper sulfate and sodium ascorbate were used as catalytic system, acetic acid as Bronsted acid, sodium sulfate as drying salt and a $\mathrm{DCM} / \mathrm{H}_{2} \mathrm{O}(1: 1)$ solvent system to provide the triazole products in good yields (Scheme 34). This method is an interesting alternative for preparing triazole compounds containing an imine group. 
Work of the Khanetskyy's group
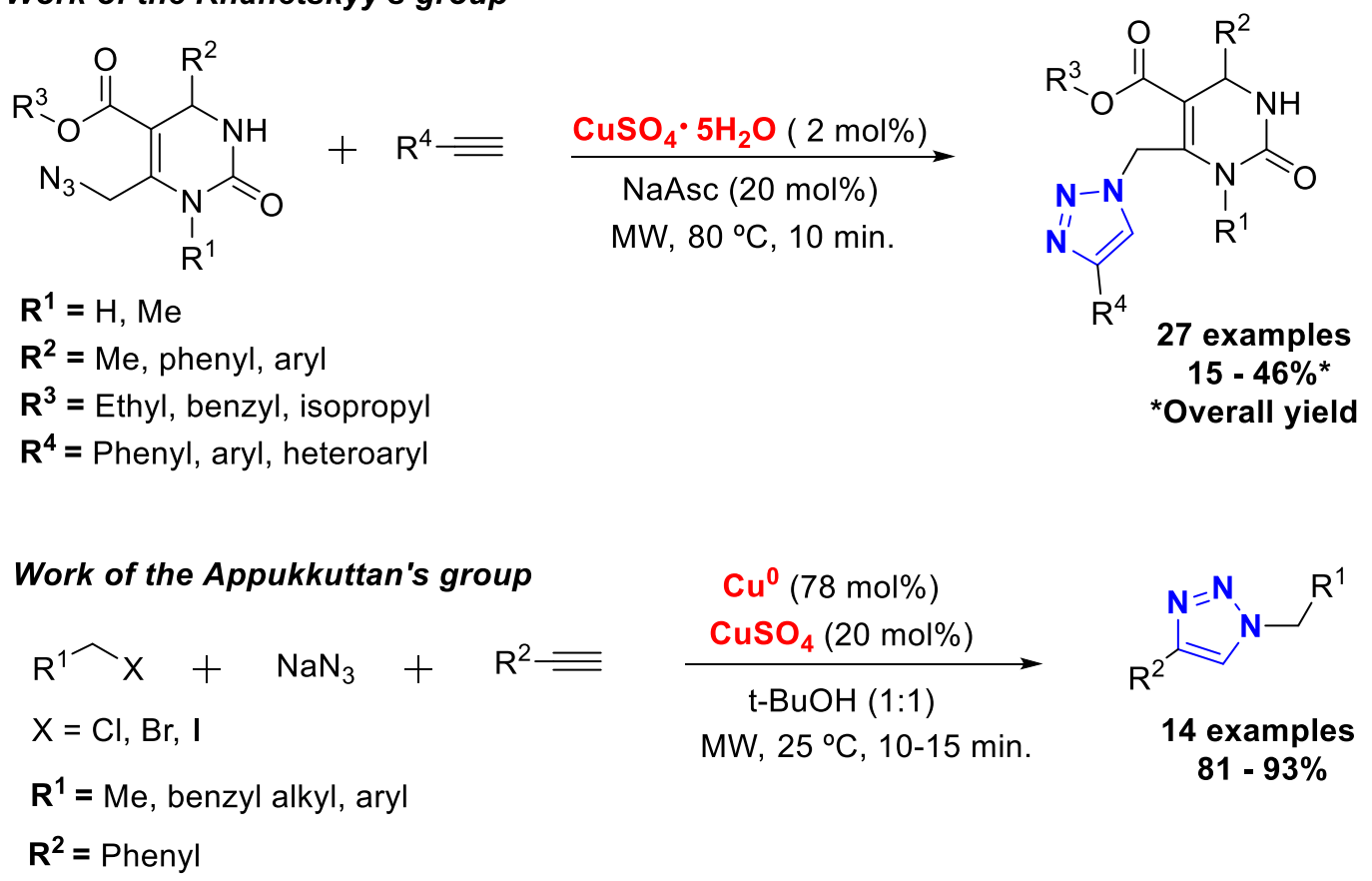

Scheme 33. First reports of microwave use in CuAAC reactions. ${ }^{215,216}$

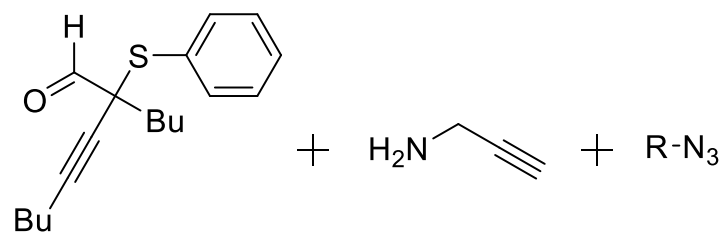

$\mathbf{R}=$ Phenyl, aryl, heteroaryl

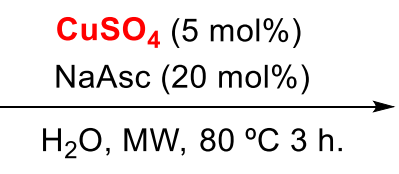

$\mathrm{H}_{2} \mathrm{O}, \mathrm{MW}, 80^{\circ} \mathrm{C} 3 \mathrm{~h}$.

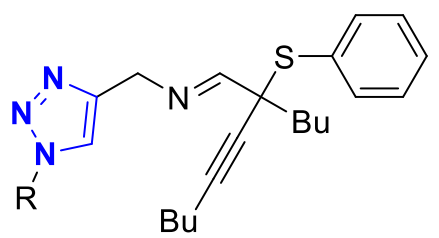

11 examples 57 - $83 \%$

Scheme 34. Application of microwave irradiation in the multicomponent synthesis of $1 H-1,2,3$-triazoles containing an imine group. ${ }^{232}$

The trend of more recent studies involving the use of microwave irradiation is focused on the development of green methods based on multicomponent reactions and the use of heterogeneous and reusable catalysts. In this sense, a green and environmentally friendly method for the synthesis of $1 \mathrm{H}-1,2,3-$ triazoles under microwave irradiation was developed by Radatz et al. ${ }^{233}$ In this multicomponent method the authors used $\mathrm{Cu} / \mathrm{SiO}_{2}$ as a recyclable catalyst, which can be reused in up to four reaction cycles. The reaction proceeded by mixing benzyl halide, sodium azide, alkyne and the catalyst in an aqueous medium to provide the triazole products in excellent yields (Scheme 35). 


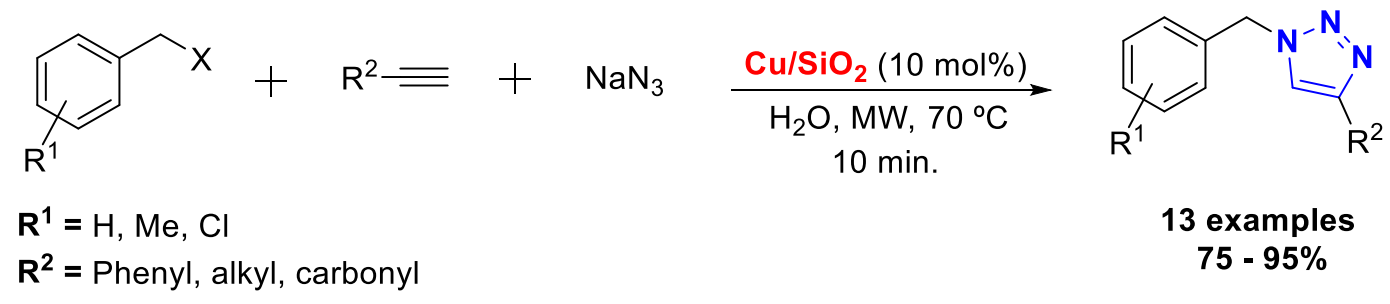

Scheme 35. Application of $\mathrm{Cu} / \mathrm{SiO}_{2}$ as a recyclable catalyst in microwave assisted multicomponent synthesis of $1 H$-1,2,3-triazole derivatives.

Agalave et al. ${ }^{234}$ also developed a heterogeneous catalyst by supporting Cul in alumina and applied to the microwave-irradiated multicomponent synthesis of 1,4-disubstituted $1 \mathrm{H}-1,2,3$-triazoles in aqueous medium. During the optimization of the reaction conditions, the authors compared the alumina-Cul with various copper catalysts [alumina- $\mathrm{CuSO}_{4}, \mathrm{SiO}_{2}-\mathrm{Cul}, \mathrm{SiO}_{2}-\mathrm{CuSO}_{4}, \mathrm{Cu}^{0}, \mathrm{CuCl}, \mathrm{Cu}(\mathrm{OAc})_{2}$ and $\mathrm{CuSO}_{4}$ ], being aluminaCul superior in terms of reaction time, yield and selectivity. Additionally, this catalyst was reused for up to eight reaction cycles without significant efficiency loss, providing the various triazole products with good yields (Scheme 36).

$$
\begin{aligned}
& \mathrm{R}^{1} \widehat{X}+\mathrm{R}^{2} \equiv+\mathrm{NaN}_{3} \underset{\mathrm{Cul}_{-} \mathrm{Al}_{2} \mathrm{O}_{3}(3 \mathrm{~mol} \%)}{\mathrm{H}_{2} \mathrm{O}, \mathrm{MW}, 70^{\circ} \mathrm{C}} \\
& \mathbf{X}=\mathrm{Cl}, \mathrm{Br}-13 \mathrm{~min} . \\
& \mathbf{R}^{1}=\mathrm{Allyl}, \text { alkyl, aryl, benzyl } \\
& \mathbf{R}^{2}=\text { Alkyl, aryl, heteroaryl }
\end{aligned}
$$

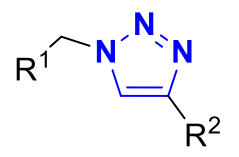

16 examples $70-98 \%$

Scheme 36. Application of microwave irradiation and recyclable alumina-Cul catalyst in the multicomponent synthesis of $1 H-1,2,3$-triazole derivatives. ${ }^{234}$

Recently, a multicomponent method involving propargyl bromide, amines and organic azides has been reported by Xiong et al. ${ }^{235} \mathrm{In}$ this procedure, $\mathrm{CuBr}$ was supported on fish bone powder residue generating the catalyst FBPs-CuBr, which was efficient in the preparation of several $\mathrm{N}$-substituted $1 \mathrm{H}-1,2,3$-triazoles and could be reused for seven reaction cycles (Scheme 37). In addition, a scaling up to $40.0 \mathrm{mmol}$ showed that the method has potential for industrial applications.

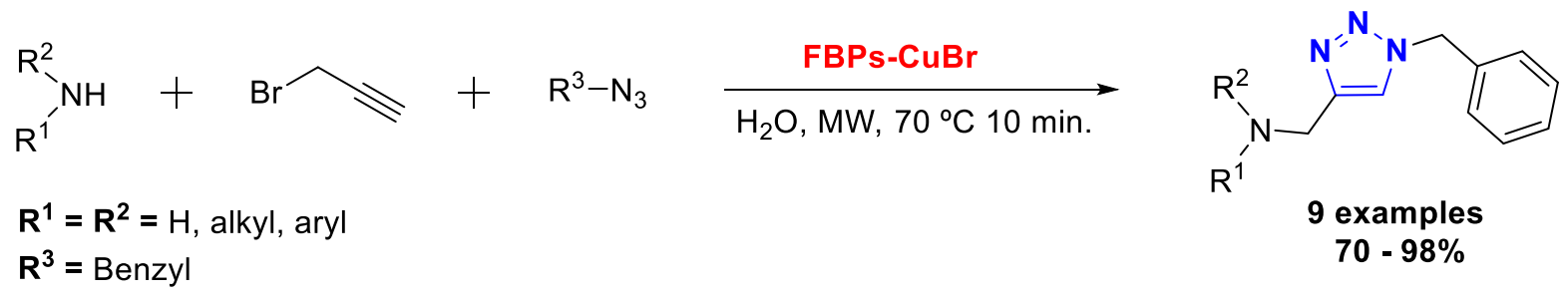

Scheme 37. Use of FBPs-CuBr as a recyclable catalyst in the multicomponent synthesis of $1 H-1,2,3-$ triazole derivatives. ${ }^{235}$

3.3.7 Multicomponent CuAAC reactions. Multicomponent Reactions provide ideal approaches for synthesizing structurally simple or complex molecules in a few reaction steps and with excellent overall yields. The use of 
such strategies has advantages in terms of environmental compatibility and atomic economics. ${ }^{236}$ Several reports have already demonstrated the practicalities of MCR in the synthesis of $1 H$-1,2,3-triazole derivatives. ${ }^{237}$

The first report of this strategy was described in 2004 by Fokin et al. ${ }^{238}$ They used benzyl halide or alkyl, terminal alkynes and sodium azide to prepare 1,4-disubstituted $1 \mathrm{H}-1,2,3$-triazoles using $\mathrm{Cu}$ (II)/NaAsc as a catalytic system (Scheme 38). This methodology offered a great advantage as it did not require the isolation of potentially unstable, toxic, or explosive azido intermediates. In addition, the reaction proceeded in two simple steps, first an $\mathrm{S}_{\mathrm{N}} 2$ reaction between sodium azide and the halogenated substrate, followed by a regioselective CUAAC reaction.

$$
\begin{array}{lcl}
\mathrm{R}^{1}-\mathrm{X}+\equiv \mathrm{R}^{2}+\mathrm{NaN}_{3} & \begin{array}{c}
\mathrm{CuSO}_{4} \cdot 5 \mathrm{H}_{2} \mathrm{O}(5-10 \mathrm{~mol} \%) \\
\mathrm{NaASc}(10-20 \mathrm{~mol} \%)
\end{array} \\
\begin{array}{l}
\mathbf{R}^{1}=\text { Phenyl, alkyl, aryl, heteroaryl } \\
\mathbf{R}^{2}=\text { Phenyl, alkyl, aryl }(20 \mathrm{~mol} \%)
\end{array}
\end{array}
$$

Scheme 38. First report of an MCR reaction in the synthesis of $1 H-1,2,3$-triazole derivatives. ${ }^{238}$

Another interesting example of a multicomponent reaction that also forms in situ organic azides was described in 2007 by Odlo et al. ${ }^{239}$ In this work, the authors used ethyl bromoacetate for ethyl azidoacetate generation, which then underwent CuAAC reactions with different terminal alkynes to provide one-pot $1 \mathrm{H}$ 1,2,3-triazole derivatives with excellent yields. $\mathrm{CuSO}_{4} \cdot 5 \mathrm{H}_{2} \mathrm{O}$ and NaAsc were used as catalytic system in the $t$ $\mathrm{BuOH} / \mathrm{H}_{2} \mathrm{O}(1: 1)$ solvent system (Scheme 39).

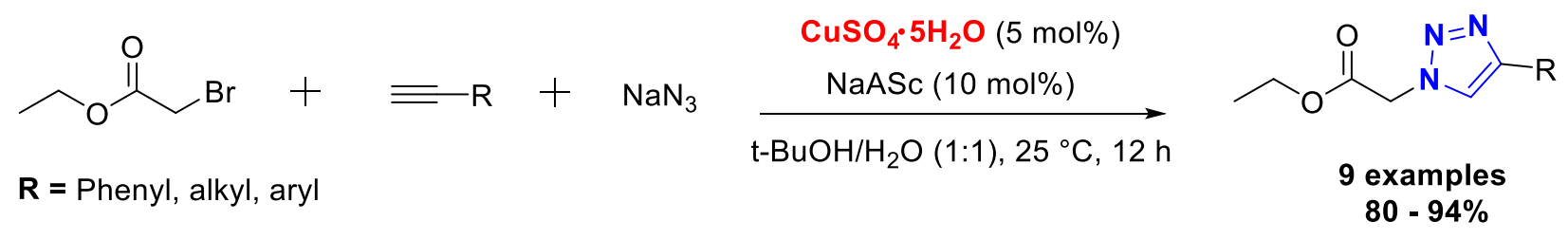

Scheme 39. Preparation of $\alpha$-carboxy-triazoles from MCR reactions. ${ }^{239}$

In situ formation of organic azides followed by CuAAC reactions for the preparation of $1 \mathrm{H}-1,2,3$-triazoles is a well-established strategy in multicomponent reactions. Halogenated substrates, such as chlorides ${ }^{240,241}$ and bromides, ${ }^{242-244}$ are the most used and undergo bimolecular nucleophilic substitution $\left(\mathrm{S}_{\mathrm{N}} 2\right)$ reaction to generate the corresponding organic azides. On the other hand, the use of tosylates ${ }^{245-247}$ and acetates ${ }^{248,249}$ have also been used for the same purpose. Additionally, in addition to $S_{N} 2$ reactions, nucleophilic aromatic substitution $\left(S_{N} A r\right)$ reactions, known as substitution-elimination reactions, have also been used for in situ organic azide formation. Electron-deficient aryl halides are ideal substrates for undergoing $S_{N} A r$ reactions and subsequent formation of $1 H$-1,2,3-triazoles with terminal alkynes. ${ }^{250,251}$

Epoxide opening by the use of sodium azide as nucleophile is also another strategy for in situ organic azide formation and the subsequent CuAAC reaction provides the 1,4-disubstituted $\beta$-hydroxy-1,2,3triazoles. ${ }^{252-254}$ Based on this strategy Velpuri and Muralidharan ${ }^{255}$ described in 2019 the preparation of $1 H$ 1,2,3-triazoles through a multicomponent reaction involving different terminal alkynes, sodium azide and 
different epoxides or alkyl halides. The authors synthesized surfactant-free copper sulfide micro flowers (sfCuS $\mathrm{mf}$ ) particles that efficiently catalyzed the reaction. Moreover, the reaction was conducted in aqueous medium and the catalyst presented low cost and recyclability, being reused five times without loss of catalytic activity (Scheme 40).

$$
\begin{aligned}
& \mathrm{R}^{1} \stackrel{\mathrm{O}}{=}+\mathrm{R}^{2}+\mathrm{NaN}_{3} \stackrel{\text { sf-CuS mf }}{\mathrm{H}_{2} \mathrm{O}, 25^{\circ} \mathrm{C}, 5-12 \mathrm{~h}} \\
& \mathbf{R}^{1}=\text { Phenyl, alkyl, cycloalkyl } \\
& \mathbf{R}^{2}=\text { Phenyl, aryl }
\end{aligned}
$$

Scheme 40. Multicomponent synthesis of $\beta$-hydroxy-1,2,3-triazoles from different epoxides. ${ }^{255}$

Multicomponent reactions involving arylboronic acids for in situ organic azide preparation have also been reported. ${ }^{256,257}$ An Interesting work involving this strategy was published in 2015 by Kumar et al. ${ }^{258}$ They described a simple, efficient and environmentally friendly protocol for the synthesis of 1,4-diaryl-1,2,3triazoles from boronic acids, sodium azide and acetylenes using chitosan-immobilized copper sulfate as a recyclable material (Scheme 41). The use of an aqueous medium at room temperature and easy catalyst recovery are other notable characteristics of this procedure.
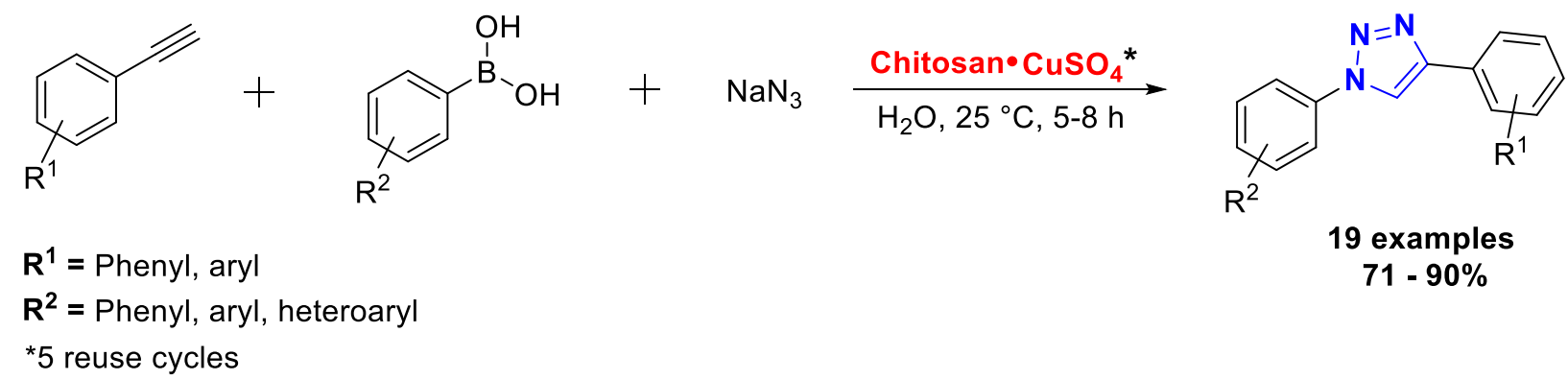

Scheme 41. Use of arylboronic acids in the multicomponent synthesis of $1 H-1,2,3$-triazole derivatives. ${ }^{258}$

Another work worth mentioning was reported in 2018 by Yu et al. ${ }^{259}$ in which the authors developed a fast, efficient, and multicomponent method for synthesizing trisubstituted 1,4,5-triazoles using organic azides, terminal alkynes and arylboronic acids. For this, $\mathrm{CuCl}$ was used as copper source, lithium methoxide and molecular oxygen as green oxidant. Several 1,4,5-trisubstituted 1,2,3-triazoles were obtained in good to excellent yields. According to the authors, this procedure provides rapid and selective access to fully substituted triazoles with a broad spectrum of functional group tolerability in the aryl portion (Scheme 42).

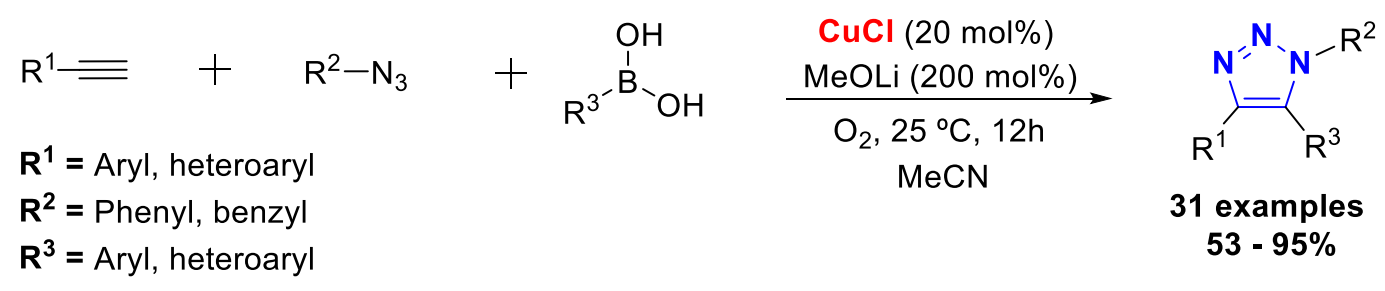

Scheme 42. Multicomponent synthesis of 1,4,5-trisubstituted $1 H$-1,2,3-triazole derivatives. ${ }^{259}$ 
Additionally, a new multicomponent method for obtaining fully substituted $1 \mathrm{H}-1,2,3$-triazoles has recently been described by Reddy et al. ${ }^{260}$ The authors used copper acetylide, organic azides and allyl iodide to obtain 1,4,5-trisubstituted $1 \mathrm{H}$-1,2,3-triazoles. In addition, copper acetylide is not formed in situ and formation of 1,4-disubstituted triazole regioisomers was not observed. Triazoles were obtained in good yields, however, long reaction times were required (Scheme 43).

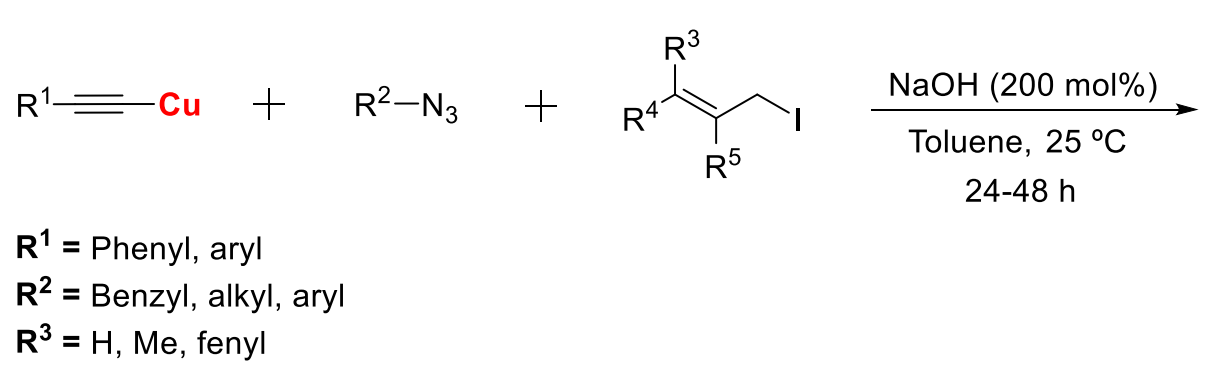

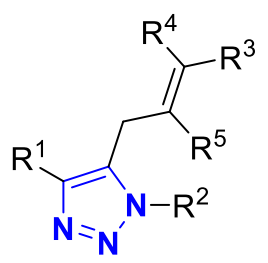

20 examples $53-94 \%$

Scheme 43. Synthesis of 1,4,5-trisubstituted $1 H$-1,2,3-triazoles by direct use of copper acetylide. ${ }^{260}$

The potential of multicomponent reactions for the preparation of $1 \mathrm{H}$-1,2,3-triazole derivatives has become extremely useful in recent years to produce complex macromolecular structures ${ }^{261}$ and several studies have reported the use of this strategy in the preparation of 1,4-disubstituted $1 \mathrm{H}-1,2,3$-triazoles. ${ }^{262-267}$

3.3.8 CuAAC light-induced reactions. A different way to generate $\mathrm{Cu}(\mathrm{I})$ species in situ in CuAAC reactions is through photoreduction, which makes use of light to reduce $\mathrm{Cu}(\mathrm{II})$ sources to $\mathrm{Cu}(\mathrm{I})$ without the addition of reducing agents. The first reports involving this strategy were described by the research groups Yagci ${ }^{268,269}$ and Bowman, ${ }^{270}$ who presented two photochemical protocols for the in situ generation of $\mathrm{Cu}(\mathrm{I})$ from a copper (II) chloride complex and the PMDETA ligand. $\mathrm{Cu}(\mathrm{l})$ species were generated directly or indirectly by ultraviolet light (UV) irradiation. In direct photolysis, UV light irradiation promotes an intramolecular electron transfer from the ligand $\pi$-system to the central ion, resulting in the desired reduction. Alternatively, in the indirect approach, a photoinitiator absorbs light in the UV-visible region, forming reactive intermediates such as radicals or carbocations, which in turn reduce $\mathrm{Cu}(\mathrm{II})$ species to active $\mathrm{Cu}(\mathrm{I})$ species (Scheme 44$){ }^{271}$

It is worth noting that the overall CUAAC reaction speed can be altered by light intensity, irradiation time and photoinitiator concentration. One of the main advantages of light-induced CuAAC reactions is that they can be controlled temporarily because the activating light beam can be turned on and off as desired. In addition, these characteristics make light-induced CuAAC reactions a promising method for biological and materials science applications. ${ }^{271}$

Given these advantages, several studies involving the use of UV or visible light, as well as the use of different photoinitiators, have been reported to activate the cycloaddition reactions between organic catalysts and copper catalyzed alkynes. ${ }^{272-276} \mathrm{~A}$ very interesting method was reported in 2016 by Taskin et al. ${ }^{277}$ in which the authors used visible light $(400-500 \mathrm{~nm})$ and fullerene $\left(C_{60}\right)$ containing linear polystyrene (PS- $\left.C_{60}\right)$ and polymer mesh (Gel- $\mathrm{C}_{60}$ ) as homogeneous and heterogeneous activators of CuAAC reactions (Scheme 45). Different azides and alkynes, including polymeric azides of low molecular weight were employed, however the products were not isolated, and yields were determined by hydrogen nuclear magnetic resonance $\left({ }^{1} \mathrm{H} N M R\right)$. 


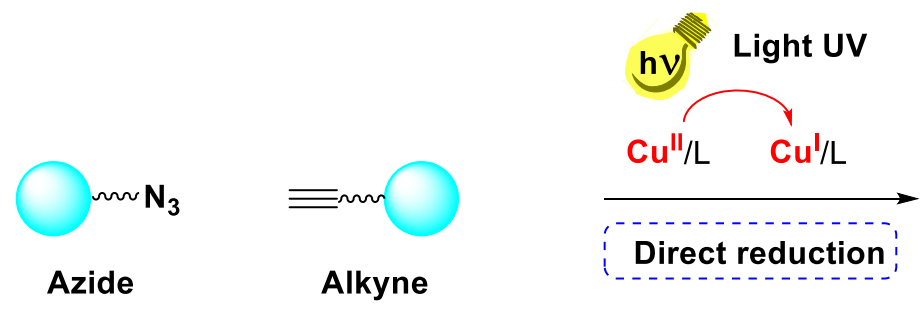

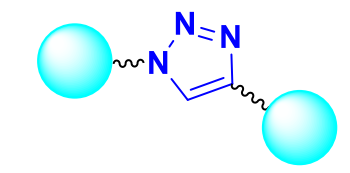

1H-1,2,3-triazole derivative

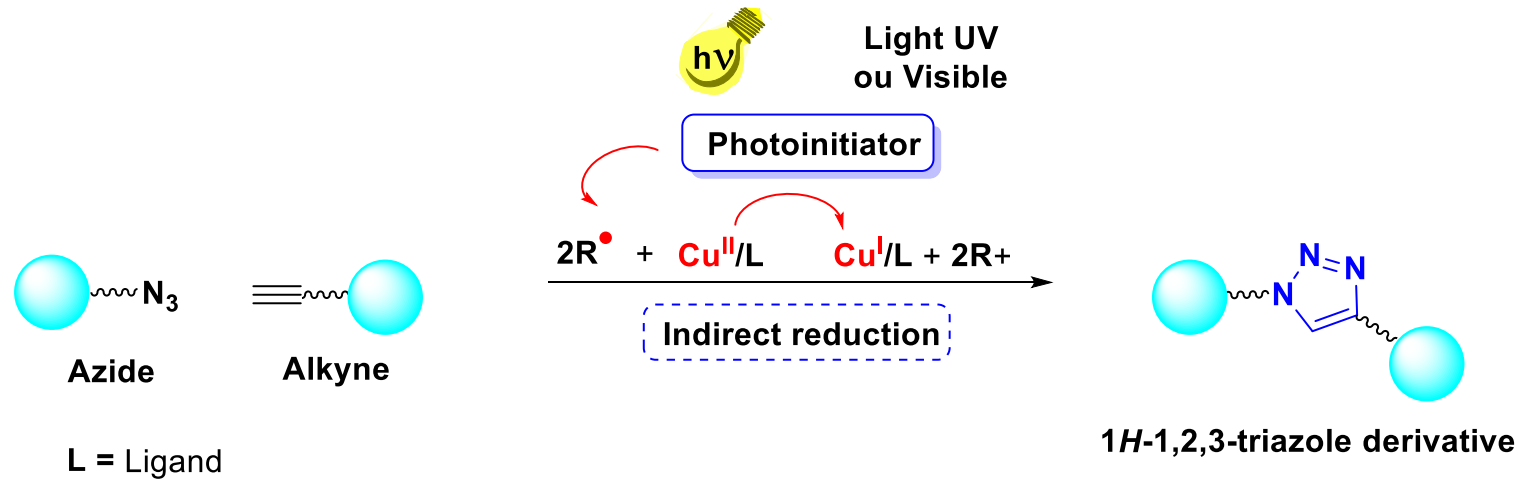

Scheme 44. Direct and indirect method for CU (II) photoreduction to CU (I). Adapted from Tasdelen, $2013 .{ }^{271}$
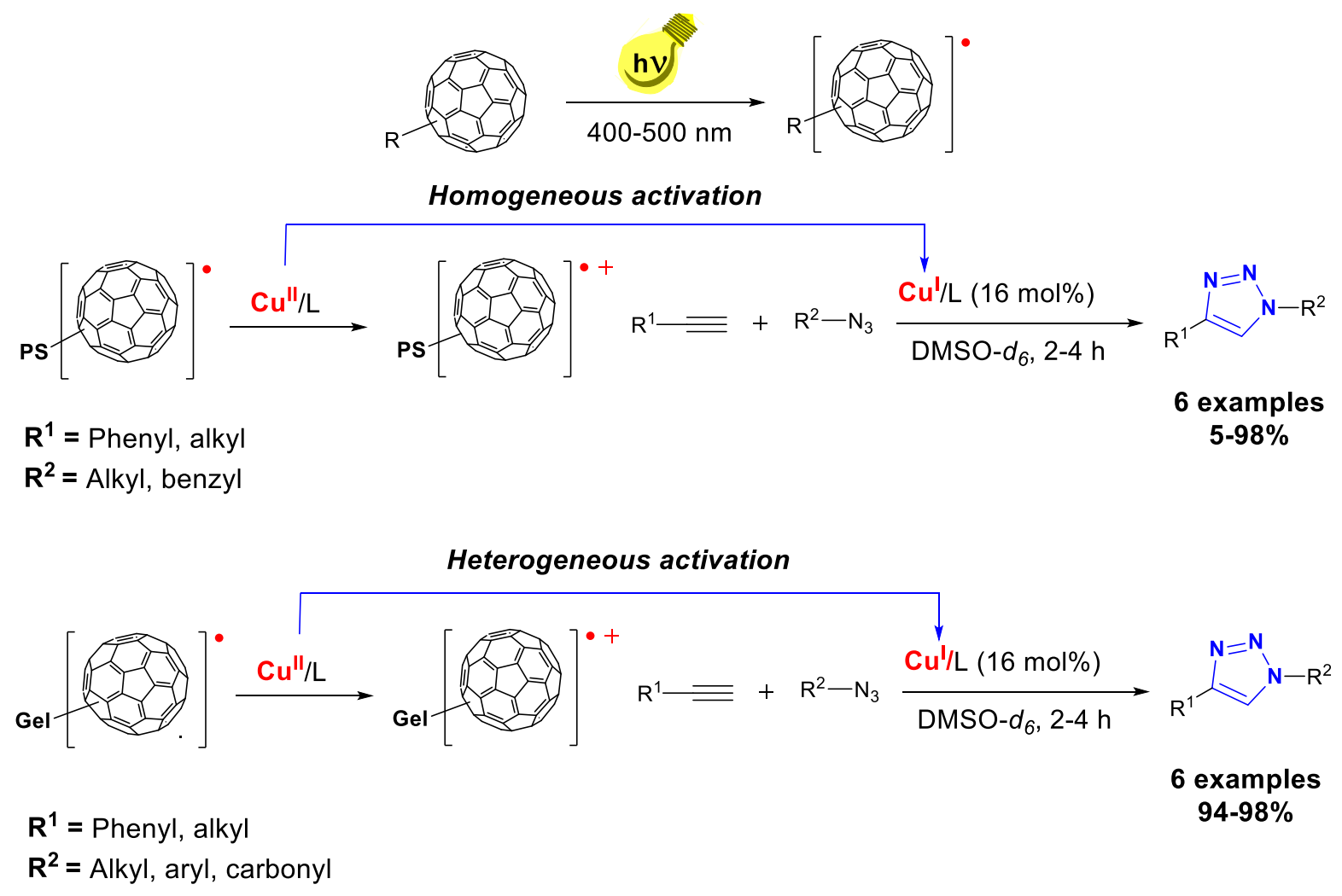

Scheme 45. Use of fullerene $\left(C_{60}\right)$ incorporated to light-activated polymers in CuAAC. ${ }^{277}$ 
3.3.9 Use of other transition metals in cycloaddition reactions involving azides and alkynes (MAAC). Alternatively, the use of different transition metals for the preparation of triazolic units has also been described to develop a new catalytic system for reaction between organic azides and alkynes. Fokin et al. ${ }^{278}$ first reported in 2005 the use of ruthenium complexes for the preparation of $1 \mathrm{H}-1,2,3$-triazole derivatives. The authors observed that, unlike copper complexes, the use of ruthenium under the conditions employed leads to the formation of highly regioselective $1 \mathrm{H}-1,2,3$-triazoles from terminal or internal alkynes (Scheme 46). Following this discovery, different ruthenium complexes were developed for the preparation of di- or trisubstituted $1 H$-1,2,3-triazole derivatives. ${ }^{279-281}$ The preparation of $1 H$-1,2,3-triazoles involving ruthenium complexes is known in the literature as RuAAC (Ruthenium-Catalyzed Azide Alkyne Cycloaddition).

$$
\begin{aligned}
& \mathrm{R}^{1}=\mathrm{R}^{2}+\mathrm{R}^{3}-\mathrm{N}_{3} \underset{\text { Dioxane, } 60^{\circ} \mathrm{C}, 2-12 \mathrm{~h}}{\stackrel{\mathrm{Cp} \mathrm{RuCl}^{*}\left(\mathrm{PPh}_{3}\right)_{2}(2 \mathrm{~mol} \%)}{\longrightarrow}} \\
& \mathbf{R}^{\mathbf{1}}=\text { Phenyl, alkyl, aryl, heteroaryl } \\
& \mathbf{R}^{\mathbf{2}}=\text { Phenyl } \\
& \mathbf{R}^{3}=\text { Benzyl, alkyl, aryl } \\
& \begin{array}{l}
\text { 1,5-disubstituted } \\
\text { and } 1,4,5 \text {-trisubstituted } \\
1 H-1,2,3 \text {-triazole } \\
11 \text { examples } \\
80-94 \%
\end{array}
\end{aligned}
$$

Scheme 46. First report of the use of ruthenium in the preparation of $1 H-1,2,3$-triazole derivatives. ${ }^{278}$

The use of metals such as silver, ${ }^{282-286}$ gold, $^{287,288}$ iridium, $^{289,290}$ nickel, $^{291}$ zinc, $^{292,293}$ samarium $^{294}$ and lanthanum ${ }^{295}$ have also been reported. Further details as well as the mechanistic aspects involved in the use of these different metals can be found in the review by Wang et al. ${ }^{296}$ and in the recent work of Gomes et al. ${ }^{35}$ Recently, Zheng's research group reported the use of Di- $\mu$-chloro-tetracarbonyldirhodium(I), a rhodium(I) complex, in the catalysis of the reaction between internal alkynes and azides in a highly regioselective form. ${ }^{297}$ The authors used internal alkynyl phosphonates to prepare 1,2,3-triazolyl-4-phosphonates with good yields (Scheme 47a). In 2019, the same researchers used that same catalyst to prepare 5-trifluoromethylthio-1,2,3triazoles (Scheme 47b) and $1 \mathrm{H}$-1,2,3-triazole from internal thioalkynes and internal alkynyl (Scheme 47c) with high yields and excellent regioselectivities. ${ }^{298}$ The main advantage in both reports is the possibility of preparing substrates at larger scales.

Although the use of different transition metals is an alternative for the preparation of $1 \mathrm{H}$-1,2,3-triazole units, these synthetic strategies still suffer from product contamination with metals and ligand residues and generally require the use of expensive and unfeasible catalysts for many research groups. During the writing of this manuscript, it is worth noting the review published in 2019 by Souza et al. ${ }^{299}$ 
a

$$
\begin{aligned}
\mathrm{R}^{1} \mathrm{O}-\mathrm{I}_{\mathrm{O}}^{\mathrm{O}}- & \stackrel{\mathrm{O} \mathrm{R}^{1}}{=} \mathrm{R}^{2}+\mathrm{R}^{3}-\mathrm{N}_{3} \quad \stackrel{\left[\mathrm{Rh}(\mathrm{CO})_{2} \mathrm{Cl}\right]_{2}(2.5 \mathrm{~mol} \%)}{\mathrm{DCM}, 40^{\circ} \mathrm{C}, 12-24 \mathrm{~h}} \\
\mathbf{R}^{1} & =\mathrm{Me}, \mathrm{iPr}, \mathrm{nBu}, \mathrm{Et} \\
\mathbf{R}^{2} & =\text { Phenyl, aryl } \\
\mathbf{R}^{3} & =\text { Phenyl, benzyl, alkyl, aryl }
\end{aligned}
$$

$$
\mathrm{R}^{1}=-\mathrm{SCF}_{3}+\mathrm{R}^{2}-\mathrm{N}_{3} \quad \frac{\left[\mathrm{Rh}(\mathrm{CO})_{2} \mathrm{Cl}_{2}(2.5 \mathrm{~mol} \%)\right.}{\mathrm{CHCl}_{3}, 25^{\circ} \mathrm{C}, 12-24 \mathrm{~h}}
$$

$$
\mathbf{R}^{\mathbf{1}}=\text { Phenyl, aryl, alkyl }
$$$$
\mathbf{R}^{\mathbf{2}}=\text { Benzyl, alkyl, aryl }
$$

$$
\mathrm{R}^{1}-\mathrm{X} \underset{-\mathrm{R}^{2}}{=} \mathrm{R}^{3}-\mathrm{N}_{3} \quad \frac{\left[\mathrm{Rh}(\mathrm{CO})_{2} \mathrm{Cl}\right]_{2}(2.5 \mathrm{~mol} \%)}{\mathrm{CHCl}_{3}, 40^{\circ} \mathrm{C}, 12-24 \mathrm{~h}}
$$

$\mathbf{R}^{\mathbf{1}}=$ Phenyl, aryl, alkyl

$\mathbf{R}^{\mathbf{2}}=$ Phenyl, aryl, alkyl

$\mathbf{R}^{\mathbf{3}}=$ Benzyl, alkyl, aryl

$\mathrm{X}=\mathrm{Se}, \mathrm{S}$

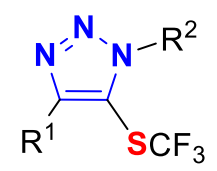

13 examples $71-92 \%$

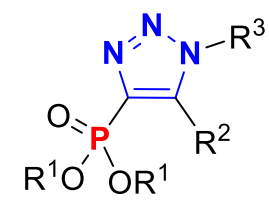

18 examples $67-94 \%$

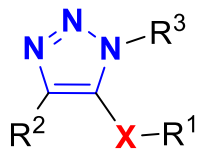

12 examples 31 - 94\%

Scheme 47. Use of the metal rhodium to catalyze reactions between internal alkynes and azides. ${ }^{297,298}$

\section{Conclusions}

CUAAC reactions are by far the most prominent example of "click" chemistry as it leads to the formation of 1,2,3-triazoles in a practical and efficient manner. Currently the literature has different synthetic strategies for the preparation of $1 \mathrm{H}-1,2,3$-triazole derivatives, and most of the methods are based on the use of copper.

In this review an overview of the main properties of the $1 \mathrm{H}-1,2,3$-triazole derivatives was reported, as well as the main methods involved in their preparation, which involved historical, mechanistic, and recent trends involving the synthesis of these triazole rings. Synthetic strategies reported in this review included 1,3dipolar thermal cyclization between azides and alkynes (AAC), $\mathrm{Cu}(\mathrm{I})$-catalyzed cycloaddition between azides and alkynes (CuAAC), heterogeneous CuAAC reactions, use of copper nanoparticles (CuNPs) in CuAAC reactions, use of ultrasonic energy and microwave irradiation in CuAAC reactions, multicomponent CuAAC reactions, CuAAC reactions induced by light and also the use of other transition metals in cycloaddition reactions involving azides and alkynes (MAAC). Each synthetic strategy has its own peculiarities and the choice of one is largely dependent on the reaction conditions and the nature of the substrates. However, despite this versatility, the use of the system involving a $\mathrm{Cu}(\mathrm{II})$ salt and a reducing agent remains the most used due to its simplicity and robustness. Nitrogen ligands, copper complexes, copper nanoparticles and even other metals have emerged as an alternative, but generally, many of these materials are costly.

One of the main factors that led to the development of different synthetic strategies for CuAAC reactions was the search for the reduction of toxic element residues in triazole products. Despite the numerous methods available, CuAAC reactions are not yet fully developed. Thus, an ideal strategy that leads to the formation of triazole products as efficiently as possible, involving azides and alkynes with several substituents and the complete elimination of copper is a challenge that has motivated researchers from 
various fields of knowledge. Additionally, given its established potential and the practicality of obtaining new and varied molecules from CuAAC reactions, it continues to be increasingly used and studied by research groups around the world.

\section{Acknowledgements}

The authors are grateful to National Council for Scientific and Technological Development - CNPq (Grants 448082/2014-4, PQ 301308/2017-9 and 434012/2018-1). This study was financed by the National Council for the Improvement of Higher Education - Brazil - CAPES (finance code 001) and the Pernambuco State Foundation for Science and Technology (FACEPE) for the scholarships granted to the authors of this study. We also thanks to Dr. Ricardo A. W. Neves Filho for proofreading.

\section{References}

1. Mishra, B. B.; Kumar, D.; Mishra, A.; Mohapatra, P. P.; Tiwari, V. K. Adv. Heterocycl. Chem. 2012, 107, 4199.

http://dx.doi.org/10.1016/B978-0-12-396532-5.00002-0

2. Mukherjee, S.; Das, M.; Manna, A.; Krishnac, R.; Das, S. J. Mater. Chem. A, 2019, 7, 1055-1068. http://dx.doi.org/10.1039/C8TA08185A

3. Joule, J. A.; Mills, K. Heterocyclic Chemistry, 5th Edn.; Wiley: United Kingdom, 2010; pp 621-664.

4. Lamberth, C.; Dinges, J. In Bioactive Heterocyclic Compound Classes: Agrochemicals; Lamberth, C.; Dinges, J. Eds.; Wiley-VCH: Weinheim, 2012; Vol. 1, p.3

5. Jalani, H. B.; Karagöz A. Ç.; Tsogoeva, S. B. Synthesis 2017, 49, 29-41. http://dx.doi.org/10.1055/s-0036-1588904

6. Dua, R.; Shrivastava, S.; Sonwane, S. K.; Srivastava, S. K. Adv. Biol. Res. 2011, 5, 120-144.

7. Thomas, K. D.; Adhikari, A. V.; Chowdhury, I. H.; Sumesh, E.; Pal, N. K. Eur. J. Med. Chem. 2011, 46, 25032512.

http://dx.doi.org/10.1016/j.ejmech.2011.03.039

8. Kant, R.; Kumar, D.; Argawal, D.; Gupta, R. D.; Tilak, R.; Awasthi, S. K.; Argawal, A. Eur. 9. J. Med. Chem. 2016, 113, 34-39.

http://dx.doi.org/10.1016/j.ejmech.2016.02.041

9. Ouahrouch, A.; Taourirte, M.; Schols, D.; Snoeck, R.; Andrei, G.; Engels, J. W.; Lazrek, H. B. Arch. Pharm. (Weinheim) 2016, 349, 30-41.

doi:10.1002/ardp.201500292

10. Ashwini, N.; Garg, M.; Mohan, C. D.; Fuchs, J. E.; Rangappa, S.; Anusha, S.; Swaroop, T. R.; Rakesh, K. S.; Kanojia, D.; Madan, V.; Bender, A.; Koeffler, H. P.; Basappa; Rangappa, K. S. Bioorg. Med. Chem. 2015, 23, 6157-6165.

http://dx.doi.org/10.1016/j.bmc.2015.07.069

11. Cassamale, T. B.; Costa, E. C.; Carvalho, D. B.; Cassemiro, N. S.; Tomazela, C. C.; Marques, M. C. S.; Ojeda, O.; Matos, M. F. C.; Albuquerque, S.; Arruda, C. C. P. Baroni, A. C. M. J. Braz. Chem. Soc. 2016, 27, 12171228. http://dx.doi.org/10.5935/0103-5053.20160017

12. Singh, A.; Gut, J.; Rosenthal, P.J.; Kumar, V. Eur. J. Med. Chem. 2017, 125, 269-277. http://dx.doi.org/10.1016/i.ejmech.2016.09.044 
13. Sreedhar, P; Srinivas, G.; Raju, R. M. Pharm. Chem. J. 2016, 8, 173-178.

14. Assis, S. P. O.; da Silva, M. T.; da Silva, F. T.; Sant'Anna, M. P.; Tenório, C. M. B. A.; dos Santos, C. F. B.; da Fonseca, C. S. M.; Seabra, G. Lima, V. L. M.; de Oliveira, R. N. Chem. Pharm. Bull. 2019, 67, 96-105. http://dx.doi.org/10.1248/cpb.c18-00607

15. Shaikh, M. H.; Subhedar, D. D.; Arkile, M.; Khedkar, V. M.; Jadhav, N.; Sarkar, D.; Shingate, B. B. Bioorg. Med. Chem. Lett. 2016, 26, 561-569. http://dx.doi.org/10.1016/j.bmcl.2015.11.071

16. Daligaux, P.; Pomel, S.; Leblanc, K.; Loiseau, P. M.; Cavé, C. Mol. Diversity 2016, 20, 507-519. http://dx.doi.org/10.1007/s11030-015-9652-9

17. Pickens, C. J.; Johnson, S. N.; Pressnall, M. M.; Leon, M. A.; Berkland, C. J. Bioconjugate Chem. 2018, 29, 686-701.

http://dx.doi.org/10.1021/acs.bioconjchem.7b00633

18. Krivopalov, V. P.; Shkurko, O. P. Russ. Chem. Rev. 2005, 74, 339-379.

http://dx.doi.org/10.1070/RC2005v074n04ABEH000893

19. Desai, P. S.; Indorwala, N. S. Int. J. Curr. Microbiol. Appl. Sci. 2015, 4, 928-938.

20. Miladinova, P. M.; Konstantinova, T. N. J. Chem. Technol. Metall. 2015, 50, 229-239.

21. Duan, T.; Fan, K.; Fu, Y.; Zhong, C.; Chen, X.; Peng, T. J. Qin, Dyes Pigm. 2012, 94, 28-33. http://dx.doi.org/10.1016/i.dyepig.2011.11.008

22. Schulze, B.; Schubert, U. S. Chem. Soc. Rev. 2014, 43, 2522-2571. http://dx.doi.org/10.1039/C3CS60386E

23. Srividhya, D.; Manjunathan, S.; Thirumaran, S.; Saravanan, C.; Senthil, S. J. Mol. Struct. 2009, 927, 7-13. http://dx.doi.org/10.1016/j.molstruc.2009.01.035

24. Arseneault, M.; Wafer, C.; Morin, J. F. Molecules 2015, 20, 92263-9294. http://dx.doi.org/10.3390/molecules20059263

25. Chen, Y.; Xianyu, Y.; Wu, J.; Yin, B.; Jiang, X. Theranostics 2016, 6, 969-985. http://dx.doi.org/10.7150/thno.14856

26. Rodriguez, C. A.; Agudelo, M.; Zuluga, A. F.; Vesga, O. Int. J. Antimicrob. Ag. 2017, 49, 189-197. http://dx.doi.org/10.1016/j.ijantimicag.2016.10.011

27. Choi, H. G.; Jun, H. W.; Kim, D. D.; Sah, H.; Yoo, B. K.; Yong, C. S. J. Pharm. Biomed. Anal. 2004, 35, 221231.

http://dx.doi.org/10.1016/j.jpba.2004.01.010

28. Kothare, S. Kluger, G.; Sachdeo, R.; Williams, B.; Olhaye, O.; Perdomo, C.; Bibbiani, F. Seizure. 2017, 47, 25-33.

http://dx.doi.org/10.1016/i.seizure.2017.02.008

29. Taylor, M. H.; Sandler, A.; Urba, W. J.; Omuro, A. M. P.; Gorman, G. S.; Karmali, R. A. J. Cancer Ther. 2015, 6, 322-333.

http://dx.doi.org/10.4236/jct.2015.64035

30. Michalska, K.; Gruba, E.; Bocian, W.; Piontek, J. C. J. Pharm. Biomed. Anal. 2017, 139, 98-108. http://dx.doi.org/10.1016/i.jpba.2017.01.041

31. Prasad, C. V.; Nayak, V. L.; Ramakrishna, S.; Mallavadhani, U. V. Chem. Biol. Drug Design. 2018, 91, 220233.

http://dx.doi.org/10.1111/cbdd.13073

32. https://www.webofknowledge.com, accessed Jun 12, 2020.

33. https://www.ncbi.nlm.nih.gov/pubmed, accessed Jun 12, 2020. 
34. https://www.scopus.com/search/form.uri?display=basic, accessed Jun 12, 2020.

35. Gomes, R. S.; Jardim, G. A. M.; de Carvalho, R. L.; Araujo, M. H.; da Silva Jr, E. N. Tetrahedron 2019, 75, 3697-3712.

http://dx.doi.org/10.1016/i.tet.2019.05.046

36. Melo, J. O. F.; Donnici, C. L.; Augusti, R.; Ferreira, V. F.; Souza, V. C. B. V.; Ferreira, M. L. G.; Cunha, A. C. Quim. Nova 2006, 29, 569-579.

http://dx.doi.org/10.1590/S0100-40422006000300028

37. Asif, M. Org. Chem.: Curr. Res. 2016, 5, 1-8.

http://dx.doi.org/10.4172/2161-0401.1000173

38. Katritzky, A.; Ramsden, C.; Joule, J.; Zhdankin, V. Handbook of Heterocyclic Chemistry, 3th Edn.; Elsevier: Amsterdam, 2010; p 1-1014.

http://dx.doi.org/10.1016/C2009-0-05547-0

39. Adam, W.; Grimison, A. Theor. Chim. Acta 1967, 7, 342-351.

http://dx.doi.org/10.1007\%2FBF00537511

40. Jug, K.; Chiodo, S.; Calaminici, P.; Avramopoulos, A.; Papadopoulos, M. G.; J. Phys. Chem. A 2003, 107, 4172-4183.

http://dx.doi.org/10.1021/ip022403m

41. Begtrup, M.; Nielsen, C. L.; Nygaard, L.; Samdal, S.; Sjøgren, C. E.; Sørensen, G. O. Acta Chem. Scand., Ser. A 1988, 42, 500-514.

http://dx.doi.org/10.3891/acta.chem.scand.42a-0500

42. Dheer, D.; Singh, V.; Shankar, R. Bioorg. Chem. 2017, 71, 30-54.

http://dx.doi.org/10.1016/j.bioorg.2017.01.010

43. Shaikh, M. H.; Subhedar, D. D.; Danne, A. B.; Mane, R. A.; Shingare, M. S.; Sathe, B. R.; Shingate, B. B.

Org. Chem.: Curr. Res. 2015, 4, 1-2.

http://dx.doi.org/10.4172/2161-0401.1000e140

44. Ferreira, S. B.; Sodero, A. C.; Cardoso, M. F.; Lima, E. S.; Kaiser, C. R.; Silva, F. P.; Ferreira, V. F. J. Med. Chem. 2010, 53, 2364-2375.

http://dx.doi.org/10.1021/jm901265h

45. Aizpurua, J. M.; Fratila, R. M.; Monasterio, Z.; Esnaola, N. P.; Andreieff, E.; Irastorza, A.; Aizpurua, M. S. New J. Chem. 2014, 38, 474-480.

http://dx.doi.org/10.1039/C3NJ00667K

46. Whiting, M.; Muldoon, J.; Lin, Y. C.; Silverman, S. M.; Lindstrom, W.; Olson, A. J.; Kolb, H. C.; Finn, M. G.; Sharpless, K. B.; Elder, J. H.; Fokin, V. V. Angew. Chem., Int. Ed. 2006, 45, 1435-1439.

http://dx.doi.org/10.1002/anie.200502161

47. Agalave, S. G.; Maujan, S. R.; Pore, V. S. Chem. - Asian J. 2011, 6, 2696-2718.

http://dx.doi.org/10.1002/asia.201100432

48. Bonandi, E.; Christodoulou, M. S.; Fumagalli, G.; Perdicchia, D.; Rastelli, G.; Passarella, D. Drug Discov. Today 2017, 22, 1572-1581.

http://dx.doi.org/10.1016/i.drudis.2017.05.014

49. Medal, M.; Tørnoe, C. W. Chem. Rev. 2008, 108, 2952-3015. http://dx.doi.org/10.1021/cr0783479

50. Montes-Ávila, J.; Sarmiento-Sánchez, J. I.; Delgado-Vargas, F.; Rivero, I. A.; Díaz-Camacho, S. P. Acta Universitaria 2016, 26, 63-67.

51. Pechmann, H. V. Ber. 1888, 21, 1411-1422. 
http://dx.doi.org/10.1002/cber.188802101262

52. Michael, A. J. Prakt. Chem. A 1893, 48, 94-95.

http://dx.doi.org/10.1002/prac.18930480114

53. Huisgen, R. Angew. Chem., Int. Ed. 1963, 2, 565-598.

http://dx.doi.org/10.1002/anie.196305651

54. Huisgen, R. Angew. Chem., Int. Ed. 1963, 2, 633-645.

http://dx.doi.org/10.1002/anie.196306331

55. Bräse, S.; Banert, K.; Organic Azides: Syntheses and Applications, 1th Edn.; John Wiley \& Sons, Ltd.:

Chichester, 2010.

56. Huisgen, R.; Szeimies, G.; Möbius, L. Chem. Ber. 1967, 100, 2494-2507.

http://dx.doi.org/10.1002/cber.19671000806

57. Huisgen, R. 1,3-Dipolar Cycloaddition Chemistry, 1th Edn.; Wiley: New York, 1984.

58. Huisgen, R. Pure Appl. Chem. 1989, 61, 613-628.

http://dx.doi.org/10.1351/pac198961040613

59. Wolwski, W. L. In 1,3-Dipolar Cycloaddition Reaction, 1th Edn.; John Wiley \& Sons: New York, 1984.

60. Houk, K. N. Acc. Chem. Res. 1975, 8, 361-369.

http://dx.doi.org/10.1021/ar50095a001.

61. Hubert, A. J. Bull. Soc. Chim. Belg. 1970, 79, 195-202.

http://dx.doi.org/10.1002/bscb.19700790303

62. Hein, J. E.; Fokin, V. V. Chem. Soc. Rev. 2010, 39, 1302-1315.

http://dx.doi.org/10.1039/B904091A

63. Himo, F.; Lovell, T.; Hilgraf, R.; Rostovtsev, V. V.; Noodleman, L.; Sharpless, K. B.; Fokin, V. V. J. Am. Chem. Soc. 2005, 127, 210-216.

http://dx.doi.org/10.1021/ja0471525

64. Sustmann, R. Tetrahedron Lett. 1971, 12, 2717-2720.

http://dx.doi.org/10.1016/S0040-4039(01)96961-8

65. Sustmann, R.; Trill, H. Angew. Chem., Int. Ed. 1972, 11, 838-840.

http://dx.doi.org/10.1002/anie.197208382

66. Houk, K. N. Acc. Chem. Res. 1975, 8, 361-369.

http://dx.doi.org/10.1021/ar50095a001

67. Fleming, I. Molecular Orbitals and Organic Chemical Reactions, Estudent Edn.; John Wiley \& Sons:

Chichester, 2009.

68. Ján Lauko, J.; Kouwer, P. H. J. Rowan, A. E. J. Heterocycl. Chem. 2016, 54, 1677-1699.

http://dx.doi.org/10.1002/ihet.2770

69. Hlasta, D. J.; Ackerman, J. H. J. Org. Chem. 1994, 59, 6184-6189.

http://dx.doi.org/10.1021/jo00100a019

70. Howell, S. J.; Spencer, N.; Philp, D. Tetrahedron 2001, 57, 4945-4954.

http://dx.doi.org/10.1016/S0040-4020(01)00402-1

71. Chen, J.; Rebek, J. Org. Lett. 2002, 4, 327-329.

http://dx.doi.org/10.1021/ol0168115

72. Tornøe, C. W.; Christensen, C.; Meldal, M. J. Org. Chem. 2002, 67, 3057-3064.

http://dx.doi.org/10.1021/jo011148j

73. Rostovtsev, V. V.; Green, L. G.; Fokin, V. V.; Sharpless, K. B. Angew. Chem., Int. Ed. 2002, 41, 2596-2599. http://dx.doi.org/10.1002/1521-3773(20020715)41:14<2596::AID-ANIE2596>3.0.CO;2-4 
74. L'abbe, G. Bull. Soc. Chim. Belg. 1984, 93, 579-592. http://dx.doi.org/10.1002/bscb.19840930706

75. Kolb, H. C.; Finn, M. G.; Sharpless, K. B. Angew. Chem., Int. Ed. 2001, 40, 2004-2021. http://dx.doi.org/10.1002/1521-3773(20010601)40:11<2004::aid-anie2004>3.3.co;2-x

76. Rodionov, V. O.; Fokin, V. V.; Finn, M. G.; Angew. Chem., Int. Ed. 2005, 44, 2210-2215. http://dx.doi.org/10.1002/anie.200461496

77. Rodionov, V. O.; Presolski, S. I.; Dıaz, D. D.; Fokin, V. V.; Finn, M. G. J. Am. Chem. Soc. 2007, 129, 1270512712. http://dx.doi.org/10.1021/ja072679d

78. Ahlquist, M.; Fokin, V. V. Organometallics 2007, 26, 4389-4391. http://dx.doi.org/10.1021/om700669v

79. Straub, B. F. Chem. Commun. 2007, 0, 3868-3870. http://dx.doi.org/10.1039/B706926J

80. Nolte, C.; Mayer, P.; Straub, B. F. Angew. Chem., Int. Ed. 2007, 46, 2101-2103. http://dx.doi.org/10.1002/anie.200604444

81. Hein, J. E; Tripp, J. C.; Krasnova, L. B.; Sharpless, K. B.; Fokin, V. V. Angew. Chem. Int. Ed. 2009, 48, 80188021. http://dx.doi.org/10.1002/anie.200903558

82. Worrell, B. T.; Malik, J. A.; Fokin, V. V. Science 2013, 340, 457-460. http://dx.doi.org/10.1126/science.1229506

83. Jin, L.; Tolentino, D. R.; Melaimi, M.; Bertrand, G. Sci. Adv. 2015, 1, e1500304, 1-5. http://dx.doi.org/10.1126/sciadv.1500304

84. Kuang, G. C.; Guha, P. M.; Brotherton, W. S.; Simmons, J. T.; Stankee, L. A.; Nguyen, B. T.; Clark, R. J.; Zhu, L. J. Am. Chem. Soc. 2011, 133, 13984-14001. http://dx.doi.org/10.1021/ja203733q

85. Guha, P. M.; Phan, H.; Kinyon, J. S.; Brotherton, W. S.; Sreenath, K.; Simmons, J. T.; Wang, Z.; Clark, R. J.; Dalal, N. S.; Shatruk, M.; Zhu, L.; Inorg. Chem. 2012, 51, 3465-3477.

http://dx.doi.org/10.1021/ic2021319

86. Escobar, L. B. L.; Guedes, G. P.; Soriano, S.; Speziali, N. L.; Jordão, A. K.; Cunha, A. C.; Ferreira, V. F.; Maxim, C.; Novak, M. A.; Andruh, M.; Vaz, M. G. F. Inorg. Chem. 2014, 53, 7508-7517. http://dx.doi.org/10.1021/ic5008044

87. Iacobucci, C.; Reale, S.; Gal, J. -F.; Angelis, F. D. Angew. Chem., Int. Ed. 2015, 54, 3065-3068. http://dx.doi.org/10.1002/anie.201410301

88. Ozkiliç; Y.; Tüzün. N. S. Organometallics 2016, 35, 2589-2599. http://dx.doi.org/10.1021/acs.organomet.6b00279

89. Calvo-Losada, S.; Pino-González M. S.; Quirante, J. J. J. Phys. Chem. B 2015, 119, 1243-1258. http://dx.doi.org/10.1021/ip5055414

90. Calvo-Losada, S.; Quirante, J. J. J. Mol. Model. 2017, 23, 337, 1-11. http://dx.doi.org/10.1007/s00894-017-3500-z

91. Ayouchia, H. B. E.; Bahsis, L.; Anane, H.; Domingo, L. R.; Stiriba, S. E. RSC Adv. 2018, 8, 7670-7678. http://dx.doi.org/10.1039/C7RA10653J

92. Moorman, R. M.; Collier, M. B.; Frohock, B. H.; Womble, M. D.; Chalker, J. M. Org. Biomol. Chem. 2014, 13, 1974-1978. 
93. Punna, S.; Kaltgrad, E.; Finn, M. G. Bioconjugate Chem. 2005, 16, 1536-1541. http://dx.doi.org/10.1021/bc0501496

94. Wang, F.; Fu, H.; Jiang, Y.; Zhao, Y. Green Chem. 2008, 10, 452-456. http://dx.doi.org/10.1039/B718051A

95. Wróblewski, A. E.; Glowacka, I. E. Tetrahedron Asymmetry 2005, 16, 4056-4064. http://dx.doi.org/10.1016/i.tetasy.2005.11.010

96. Israr, M.; Ye, C.; Muhammad, M. T.; Li, Y.; Bao, H. Beilstein J. Org. Chem. 2018, 14, 2916-2922. http://dx.doi.org/10.3762/bjoc.14.270

97. Zhou, F.; Tan, C.; Tang, J.; Zhang, Y. -Y.; Gao, W. -M.; Wu, H. -H.; Yu, Y. -H.; Zhou, J. J. Am. Chem. Soc. 2013, 135, 10994-10997. http://dx.doi.org/10.1021/ja4066656

98. Freitas, L. B. O.; Ruela, F. A.; Pereira, G. R.; Alves, R. B. Freitas, R. P. Quim. Nova 2011, 34, 1791-1804. http://dx.doi.org/10.1590/S0100-40422011001000012

99. Gerard, B.; Ryan, J.; Beeler, A. B.; Porco, J. A. Tetrahedron 2006, 62, 6405-6411. http://dx.doi.org/10.1016/j.tet.2006.04.025

100. Angell, Y.; Burgess, K. Angew. Chem., Int. Ed. 2007, 46, 3649-3651. http://dx.doi.org/10.1002/anie.200700399

101. Haldón, E.; Nicasio, M. C.; Pérez, P. J. Org. Biomol. Chem. 2015, 13, 9528-9550. http://dx.doi.org/10.1039/C5OB01457C

102. Lal, S.; González, S. D. J. Org. Chem. 2011, 76, 2367-2373. http://dx.doi.org/10.1021/jo200085j

103. Bates, C. G.; Saejueng, P.; Murphy, J. M.; Venkataraman, D. Org. Lett. 2002, 4, 4727-4729. http://dx.doi.org/10.1021/ol0272040

104. Barrè, G.; Taton, D.; Lastécouères, D.; Vincent, J. -M. J. Am. Chem. Soc. 2004, 126, 7764-7765. http://dx.doi.org/10.1021/ja048096a

105. Liang, L.; Ruiz, J.; Astruc, D. Adv. Synth. Catal. 2011, 353, 3434-3450. http://dx.doi.org/10.1002/adsc.201100449

106. Özçubukçu, S.; Ozkal, E.; Jimeno, C.; Pericàs, M. A. Org. Lett. 2009, 11, 4680-4683. http://dx.doi.org/10.1021/ol9018776

107. Li, L.; Lopes, P. S.; Rosa, V.; C. Figueira, C. A.; Lemos, M. A. N. D. A.; Duarte, M. T.; Avilés, T.; Gomes, P. T. Dalton Trans. 2012, 41, 5144-5154. http://dx.doi.org/10.1039/C2DT11854H

108. Barta, M.; González, S. D. Molecules 2013, 18, 8919-8928. http://dx.doi.org/10.3390/molecules18088919

109. Golas, P. L.; Tsarevsky, N. V.; Sumerlin, B. S.; Matyjaszewski, K. Macromolecules 2006, 39, 6451-6457. http://dx.doi.org/10.1021/ma061592u

110. Wang, Q.; Chan, T. R.; Higraf, R.; Fokin, V. V.; Sharpless, K. B.; Finn, M. G. J. Am. Chem. Soc. 2003, 125, 3192-3193. http://dx.doi.org/10.1021/ja021381e

111. Hong, V.; Udit, A. K.; Evans, R. A.; Finn, M. G. ChemBioChem. 2008, 9, 1481-1486. http://dx.doi.org/10.1002/cbic.200700768

112. Wang, S.; Jia, K.; Cheng, J.; Chen, Y.; Yuan, Y. Tetrahedron Lett. 2017, 58, 3717-3721. http://dx.doi.org/10.1016/j.tetlet.2017.08.029 
113. Nie, R.; Sang, R.; Ma, X.; Zheng, Y.; Cheng, X.; Li, W.; Guo, L.; Jin, H.; Wu, Y. J. Catal. 2016, 344, $286-292$. http://dx.doi.org/10.1016/j.jcat.2016.09.022

114. Amini, M.; Hassandoost, R.; Bagherzadeh, M.; Gautam, S.; Chae, K. H. Catal. Commun. 2016, 85, 13-16. http://dx.doi.org/10.1016/i.catcom.2016.07.006

115. Amini, M.; Bayrami, A.; Marashi, M. N.; Arab, A.; Ellern, A.; Woo, L. K. Inorg. Chim. Acta. 2016, 443, 2227.

http://dx.doi.org/10.1016/i.ica.2015.12.015

116. Jlalia, I.; Gallier, F.; Brodie-Linder, N.; Uziel, J.; Augé, J.; Lubin-Germain, N. J. Mol. Catal. A: Chem. 2014, 393, 56-61.

http://dx.doi.org/10.1016/j.molcata.2014.06.003

117. You, X.; Wei, Z. Transition Met. Chem. 2014, 39, 675-680.

http://dx.doi.org/10.1007/s11243-014-9849-2

118. Akbari, A.; Arsalani, N.; Amini, M.; Jabbari, E. J. Mol. Catal. A: Chem. 2016, 414, 47-54.

http://dx.doi.org/10.1016/j.molcata.2015.12.022

119. Zhou, C.; Zhang, J.; Liu, P.; Xie, J.; Dai, B. RSC Adv. 2015, 5, 6661-6665. http://dx.doi.org/10.1039/C4RA13423K

120. Nunes, A.; Djakovitch, L.; Khrouz, L.; Felpin, F.-X.; Dufaud, V. Mol. Catal. 2017, 437, 150-157. http://dx.doi.org/10.1016/j.molcata.2016.11.017

121. Bagherzadeha, M.; Mahmoudia, H.; Ataiea, S.; Hafezi-Kahnamoueia, M.; Shahrokhiana, S.; Bellachiomab, G.; Vaccaro, L. Inorganica Chim. Acta. 2019, 492, 213-220.

http://dx.doi.org/10.1016/j.ica.2019.04.036

122. Bakherad, M.; Rezaeimanesh, F.; Hossein Nasr-Isfahani, H. ChemistrySelect. 2018, 3, 2594-2598. http://dx.doi.org/10.1002/slct.201703088

123. Teixeira, R. R.; Silva, A. M.; Siqueira, R. P.; Gonçalves, V. H. S.; Pereira, H. S.; Ferreira, R. S.; Costa, A. V.; Melo, E. B.; Paula, F. R.; Ferreira, M. M. C.; Bressan, G. C. J. Braz. Chem. Soc. 2019, 30, 541-561. http://dx.doi.org/10.21577/0103-5053.20180203

124. Lallana, E.; Fernandez-Megia, E.; Riguera, R. J. Am. Chem. Soc. 2009, 131, 5748-5750. http://dx.doi.org/10.1021/ja8100243

125. Baskin, J. M.; Prescher, J. A.; Laughlin, S. T.; Agard, N. J.; Chang, P. V.; Miller, I. A.; Lo, A.; Codelli, J. A.; Bertozzi, C. R. Proc. Natl. Acad. Sci. U. S. A. 2007, 104, 16793-16797. http://dx.doi.org/10.1073/pnas.0707090104

126. Chan, T. R.; Hilgraf, R.; Sharpless, K. B.; Fokin, V. V. Org. Lett. 2004, 6, 2853-2855. http://dx.doi.org/10.1021/ol0493094

127. Mandoli, A. Molecules 2016, 21, 1174-1216. http://dx.doi.org/10.3390/molecules21091174

128. Lewis, W. G.; Magallon, F. G.; Fokin, V. V.; Finn, M. J. Am. Chem. Soc. 2004, 126, 9152-9153. http://dx.doi.org/10.1021/ja048425z

129. Hong, V.; Presolski, S. I.; Ma, C.; Finn, M. Angew. Chem. Int. Ed. 2009, 48, 9879-9883. http://dx.doi.org/10.1002/anie.200905087

130. Besanceney-Webler, C.; Jiang, H.; Zheng, T.; Feng, L.; Soriano del Amo, D.; 3192, W.; Klivansky, L. M.; Marlow, F. L.; Liu, Y.; Wu, P. Angew. Chem. Int. Ed. 2011, 50, 8051-8056. http://dx.doi.org/10.1002/anie.201101817

131. Wang, W.; Hong, S.; Tran, A.; Jiang, H.; Triano, R.; Liu, Y.; Chen, X.; Wu, P. Chem. Asian J. 2011, 6, 27962802. 
http://dx.doi.org/10.1002/asia.201100385

132. Kennedy, D. C.; McKay, C. S.; Legault, M. C.; Danielson, D. C.; Blake, J. A. J. Am. Chem. Soc. 2011, 133, 17993-18001.

http://dx.doi.org/10.1021/ja2083027

133. Campbell-Verduyn, L. S.; Mirfeizi, L.; Dierckx, R. A.; Elsinga, P. H.; Feringa, B. L. Chem. Commun. 2009, 2139-2141.

http://dx.doi.org/10.1039/B822994E

134. Dwars, T.; Paetzold, E.; Oehme, G. Angew. Chem., Int. Ed. 2005, 44, 7174-7199.

http://dx.doi.org/10.1002/anie.200501365

135. Lipshutz, B. H.; Bošković, Z.; Crowe, C. S.; Davis, V. K.; Whittemore, H. C.; Vosburg, D. A.; Wenzel, A. G. J. Chem. Educ. 2013, 90, 1514-1517.

http://dx.doi.org/10.1021/ed300893u

136. Lipshutz, B. H.; Ghorai, S. Green Chem. 2014, 16, 3660-3679.

http://dx.doi.org/10.1039/C4GC00503A

137. Shin, J. -A.; Lim, Y. -G. Bull. Korean Chem. Soc. 2015, 36, 2367-2370.

http://dx.doi.org/10.1002/bkcs.10434

138. Shin, J. -A.; Lim, Y. -G.; Lee, K. -H. J. Org. Chem. 2012, 77, 4117-4122.

http://dx.doi.org/10.1021/jo3000095

139. Shin, J. -A.; Oh, S. -J.; Lee, H. -Y.; Lim, Y. -G. Catal. Sci. Technol. 2017, 7, 2450-2456.

http://dx.doi.org/10.1039/C7CY00518K

140. Appukkuttan, P.; Dehaen, W.; Fokin, V. V.; Van Der Eycken, E. Org. Lett. 2004, 6, 4223-4225. http://dx.doi.org/10.1021/ol048341v

141. Pachón, L. D.; Van Maarseveen, J. H.; Rothenberg, G. Adv. Synth. Catal. 2005, 347, 811-815. http://dx.doi.org/10.1002/adsc.200404383

142. Wan, Q.; Chen, J.; Chen, G.; Danishefsky, S. J. J. Org. Chem. 2006, 71, 8244-8249. http://dx.doi.org/10.1021/jo061406i

143. Urbani, C. N.; Bell, C. A.; Whittaker, M. R.; Monteiro, M. J. Macromolecules 2008, 41, 1057-1060. http://dx.doi.org/10.1021/ma702707e

144. Kumar, N.; Ansari, M. Y.; Kantb, R.; Kumar, A. Chem. Commun. 2018, 54, 2627-2630. http://dx.doi.org/10.1039/C7CC09934G

145. Chassaing, S.; Bénéteaub, V.; Pale, P. Catal. Sci. Technol. 2016, 6, 923-957. http://dx.doi.org/10.1039/C5CY01847A

146. Girard, C.; Önen, E.; Aufort, M.; Beauvière, S.; Samson, E.; Herscovici, J. Org. Lett. 2006, 8, 1689-1692. http://dx.doi.org/10.1021/ol060283|

147. Jlalia, I.; Meganem, F.; Herscovici, J.; Girard, C. Molecules 2009, 14, 528-539.

http://dx.doi.org/10.3390/molecules14010528

148. Slimi, R.; Kalhor-Monfared, S.; Plancq, B.; Girard, C. Tetrahedron Lett. 2015, 56, 4339-4344. http://dx.doi.org/10.1016/i.tetlet.2015.05.079

149. Coelho, A.; Diz, P.; Caamaño, O.; Sotelo, E. Adv. Synth. Catal. 2010, 352, 1179-1192. http://dx.doi.org/10.1002/adsc.200900680

150. Li, P.; Wang, L.; Zhang, Y. Tetrahedron 2008, 64, 10825-10830. http://dx.doi.org/10.1016/j.tet.2008.09.021

151. Wan, L.; Cai, C. Catal. Lett. 2012, 142, 1134-1140. http://dx.doi.org/10.1007/s10562-012-0880-7 
152. Monguchi, Y.; Nozaki, K.; Maejima, T.; Shimoda, Y.; Sawama, Y.; Kitamura, Y.; Kitade, Y.; Sajiki, H. Green Chem. 2013, 15, 490-495. http://dx.doi.org/10.1039/C2GC36584G

153. Zarchi, M. A. K; Nazem, F. J. Iran. Chem. Soc. 2014, 11, 1731-1742. http://dx.doi.org/10.1007/s13738-014-0446-2

154. Movassagh, B.; Rezaei, N. Tetrahedron 2014, 70, 8885-8892. http://dx.doi.org/10.1016/i.tet.2014.09.092

155. Wu, H.; Dong, W.; Wang, Z.; Yao, B.; Chen, M.; Sun, J.; Qin, A.; Tang, B. Z. Sci. China: Chem. 2015, 58, 1748-1752.

http://dx.doi.org/10.1007/s11426-015-5475-x

156. Roy, S.; Chatterjee, T.; Islam, S. M. Green Chem. 2013, 15, 2532-2539. http://dx.doi.org/10.1039/C3GC41114A

157. Hu, Q.; Shi, X. -L.; Chen, Y.; Wang, F.; Weng, Y.; Duan, P. J. Ind. Eng. Chem. 2019, 69, 387-396. http://dx.doi.org/10.1016/j.jiec.2018.09.047

158. Chavan, P. V.; Pandit, K. S.; Desay, U. V.; Kulkarni, M. A.; Wadgaonkar, P. P. RSC Adv. 2014, 4, 4213742146. http://dx.doi.org/10.1039/C4RA05080K

159. Lipshutz, B. H.; Taft, B. R. Angew. Chem., Int. Ed. 2006, 45, 8235-8238. http://dx.doi.org/10.1002/anie.200603726

160. Rojas-Lima, S.; López-Ruiz, H.; de la Cerda-Pedro, J. E.; Rojas-Lima, S.; Pérez-Pérez, I.; Rodríguez-Sánchez, B. V.; Santillán, R.; Coreño, O. Arch. Org. Chem. 2013, 139-164.

http://dx.doi.org/10.3998/ark.5550190.0014.312

161. Sharghi, H.; Beyzavi, M. H.; Safavi, A.; Doroodmand, M. M.; Khalifeh, R. Adv. Synth. Catal. 2009, 351, 2391-2410. http://dx.doi.org/10.1002/adsc. 200900353

162. Sharghi, H.; Ebrahimpourmoghaddam, S.; Doroodmand, M. M.; Purkhosrow, A. Asian J. Org. Chem. 2012, 1, 377-388.

http://dx.doi.org/10.1002/ajoc.201200012

163. Song, Y. H.; He, Z. F.; Hou, H. Q.; Wang, X. L.; Wang, L. Electr. Acta. 2012, 71, 58-65. http://dx.doi.org/10.1016/j.electacta.2012.03.077

164. Vats, T.; Gogoi, R.; Gaur, P.; Sharma, A.; Ghosh, S.; Siril, P. F. ACS Sustainable Chem. Eng. 2017, 5, 76327641.

http://dx.doi.org/10.1021/acssuschemeng.7b00960

165. Cernat, A.; Györfi, S. J.; Irimes, M. B.; Tertiș, M.; Bodoki, A.; Pralea, I. E.; Suciu, M.; Cristea, C. Electrochem. Commun. 2019, 98, 23-27. http://dx.doi.org/10.1016/i.elecom.2018.11.008

166. Rad, M. N. S.; Behrouz, S.; Behrouz, M.; Sami, A.; Mardkhoshnood, M.; Zarenezhad, A.; Zarenezhad, E. Mol. Diversity 2016, 20, 705-718. http://dx.doi.org/10.1007/s11030-016-9678-7

167. Fehér, K.; Nagy, E.; Szabó, P.; Juzsakova, T.; Srankó, D.; Gömöry, A.; Kollár, L.; Földes, R. S. Appl. Organomet. Chem. 2018, 32, e4343, 1-13. http://dx.doi.org/10.1002/aoc.4343

168. Agalave, S. G.; Pharande, S. G.; Gade, S. M.; Pore, V. S. Asian J. Org. Chem. 2015, 4, 943-951. http://dx.doi.org/10.1002/ajoc.201500189 
169. Yamaguchi, K.; Oishi, T.; Katayama, T.; Mizuno, N. Chem. - Eur. J. 2009, 15, 10464-10472. http://dx.doi.org/10.1002/chem.200901444

170. Chassaing, S.; Kumarraja, M.; Sido, A. S. S.; Pale, P.; Sommer, J. Org. Lett. 2007, 9, 883-886. http://dx.doi.org/10.1021/ol0631152

171. Khun, P.; Alix, A.; Kumarraja, M.; Louis, B.; Pale, P.; Sommer, J. Eur. J. Org. Chem. 2009, 3, 423-429. http://dx.doi.org/10.1002/ejoc.200800848

172. Luz, I.; Llabrés i Xamena, F. X.; Corma, A. J. Catal. 2010, 276, 134-140. http://dx.doi.org/10.1016/i.jcat.2010.09.010

173. Li, P.; Regati, S.; Huang, H.; Arman, H. D.; Zhao, J. C. -G.; Chen, B. Inorg. Chem. Front. 2015, 2, $42-46$. http://dx.doi.org/10.1039/C4QI00148F

174. Xiong, X.; Chen, H.; Tang, Z.; Jiang, Y. RSC Adv. 2014, 4, 9830-9837. http://dx.doi.org/10.1039/C3RA45994B

175. Kumar, A. B. S. P.; Reddy, K. H. V.; Madhav, B.; Ramesh, K.; Nageswar, Y. V. D. Tetrahedron Lett. 2012, 53, 4595-4599.

http://dx.doi.org/10.1016/j.tetlet.2012.06.077

176. Jlalia, I.; Elamari, H.; Meganem, F.; Herscovici, J.; Girard, C. Tetrahedron Lett. 2008, 49, 6756-6758. http://dx.doi.org/10.1016/i.tetlet.2008.09.031

177. Dubey, N.; Sharma, P.; Kumar, A. Synth. Commun. 2015, 45, 2608-2626. http://dx.doi.org/10.1080/00397911.2015.1099675

178. Bahsis, L.; Ayouchia, H. B. E.; Anane, H. Álvarez, A. P.; Munno, G.; Julve, M.; Stiriba, S. E. Appl. Organomet. Chem. 2019, 33, e4669, 1-15. http://dx.doi.org/10.1002/aoc.4669

179. Roy, S.; Chatterjee, T.; Islam, S. M. Green Chem. 2013, 15 2532-2539. http://dx.doi.org/10.1039/C3GC41114A

180. Bahsis, L.; Ayouchia, H. B. E.; Anane, H.; Benhamou, K.; Kaddami, H.; Miguel Julve, M.; Stiriba, S. E. Int. J. Biol. Macromol. 2018, 119, 849-856. http://dx.doi.org/10.1016/j.ijbiomac.2018.07.200

181. Aflak, N.; Ayouchia, H, B. L.; Bahsis, L.; Mouchtari, E. M. E.; Julve, M.; Rafqah, S.; Anane, H.; Stiriba, S. E. Front. Chem. 2019, 7, 81-93. http://dx.doi.org/10.3389/fchem.2019.00081

182. Ghosh, S. K.; Pal, T. Chem. Rev. 2007, 107, 4797-4862. http://dx.doi.org/10.1021/cr0680282

183. Ranu, B. C.; Dey, R.; Chatterjee, T.; Ahmmed, S. ChemSusChem. 2012, 5, 22-44. http://dx.doi.org/10.1002/cssc.201100348

184. Jin, T.; Yan, M.; Yamamoto, Y. ChemCatChem. 2012, 4, 1217-1229. http://dx.doi.org/10.1002/cctc.201200193

185. Gawande, M. B.; Goswami, A.; Felpin, F. X.; Asefa, T.; Huang, X. X.; Silva, R.; Zou, X. X.; Zboril, R.; Varma, R. S. Chem. Rev. 2016, 116, 3722-3811. http://dx.doi.org/10.1021/acs.chemrev.5b00482

186. Orgueira, H. A.; Fokas, D.; Isome, Y.; Chan, P. C. -M.; Baldino, C. M. Tetrahedron Lett. 2005, 46, 29112914.

http://dx.doi.org/10.1016/j.tetlet.2005.02.127

187. Molteni, G.; Bianchi, C. L.; Marinoni, G.; Santo, N.; Ponti, A. New J. Chem. 2006, 30, 1137-1139. http://dx.doi.org/10.1039/B604297J 
188. Alonso, F.; Moglie, Y.; Radivoy, G.; Yus, M. Tetrahedron Lett. 2009, 50, 2358-2362. http://dx.doi.org/10.1016/j.tetlet.2009.02.220

189. Alonso, F.; Moglie, Y.; Radivoy, G.; Yus, M. Eur. J. Org. Chem. 2010, 10, 1875-1884. http://dx.doi.org/10.1002/ejoc.200901446

190. Pressly, D. D.; Amir, R. J.; Hawker, C. J. J. Polym. Sci., Part A: Polym. Chem. 2011, 49, 814-819. http://dx.doi.org/10.1002/pola.24504

191. Pathigoolla, A.; Pola, R. P.; Sureshan, K. M. Appl. Catal., A 2013, 453, 151-158. http://dx.doi.org/10.1016/i.apcata.2012.12.025

192. Mohan, B.; Woo, H.; Jang, S.; Lee, S.; Park, S. Solid State Sci. 2013, 22, 16-20. http://dx.doi.org/10.1016/j.solidstatesciences.2013.05.004

193. Kantam, M. L.; Jaya, V. S.; Sreedhar, B.; Rao, M. M.; Choudary, B. M. J. Mol. Catal. A: Chem. 2006, 256, 273-277.

http://dx.doi.org/10.1016/j.molcata.2006.04.054

194. Park, I. S.; Kwon, M. S.; Kim, Y.; Lee, J. S.; Park, J. Org. Lett. 2008, 10, 497-500. http://dx.doi.org/10.1021/ol702790w

195. Borah, B. J.; Dutta, D.; Saikia, P. P.; Barua, N. C.; Dutta, D. K. Green Chem. 2011, 13, 3453-3460. http://dx.doi.org/10.1039/C1GC16021D

196. Jayaramulu, K.; Suresh, V. M.; Maji, T. K. Dalton Trans. 2015, 44, 83-86. http://dx.doi.org/10.1039/C4DT02661F

197. Fu, Q.; Xie, K.; Tan, S.; Ren, J. M.; Zhao, Q.; Webley, P. A.; Qiao, G. G. Chem. Commun. 2016, 52, 1222612229.

http://dx.doi.org/10.1039/C6CC06890A

198. Shaabani, S.; Tavousi Tabatabaei, A.; Shaabani, A. Appl. Organomet. Chem. 2017, 31, e3559, 1-6. http://dx.doi.org/10.1002/aoc.3559

199. Yu, W.; Jiang, L.; Shen, C.; Xu, W.; Zhang, P. Catal. Commun. 2016, 79, 11-16. http://dx.doi.org/10.1016/j.catcom.2016.02.015

200. Fu, F.; Martinez, A.; Wang, C.; Ciganda, R.; Yate, L.; Escobar, A.; Moya, S.; Fouquet, E.; Ruiz, J.; Astruc, D. Chem. Commun. 2017, 53, 5384-5387.

http://dx.doi.org/10.1039/C7CC02504A

201. Siuki, M. M. K.; Bakavoli, M.; Eshghi, H. Appl. Organometal. Chem. 2019, 33, e4774, 1-9. http://dx.doi.org/10.1002/aoc.4774

202. Sanka, R. V. S. P.; Balaji, K.; Leterrier, Y.; Pandey, S.; Srivastava, M.; Srivastava, A.; Binder, W. H.; Rana, S.; Michaud, V. Chem. Commun. 2019, 55, 6249-6252. http://dx.doi.org/10.1039/C9CC02057H

203. Gholinejad, M.; Erfan Oftadeh, E.; Sansano, J. M. ChemistrySelect. 2019, 4, 3151-3160. http://dx.doi.org/10.1002/slct.201803599

204. Totobenazara, J.; Burke, A. J. Tetrahedron Lett. 2015, 56, 2853-2859. http://dx.doi.org/10.1016/i.tetlet.2015.03.136

205. Cintas, P.; Barge, A.; Tagliapietra, S.; Boffa, L.; Cravotto, G. Nat. Protoc. 2010, 5, 607-616. http://dx.doi.org/10.1038/nprot.2010.1

206. Dar, B. A.; Bhowmik, A.; Sharma, A.; Sharma, P. R.; Lazar, A.; Singh, A. P.; Sharma, M.; Singh, B. Appl. Clay Sci. 2013, 80, 351-357.

http://dx.doi.org/10.1016/j.clay.2013.06.030 
207. Silva, M. T.; Oliveira, R. N.; Valença, W. O.; Barbosa, F. C. G.; Silva, M. G.; Camara, C. A. J. Braz. Chem. Soc. 2012, 23, 1839-1843.

http://dx.doi.org/10.1590/S0103-50532012005000053

208. Stefani, H. A.; Silva, N. C. S.; Manarin, F.; Lüdtke, D. S.; Zukerman-Schpector, J.; Madureira, L. S.; Tiekink, E. R. T. Tetrahedron Lett. 2012, 53, 1742-1747. http://dx.doi.org/10.1016/j.tetlet.2012.01.102

209. Silva, G. B.; Guimarães, B. M.; Assis, S. P. O.; Lima, V. L. M.; Oliveira, R. N. J. Braz. Chem. Soc. 2013, 24, 914-921. http://dx.doi.org/10.5935/0103-5053.20130117

210. Nallapati, S. B.; Sreenivas, B. Y.; Bankala, R.; Parsa, K. V. L.; Sripelly, S.; Mukkanti, K.; Pal, M. RSC Adv. 2015, 5, 94623-94628.

http://dx.doi.org/10.1039/C5RA20380E

211. Zhang, D. -W.; Zhang, Y. -M.; Li, J.; Zhao, T. -Q.; Qiang Gu, Q.; Lin, F. Ultrason. Sonochem. 2017, 36, 343353.

http://dx.doi.org/10.1016/i.ultsonch.2016.12.011

212. Naeimi, H.; Nejadshafiee, V.; Masoum, S. RSC Adv. 2015, 5, 15006-15016. http://dx.doi.org/10.1039/C4RA17229A

213. Lv, M.; Wang, M.; Lu, K.; Peng, L.; Zhao, Y. Phosphorus, Sulfur Silicon Relat. Elem. 2018, 193, $206-210$. http://dx.doi.org/10.1080/10426507.2017.1417299

214. Oliveira, R. N.; Silva, M. G.; Silva, M. T.; Melo, V. N.; Valença, W. O.; Paza, J. A.; Camara, C. A.; J. Braz. Chem. Soc. 2017, 28, 681-688. http://dx.doi.org/10.21577/0103-5053.20160207

215. Khanetskyy, B.; Dallinger D.; Kappe, C. O. J. Comb. Chem. 2004, 6, 884-892. http://dx.doi.org/10.1021/cc0498938

216. Appukkuttan, P.; Dehaen, W.; Fokin V. V.; Van der Eycken, E. Org. Lett. 2004, 6, 4223-4225. http://dx.doi.org/10.1021/ol048341v

217. Beckmann H. S. G.; Wittmann, V. Org. Lett. 2007, 9, 1-4. http://dx.doi.org/10.1021/ol0621506

218. Kocalka, P.; Andersen, N. K.; Jensen F.; Nielsen, P. ChemBioChem 2007, 8, 2106-2116. http://dx.doi.org/10.1002/cbic.200700410

219. Glasnov T. N.; Kappe, C. O. QSAR Comb. Sci. 2007, 26, 1261-1265. http://dx.doi.org/10.1002/qsar.200740122

220. Ashok, D.; Gandhi, D. M.; Srinivas, G.; Vikas Kumar, A. Med. Chem. Res. 2014, 23, 3005-3018. http://dx.doi.org/10.1007/s00044-013-0880-1

221. Głowacka, I. E.; Balzarini, J.; Wróblewski, A. E. Arch. Pharm. Chem. Life Sci. 2013, 346, 278-291. http://dx.doi.org/10.1002/ardp.201200421

222. Angelo N. G.; Arora, P. S. J. Org. Chem. 2007, 72, 7963-7967. http://dx.doi.org/10.1021/jo701292h

223. Van Dijk, M.; Mustafa, K.; Dechesne, A. C.; van Nostrum, C. F.; Hennink, W. E.; Rijkers D. T. S.; Liskamp R. M. Biomacromol. 2007, 8, 327-330. http://dx.doi.org/10.1021/bm061010g

224. Munteanu, M.; Choi S.; Ritter, H. Macromolecules 2008, 41, 9619-9623. http://dx.doi.org/10.1021/ma8018975 
225. Mallard-Favier, I.; Blach, P.; Cazier F.; Delattre, F. Carbohydr. Res. 2009, 344, 161-166. http://dx.doi.org/10.1016/j.carres.2008.10.014

226. Fazio, M. A.; Lee O. P.; Schuster, D. I. Org. Lett. 2008, 10, 4979-4982. http://dx.doiorg/10.1021/ol802053k

227. Géci, I.; Filichev V. V.; Pedersen, E. B. Chem.-Eur. J. 2007, 13, 6379-6386. http://dx.doi.org/10.1002/chem.200700053

228. Lucas, R.; Zerrouki, R.; Granet, R.; Krausz P.; Champavier, Y. Tetrahedron 2008, 64, 5467-5471. http://dx.doi.org/10.1016/i.tet.2008.04.006

229. Pietrzik, N.; Schmollinger, D.; Ziegler, T. Belstein J. Org. Chem. 2008, 4, 1-5. http://dx.doi.org/10.3762/bjoc.4.37

230. Pourceau, F.; Meyer, A.; Vasseur, J. J.; Morvan, F. J. Org. Chem. 2008, 73, 6014-6017. http://dx.doi.org/10.1021/jo8009837

231. Broggi, J.; Kumamoto, H.; Berteina-Raboin, S.; Nolan, S. P.; Agrofoglio, L. A. Eur. J. Org. Chem. 2009, 1880-1888.

http://dx.doi.org/10.1002/ejoc.200801124

232. Souza, F. B.; Pimenta, D. C.; Stefani, H. A. Tetrahedron Lett. 2016, 57, 1592-1596. http://dx.doi.org/10.1016/i.tetlet.2016.02.105

233. Radatz, C. S.; Soares, L. A.; Vieira, E. F.; Alves, D.; Russowsky, D.; Schneider, P. H. New J. Chem. 2014, 38, 1410-1417. http://dx.doi.org/10.1039/C3NJ01167D

234. Agalave, S.G.; Pharande, S.G.; Gade, S.M.; Pore, V.S. Asian J. Org. Chem. 2015, 4, 943-951. http://dx.doi.org/10.1002/ajoc.201500189

235. Xiong, X.; Tang, Z.; Sun, Z.; Meng, X.; Song, S.; Quan, Z. Appl. Organometal. Chem. 2018, 32, e3946, 1-10. http://dx.doi.org/10.1002/aoc.3946

236. Dömling, A.; Wang, W.; Wang, K. Chem. Rev. 2012, 112, 3083-3135. http://dx.doi.org/10.1021/cr100233r

237. Hassana, S.; Müller, T. J. J. Adv. Synth. Catal. 2015, 357, 617-666. http://dx.doi.org/10.1002/adsc.201400904

238. Feldman, A. K.; Colasson, B.; Fokin, V. V. Org. Lett. 2004, 6, 3897-3899. http://dx.doi.org/10.1021/ol048859z

239. Odlo, K.; Hoydahl, E. A.; Hansen, T. V. Tetrahedron Lett. 2007, 48, 2097-2099. http://dx.doi.org/10.1016/j.tetlet.2007.01.130

240. Bonnamour, J.; Legros, J.; Crousse, B.; Delpon, D. B. Tetrahedron Lett. 2007, 48, 8360-8362. http://dx.doi.org/10.1016/j.tetlet.2007.09.118

241. Gonzalez-Olvera, R.; Espinoza-Vázquez, A.; Negrón-Silva, G. E.; Palomar-Pardavé, M. E.; Romero-Romo, M. A.; Santillan, R. Molecules. 2013, 18, 15064-15079.

http://dx.doi.org/10.3390/molecules181215064

242. Kumar, D.; Patel, G.; Reddy, V. B. Synlett. 2009, 3, 399-402. http://dx.doi.org/10.1055/s-0028-1087556

243. Garudachari, B.; Isloor, A. M.; Satyanarayana, M. N.; Fun, H. -K.; Hegde, G. Eur. J. Med. Chem. 2014, 74, 324-332.

http://dx.doi.org/10.1016/j.ejmech.2014.01.008

244. Mularski, J.; Czaplińska, B.; Cieślik, W.; Bebłot, J.; Bartczak, P.; Sitko, R.; Polański, J.; Musiol, R. Sci. Rep. 2018, 8, 4496, 1-11. 
http://dx.doi.org/10.1038/s41598-018-22703-0

245. Huang, Y.; Gard, G. L.; Shreeve, J. M. Tetrahedron Lett. 2010, 51, 6951-6954. http://dx.doi.org/10.1016/i.tetlet.2010.10.149

246. Stefani, H. A.; Canduzini, H. A.; Manarin, F. Tetrahedron Lett. 2011, 52, 6086-6090. http://dx.doi.org/10.1016/i.tetlet.2011.09.004

247. Zhang, J.; Wu, J.; Shen, L.; Jin, G.; Cao, S. Adv. Synth. Catal. 2011, 353, 580-584. http://dx.doi.org/10.1002/adsc.201000791

248. Fukuzawa, S. -I.; Shimizu, E.; Kikuchi, S. Synlett. 2007, 15, 2436-2438. http://dx.doi.org/10.1055/s-2007-986638

249. Sreedhar, B.; Reddy, P. S.; Krishna, V. R. Tetrahedron Lett. 2007, 48, 5831-5834. http://dx.doi.org/10.1016/j.tetlet.2007.06.069

250. Dururgkar, K. A.; Gonnade, R. G.; Ramana, C. V. Tetrahedron 2009, 65, 3974-3979. http://dx.doi.org/10.1016/j.tet.2009.03.035

251. Li, W.-T.; Wu, W.-H.; Tang, C.-H.; Tai, R.; Chen, S.-T. ACS Comb. Sci. 2011, 13, 72-78. http://dx.doi.org/10.1021/co1000234

252. Kumaraswamy, G.; Ankamma, K.; Pitchaiah, A. J Org. Chem. 2007, 72, 9822-9825. http://dx.doi.org/10.1021/jo701724f

253. Yadav, S.; Reddy, B. V. S.; Reddy, G. M.; Chary, D. N. Tetrahedron Lett. 2007, 48, 8773-8776. http://dx.doi.org/10.1016/j.tetlet.2007.09.160

254. Campbell-Verduyn, L. S.; Szymanski, W.; Postema, C. P.; Dierckx, R. A.; Elsinga, P. H.; Janssen, D. B.; Feringa, B. L. Chem. Commun. 2010, 46, 898-900. http://dx.doi.org/10.1039/B919434G

255. Velpuri, V. R.; Muralidharan, K. J. Organomet. Chem. 2019, 884, 59-65. http://dx.doi.org/10.1016/j.jorganchem.2019.01.016

256. Tao, C. -Z.; Cui, X.; Li, J.; Liu, A. -X.; Liu, L.; Guo, Q. -X. Tetrahedron Lett. 2007, 48, 3525-3529. http://dx.doi.org/10.1016/i.tetlet.2007.03.107

257. Seerden, J. -P. G.; Leusink-Ionescu, G.; Leguijt, R.; Saccavini, C.; Gelens, E.; Dros, B.; WoudenbergVrenken, T.; Molema, G.; Kamps, J. A. A. M.; Kellogg, R. M. Bioorg. Med. Chem. Lett. 2014, 24, 13521357.

http://dx.doi.org/10.1016/j.bmcl.2014.01.034

258. Kumar, B. S. P. A.; Reddy, K. H. V.; Karnakar, K.; Satish, G.; Nageswar, Y. V. D. Tetrahedron Lett. 2015, 56, 1968-1972.

http://dx.doi.org/10.1016/j.tetlet.2015.02.107

259. Yu, X.; Xu, J.; Zhou, Y.; Song, Q. Org. Chem. Front. 2018, 5, 2463-2467.

http://dx.doi.org/10.1039/C8Q000590G

260. Reddy, P. R.; Cui, L.; Ryu, J. RSC Adv. 2018, 8, 2759-2767.

http://dx.doi.org/10.1039/C7RA12889D

261. Tunca, U. Macromol. Chem. Phys. 2018, 219, 1800163, 1-9. http://dx.doi.org/10.1002/macp.201800163

262. Shi, X. L.; Chen, Y.; Hu, Q.; Zhang, W.; Luo, C.; Duan, P. J. Ind. Eng. Chem. 2017, 53, 134-142. http://dx.doi.org/10.1016/j.jiec.2017.04.014

263. Díaz-Marta, A. S.; Tubio, C. R.; Carbajales, C.; Fernández, C.; Escalante, L.; Sotelo, E.; Guitian, F.; Barrio, V. L.; Gil, A.; Coelho, A. ACS Catal. 2018, 8, 392-404. http://dx.doi.org/10.1021/acscatal.7b02592 
264. Hussein, W. M.; Xu, J.; Simerska, P.; Toth, I. Aust. J. Chem. 2017, 70, 184-190. http://dx.doi.org/10.1071/CH16501

265. Lim, M.; Lee, H.; Kang, M.; Yoo, W.; Rhee, H. RSC Adv. 2018, 8, 6152-6159. http://dx.doi.org/10.1039/C8RA00306H

266. Li, P.; Liu, Y.; Wang, L.; Xiao, J.; Tao, M. Adv. Synth. Catal. 2018, 360, 1673-1684. http://dx.doi.org/10.1002/adsc.201701475

267. Chavan, P. V.; Desai, U. V.; Wadgaonkar, P. P.; Tapase, S. R.; Kodam, K. M.; Choudhari, A. Bioorg. Chem. 2019, 85, 475-486. http://dx.doi.org/10.1016/j.bioorg.2019.01.070

268. Tasdelen, M. A.; Yagci, Y. Tetrahedron Lett. 2010, 51, 6945-6947. http://dx.doi.org/10.1016/j.tetlet.2010.10.166

269. Tasdelen, M. A.; Yilmaz, G.; Iskin, B.; Yagci, Y. Macromolecules 2012, 45, 56-61. http://dx.doi.org/10.1021/ma202438w

270. Adzima, B. J.; Tao, Y.; Kloxin, C. J.; DeForest, C. A.; Anseth, K. S.; Bowman, C. N. Nat. Chem. 2011, 3, 256259. http://dx.doi.org/10.1038/nchem.980

271. Tasdelen, M. A.; Yagci, Y. Angew. Chem., Int. Ed. 2013, 52, 5930-5938. http://dx.doi.org/10.1002/anie.201208741

272. Yagci, Y.; Tasdelen, M. A.; Jockusch, S. Polym. 2014, 55, 3468-3474. http://dx.doi.org/10.1016/j.polymer.2014.06.068

273. Gong, T.; Adzima, B. J.; Baker, N. H.; Bowman, C. N. Adv. Mater. 2013, 25, 2024-2028. http://dx.doi.org/10.1002/adma.201203815

274. Alzahrani, A. A.; Erbse, A. H.; Bowman, C. N. Polym. Chem. 2014, 5, 1874-1882. http://dx.doi.org/10.1039/C3PY01064C

275. Beniazza, R.; Lambert, R.; Harmand, L.; Molton, F.; Duboc, C.; Denisov, S.; Jonusauskas, G.; McClenaghan, N. D.; Lastécouères, D.; Vincent, J. -M. Chem. - Eur. J. 2014, 20, 13181-13187. http://dx.doi.org/10.1002/chem.201404056

276. Harmand, L.; Cadet, S.; Kauffmann, B.; Scarpantonio, L.; Batat, P.; Jonusauskas, G.; McClenaghan, N. D.; Lastécouères, D.; Vincent, J. -M. Angew. Chem., Int. Ed. 2012, 51, 7137-7141.

http://dx.doi.org/10.1002/anie.201203014

277. Taskin, O. S.; Yilmaz, G.; Yagci, Y. ACS Macro Lett. 2016, 5, 103-107. http://dx.doi.org/10.1021/acsmacrolett.5b00885

278. Zhang, L.; Chen, X. G.; Xue, P.; Sun, H. H. Y.; Williams, I. D.; Sharpless, K. B.; Fokin, V. V.; Jia, G. C. J. Am. Chem. Soc. 2005, 127, 15998-15999. http://dx.doi.org/10.1021/ja054114s

279. Liu, P. N.; Li, J.; Su, F. H.; Ju, K. D.; Zhang, L.; Shi, C.; Sung, H. H. Y.; Williams, I. D.; Fokin, V. V.; Lin, Z. Y.; Jia, G. C. Organometallics 2012, 31, 4904-4915.

http://dx.doi.org/10.1021/om300513w

280. Wang, T. -H.; Wu, F. -L.; Chiang, G. -R.; He, S. -T.; Lo, Y. -H.; J. Organomet. Chem. 2014, 774, 57-60. http://dx.doi.org/10.1016/j.jorganchem.2014.09.038

281. Lo, Y. -H.; Wang, T. -H.; Lee, C. -Y.; Feng, Y. -H. Organometallics 2012, 31, 6887-6899. http://dx.doi.org/10.1021/om300687a

282. McNulty, J.; Keskar, K. Eur. J. Org. Chem. 2012, 0, 5462-5470. http://dx.doi.org/10.1002/ejoc.201200930 
283. Ortega-Arizmendi, A. I.; Aldeco-Perez, E.; Cuevas-Yanez, E. Sci. World J. 2013, 0, 186537, 1-8. http://dx.doi.org/10.1155/2013/186537

284. Salam, N.; Sinha, A.; Roy, A. S.; Mondal, P.; Jana, N. R.; Islam, S. M. RSC Adv. 2014, 4, 10001-10012. http://dx.doi.org/10.1039/C3RA47466F

285. Ferretti, A. M.; Ponti, A.; Molteni, G. Tetrahedron Lett. 2015, 56, 5727-5730. http://dx.doi.org/10.1016/i.tetlet.2015.08.083

286. Ali, A. A.; Chetia, M.; Saikia, B.; Saikia, P. J.; Sarma, D. Tetrahedron Lett. 2015, 56, 5892-5895. http://dx.doi.org/10.1016/i.tetlet.2015.09.025

287. Bebensee, F.; Bombis, C.; Vadapoo, S. -R.; Cramer, J. R.; Besenbacher, Gothelf, F. K. V.; Linderoth, T. R. J. Am. Chem. Soc. 2013, 135, 2136-2139.

http://dx.doi.org/10.1021/ja312303a

288. Boominathan, M.; Pugazhenthiran, N.; Nagaraj, M.; Muthusubramanian, S.; Murugesan, S.; Bhuvanesh, N. ACS Sustainable Chem. Eng. 2013, 1, 1405-1411.

http://dx.doi.org/10.1021/sc400147r

289. Rasolofonjatovo, E.; Theeramunkong, S.; Bouriaud, A.; Kolodych, S.; Chaumontet, M.; Taran, F. Org. Lett. 2013, 15, 4698-4701.

http://dx.doi.org/10.1021/ol402008u

290. Ding, S.; Jia, G.; Sun, J. Angew. Chem., Int. Ed. 2014, 53, 1877-1880.

http://dx.doi.org/10.1002/anie.201309855

291. Rao, H. S. P.; Chakibanda, G.; RSC Adv. 2014, 4, 46040-46048.

http://dx.doi.org/10.1039/C4RA07057G

292. Meng, X.; Xu, X.; Gao, T.; Chen, B. Eur. J. Org. Chem. 2010, 0, 5409-5414.

http://dx.doi.org/10.1002/ejoc.201000610

293. Smith, C. D.; Greaney, M. F. Org. Lett. 2013, 15, 4826-4829.

http://dx.doi.org/10.1021/ol402225d

294. Hong, L.; Lin, W.; Zhang, F.; Liu, R.; Zhou, X. Chem. Commun. 2013, 49, 5589-5591.

http://dx.doi.org/10.1039/C3CC42534G

295. Sasikala, R.; Rani, S.K.; Easwaramoorthy, D.; Karthikeyan, K. RSC Adv. 2015, 5, 56507-56517. http://dx.doi.org/10.1039/C5RA05468K

296. Wang, C.; Ikhlef, D.; Kahlal, S.; Saillard, J. -Y.; Astruc, D.; Coord. Chem. Rev. 2016, 316, 1-20. http://dx.doi.org/10.1016/j.ccr.2016.02.010

297. Song, W.; Zheng, N.; Li, M.; Ullah, K.; Zheng, Y.; Adv. Synth. Catal. 2018, 360, 2429-2534. http://dx.doi.org/10.1002/adsc.201800336

298. Song, W.; Zheng N.; Li, M.; He, J.; Li, J.; Dong, K.; Ullah, K.; Zheng, Y.; Adv. Synth. Catal. 2019, 361, 469475.

http://dx.doi.org/10.1002/adsc.201801216

299. Souza, M. V. N.; Costa, C. F.; Facchinetti, V.; Gomes, C. R. B.; Paula Mázala Pacheco, P. M. Curr. Org. Synth. 2019, 16, 244-257. http://dx.doi.org/10.2174/1570179416666190104141454 


\section{Authors' Biographies}

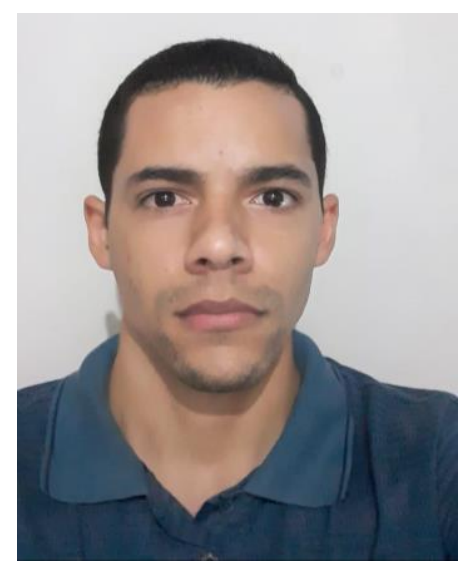

Cosme Silva Santos was born in Cuité, Brazil in 1991. Graduated in Chemistry Degree in 2014 from the Education and Health Center of the Federal University of Campina Grande (Brazil). Master in Chemistry in 2016 by the Federal Rural University of Pernambuco (Brazil). PhD student in Chemistry at the Federal Rural University of Pernambuco (Brazil). He has experience in Organic Chemistry, being a researcher in the areas of synthesis and evaluation of the biological activity of carbohydrates and heterocyclic compounds.

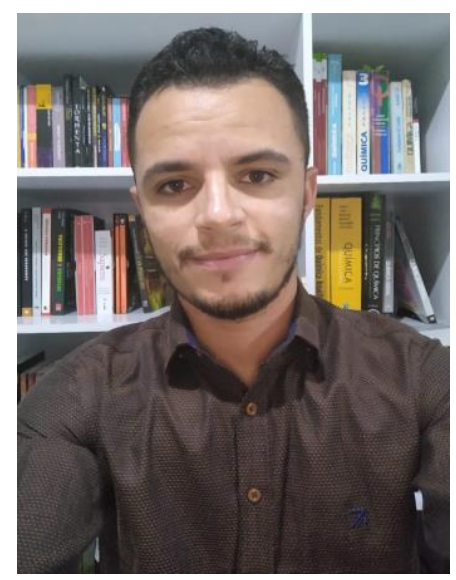

Romário Jonas de Oliveira was born in Barra de Santa Rosa, Brazil in 1994. He graduated in Chemistry in 2016 from the Federal University of Campina Grande (Brazil). He obtained a Master's Degree in 2018 in the area of Organic Chemistry and is currently a PhD student in Chemistry both from the Federal University of Pernambuco (Brazil) under the guidance of Prof. Juliano Freitas. His research interests include the synthesis of heterocycles and the study of their respective biological activities.

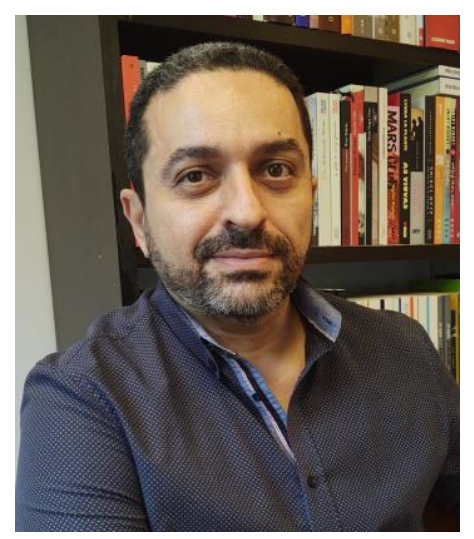


Ronaldo Nascimento de Oliveira was born in Recife, Brazil in 1970. He graduated in Chemistry from Federal Rural University of Pernambuco, Brazil in 1996. His Ph.D. in Chemistry was co-tutored between the Claude Bernard Lyon 1 University, France, and the Federal University of Pernambuco, Brazil in 2006, under the supervision of Prof Rajendra Mohan Srivastava, Brazil, and Denis Sinou, France. Master in Chemistry from the Federal University of Pernambuco, Brazil in 2002. He is currently an Associate Professor at the Federal Rural University of Pernambuco working in the area of Organic Chemistry. Has experience in Chemistry, focusing on Organic Synthesis, acting on the following subjects: heterocycles and carbohydrates. Research interest includes the design, synthesis, and biological evaluation of small molecules.

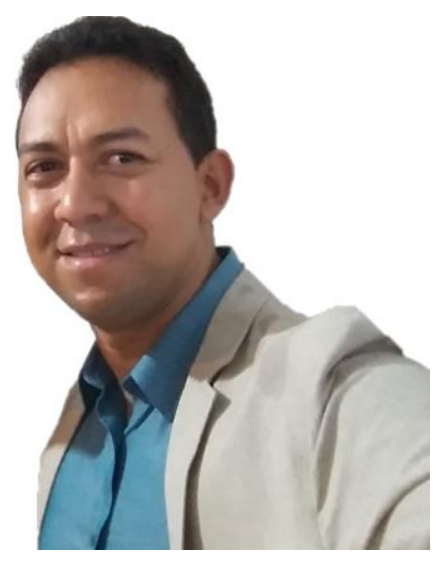

Juliano Carlo Rufino Freitas is a professor in the Education and Health Center at the Federal University of Campina Grande (Cuité, PB, Brazil). Prof Freitas received his PhD in Chemistry (2013) from DQF-UFPE working under the supervision of Prof Paulo $\mathrm{H}$. Menezes in the AOL (Applied Organic Laboratory at the Federal University of Pernambuco, 2010-2013) on the synthetic applications of tellurium and boron reagents. He got a Master's in Chemistry degree (2010) from DQFUFPE working on the total synthesis of natural products Massoialactone under the supervision of Prof Paulo H. Menezes; and he got a degree in chemistry from the Chemistry Department of the Federal Rural University of Pernambuco (2008). Prof Freitas research interests include the design and synthesis of new chemicals potentially useful as anticancer drugs. 